\title{
Physical forcing and physical/biochemical variability of the Mediterranean Sea: a review of unresolved issues and directions for future research
}

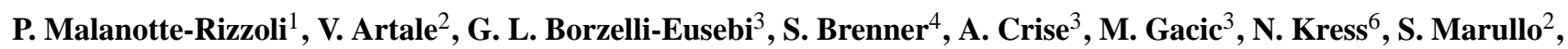

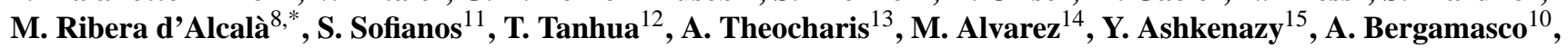
V. Cardin $^{3}$, S. Carniel ${ }^{10}$, G. Civitarese ${ }^{3}$, F. D'Ortenzio ${ }^{16}$, J. Font ${ }^{5}$, E. Garcia-Ladona ${ }^{5}$, J. M. Garcia-Lafuente ${ }^{17}$, A. Gogou ${ }^{13}$, M. Gregoire ${ }^{18}$, D. Hainbucher ${ }^{19}$, H. Kontoyannis ${ }^{13}$, V. Kovacevic ${ }^{3}$, E. Kraskapoulou ${ }^{13}$, G. Kroskos ${ }^{13}$, A. Incarbona ${ }^{20}$, M. G. Mazzocchi ${ }^{8}$, M. Orlic ${ }^{21}$, E. Ozsoy ${ }^{7}$, A. Pascual ${ }^{22}$, P.-M. Poulain ${ }^{3}$, W. Roether ${ }^{9}$, A. Rubino ${ }^{23}$, K. Schroeder ${ }^{10}$, J. Siokou-Frangou ${ }^{13}$, E. Souvermezoglou ${ }^{13}$, M. Sprovieri ${ }^{24}$, J. Tintorée ${ }^{22}$, and G. Triantafyllou ${ }^{13}$

${ }^{1}$ Massachusetts Institute of Technology, Cambridge, MA, USA

${ }^{2}$ ENEA, Agenzia nazionale per le nuove tecnologie, l'energia e lo sviluppo economico sostenibile, Centri ricerca Frascati e Roma, Rome, Italy

${ }^{3}$ Istituto Nazionale di Oceanografia e di Geofisica Sperimentale - OGS, Trieste, Italy

${ }^{4}$ Department of Geography and Environment, Bar llan University, Ramat Gan 52900, Israel

${ }^{5}$ Institut de Ciencies del Mar - CSIC, Barcelona, Spain

${ }^{6}$ National Institute of Oceanography, Israel Oceanographic \& Limnological Research, Haifa, Israel

${ }^{7}$ Middle East Technical University, Institute of Marine Sciences, Erdemli, Turkey

${ }^{8}$ Stazione Zoologica Anton Dohrn, Naples, Italy

${ }^{9}$ University of Bremen, Bremen, Germany

${ }^{10} \mathrm{CNR}$ ISMAR, Istituto di Scienze Marine, Venice, Italy

${ }^{11}$ University of Athens, Division of Environmental Physics, Ocean Physics and Modeling Group, Athens, Greece

${ }^{12}$ GEOMAR Helmholz Center for Ocean Research, Kiel, Germany

${ }^{13}$ Institute of Oceanography, Hellenic Centre for Marine Research, Sounio Ave., P.O. Box 712, Athens, Greece

${ }^{14}$ Instituto Espanol de Oceanografia, Calle del Corazon de Maria 8, Madrid 28020, Spain

${ }^{15}$ Department of Solar Energy \& Environmental Physics, The Jacob Blaustein Institutes for Desert Research,

Ben-Gurion University of the Negev, Israel

${ }^{16}$ Laboratoire d'Oceanographie de Villefranche (LOV), CNRS and Université Pierre et Marie Curie, Paris 06, UMR7093,

Villefraneche-sur-mer, France

${ }^{17}$ Physical Oceanography Group University of Malaga, Malaga, Spain

${ }^{18}$ Universite de Liege - Laboratoire d'Oceanologie - Centre MARE, Liege, Belgium

${ }^{19}$ University of Hamburg - Institute of Oceanography, Hamburg, Germany

${ }^{20}$ Universita di Palermo, Dipartimenti di Geologia \& Geodesia, Palermo, Italy

${ }^{21}$ University of Zagreb, Faculty of Science Andrija Mohoroviviv Geophysical Institute, Zagreb, Croatia

${ }^{22}$ Instituto Mediterraneo de Estudio Avanzados, IMEDEA (CSIC-UIB), Balearic Islands, Spain

${ }^{23}$ Universita Ca' Forscari di Venezia, Venice, Italy

${ }^{24}$ CNR IAMC, Unita Operativa di Capo Granitola, Trapani, Italy

Correspondence to: P. Malanotte-Rizzoli (rizzoli@mit.edu)

Received: 7 June 2013 - Published in Ocean Sci. Discuss.: 24 July 2013

Revised: 30 January 2014 - Accepted: 4 February 2014 - Published: 6 May 2014 
Abstract. This paper is the outcome of a workshop held in Rome in November 2011 on the occasion of the 25th anniversary of the POEM (Physical Oceanography of the Eastern Mediterranean) program. In the workshop discussions, a number of unresolved issues were identified for the physical and biogeochemical properties of the Mediterranean Sea as a whole, i.e., comprising the Western and Eastern sub-basins. Over the successive two years, the related ideas were discussed among the group of scientists who participated in the workshop and who have contributed to the writing of this paper.

Three major topics were identified, each of them being the object of a section divided into a number of different subsections, each addressing a specific physical, chemical or biological issue:

1. Assessment of basin-wide physical/biochemical properties, of their variability and interactions.

2. Relative importance of external forcing functions (wind stress, heat/moisture fluxes, forcing through straits) vs. internal variability.

3. Shelf/deep sea interactions and exchanges of physical/biogeochemical properties and how they affect the sub-basin circulation and property distribution.

Furthermore, a number of unresolved scientific/methodological issues were also identified and are reported in each sub-section after a short discussion of the present knowledge. They represent the collegial consensus of the scientists contributing to the paper. Naturally, the unresolved issues presented here constitute the choice of the authors and therefore they may not be exhaustive and/or complete. The overall goal is to stimulate a broader interdisciplinary discussion among the scientists of the Mediterranean oceanographic community, leading to enhanced collaborative efforts and exciting future discoveries.

\section{Introduction}

The motivation for this paper stems from a workshop held in Rome in November 2011, on the occasion of the 25th anniversary of the POEM (Physical Oceanography of the Eastern Mediterranean) program. The objectives of the workshop were however rather more ambitious than simply having a memorial. First, the workshop was meant to provide a synopsis of the state-of-the-art of research and present knowledge of the Mediterranean Sea's physical, chemical, and biological properties. Second, it wanted to offer the opportunity to scientists working in different regions of the sea, both the Western and Eastern basins, to meet and share ideas, and hence foster pan-Mediterranean collaborations.
The importance of the Mediterranean Sea for the world ocean has long been recognized. First, the Mediterranean Sea has a profound impact on the Atlantic Ocean circulation and, consequently, on the global thermohaline conveyor belt. Maps of the Mediterranean salty water tongue exiting from the Gibraltar Strait at intermediate depths and spreading throughout the Atlantic interior have been well known since the 1950s. Through direct pathways to the Atlantic's polar regions or through indirect mixing processes, the salty Mediterranean water preconditions the deep convection cells of the polar Atlantic. There the North Atlantic Deep Water is formed that successively spreads throughout the world ocean, constituting the core of the global thermohaline circulation.

Even more importantly, the Mediterranean Sea is a laboratory basin for the investigation of processes of global importance, being much more amenable to observational surveys because of its location at mid-latitude and its dimensions. Both the western and eastern basins in fact possess closed thermohaline circulations analogous to the global conveyor belt. A unique upper layer open thermohaline cell connects the eastern basin to the western basin and, successively, to the North Atlantic through the Gibraltar Strait. In it, the Atlantic water entering into Gibraltar in the surface layer, after travelling to the easternmost Levantine Basin, is transformed into one of the saltiest water masses through air-sea heat and moisture fluxes. This is the salty water that, crossing the entire basin in the opposite direction below the surface Atlantic water, finally exits from the Gibraltar Strait at mid-depths.

Both the western and eastern basins are endowed with deep/intermediate convection cells analogous to the polar Atlantic deep convection cells or to the intermediate mode water ones. Deep and intermediate water masses are therefore formed in different sites of the entire basin. Because of their easily accessible locations, these convection cells are much more amenable to direct observational surveys and mooring arrays.

A ubiquitous, energetic mesoscale and sub-mesoscale eddy field is superimposed onto and interacts with the subbasin scale, wind-driven gyres that characterize the upper thermocline circulation. Three different scales of motion are therefore superimposed, producing a richness of interaction processes which typify similar interactions in unexplored ocean regions.

Both wide and narrow shelves are at present separated by steep continental slopes from the deep interiors. Cross-shelf fluxes of physical as well as biogeochemical parameters are crucial in determining the properties of the shallow vs. deep local ecosystems and their trophic chain. Most importantly, the Mediterranean Sea is a basin of contrasting ecosystems, from the strongly oligotrophic deep interiors to the fully eutrophic northern Adriatic characterized by recurrent, anomalous algal blooms and related anoxia events. 
This review focuses on the identification of major unresolved scientific issues and provides directions for future research to address these issues both theoretically and observationally. However, the unresolved issues discussed here constitute the selection of the group of authors who have contributed to the review. It cannot therefore be either exhaustive or complete. Furthermore, a different group of scientists might have provided a different set of unresolved issues for physical/biogeochemical properties. The major purpose in presenting the present choices is to induce the Mediterranean oceanographic community to a broader, more inclusive and fully interdisciplinary discussion to move forward in the theoretical and observational investigation of the Mediterranean Sea.

\section{Assessment of basin-wide physical/biochemical properties and their variability and interactions}

\subsection{Scales of variability of the Mediterranean circulation}

\subsubsection{State of knowledge}

It is of paramount importance to know which are the dominant scales of variability of the circulation characterizing a specific oceanic basin. External wind forcing determines the large barotropic circulation pattern while stratification determines the internal baroclinic deformation radius, the scale of the ubiquitous, energetic mesoscale eddy field. Furthermore, oceanic motions cover the entire space and time spectrum, from the global thermohaline conveyor belt to microturbulence. Therefore, to capture the variability of a specific oceanic region, knowledge of the dominant scales of motion and their variability and interactions is crucial, both theoretically and for the design of sampling strategies.

The Mediterranean circulation is characterized by three predominant interacting spatial scales, which represent the wide variety of forcings that characterize the basin: basin, sub-basin and mesoscale. The basin-scale circulation is broadly described in terms of a surface flow from the Atlantic Ocean entering through the Strait of Gibraltar and proceeding to the eastern basin, and a return flow of intermediate water, originating in the Levantine Basin, proceeding towards Gibraltar and finally exiting into the Atlantic. This basin-scale open cell is mainly driven by thermohaline forcing: an east-west density gradient, associated with enhanced heat and moisture fluxes in the Levantine Sea, drives the eastward flow of surface Atlantic water. In the Levantine Basin the ocean releases buoyancy into the atmosphere through heat loss and an evaporation/precipitation deficit. The buoyancy loss reduces the stability of the water column, with loss of potential energy in the Levantine. This energy deficit is compensated for by a buoyancy gain associated with the inflow of the fresh surface Atlantic water. For this open cell, the forcings of the Mediterranean basin-scale circulation are the inflows through the Gibraltar and Sicily straits. Sannino et al. (2009) discuss the importance of including variations of the Atlantic water inflow through the Gibraltar Strait to describe decadal variations in the western Mediterranean circulation pattern. Similarly, Malanotte-Rizzoli and Bergamasco (1991), investigating the relative contribution of wind forcing, thermohaline surface fluxes and boundary conditions to the EMed circulation, showed that flow changes in the Sicily Strait can induce variability in the circulation pattern on the basin scale. Pierini and Rubino (2001) modeled the remotely forced dynamics in the areas surrounding the Strait of Sicily and, imposing steady fluxes along the open boundaries, obtained in the absence of meteorological forcing, quasi-stationary circulations representing the local manifestation of the large-scale Mediterranean conveyor belt. It is interesting to note that Demirov and Pinardi (2002), discussing changes in the Ionian circulation in relation to the variability in the thermohaline properties of the water mass formed in the Levantine, provided evidence that variations in the latter one could be associated with changes in the Ionian circulation. Gačić et al. $(2010,2011)$ showed that these changes may be responsible for modifications of the eastern Mediterranean thermohaline cell, thus impacting the overall structure of the eastern Mediterranean circulation. This finding constitutes an example in which changes in the sub-basin scale alter the basin-scale circulation pattern.

Air-sea heat and moisture fluxes also drive the eastern and western convection cells through the formation of dense water in the southern Adriatic and the Gulf of Lion, respectively. In these cases, the related downslope flow modifies the vertical structure of the water column and determines changes in the horizontal scales of the circulation (Winters et al., 1995; CIESM, 2009; Winters and Young, 2009). Wintertime Dense Shelf Water Cascades (DSWC) can transport large amounts of water and sediment through submarine canyons, reshaping the canyons and affecting the deep water environment in the process. An excellent example was presented by Canals et al. (2006) from observations in the Cap de Creus Canyon in the Gulf of Lions in the Mediterranean Sea (one of his figures shows measurements made during a gravity/turbidity current event, which shows current speeds as high as $80 \mathrm{~cm}$ and high sediment concentrations). Similar events can be expected to occur in the Bari Canyon when North Adriatic Deep Water (NADW) formed in the northern parts reaches the Bari Canyon System (BCS) in a few months. The BCS intercepts sediments derived from the Po and southern Apennine rivers and funnels this material into the deep South Adriatic Basin.

A useful approach to describing scales of oceanic circulation relates to the vertical partitioning of oceanic energy into barotropic and baroclinic components (Wunsch and Stammer, 1995; Stammer, 1997; Wunsch, 1997). This allows us to identify the dominant components of the motion and estimate its characteristic scales in terms of the Rossby deformation radius (Lermusiaux and Robinson, 2001). However, 
the quantification of the relative importance of the barotropic and baroclinic mode(s) in determining the horizontal circulation is difficult, due to the fact that, for a faithful description of a given region of the ocean, nearly continuous sampling over wide areas is necessary. Another possible approach is based on satellite remote sensing, which allows data to be gained over wide areas of the ocean nearly continuously. An example is given in Fig. 1.

This approach implies direct evaluation of the scales of variability of a specific passive scalar, assumed to be a tracer of the surface circulation (Barron and Kara, 2006; Borzelli and Ligi, 1999a, b; Borzelli, 2008), or evaluation of the scales of variability of the sea level anomaly (SLA, Ioannone et al., 2011) obtained by orbiting satellite altimeters. In practice, this technique relies upon the estimation of the autocorrelation function of the parameter represented by satellite remotely sensed data and the evaluation of characteristic scales of the autocorrelation function, which are assumed to represent the scales of the sea surface structure. Figure 2 shows examples of SLA autocorrelation functions computed in the Ionian Sea in the different seasons. Figure 3 gives the time variability of the scales of the same autocorrelation function.

This approach, however, leads to great uncertainties since, first, through direct evaluation of scales, it is difficult to determine which is the dominant vertical component determining the horizontal circulation and, second, interacting components due to nonlinearities and active over short scales are filtered out.

\subsubsection{Unresolved issues}

1. Stratification, stratification changes and variability in the horizontal circulation scales

The horizontal circulation of the sea can be represented as the superposition of barotropic and baroclinic modes (normal modes). This representation is convenient, since it allows us to express the characteristic scales of the horizontal motion in terms of Rossby radii of deformation. In the Mediterranean, the overturning circulation concurs in determining considerable variability over time in the stratification regime and producing changes both in the structure of individual modes and in the way in which these modes compete with each other to determine the horizontal motion. This requires an analysis of how, in the Mediterranean, stratification changes modify horizontal scales of motion.

2. Energy exchanges and excitation of normal dynamical modes (i.e., barotropic and baroclinic modes)

In the available literature (see, e.g., Malanotte-Rizzoli and Bergamasco, 1989) it has been pointed out that, in the Mediterranean, the wind excites primarily the barotropic mode, which is a long, fast and transient component of the circulation. Over the longer
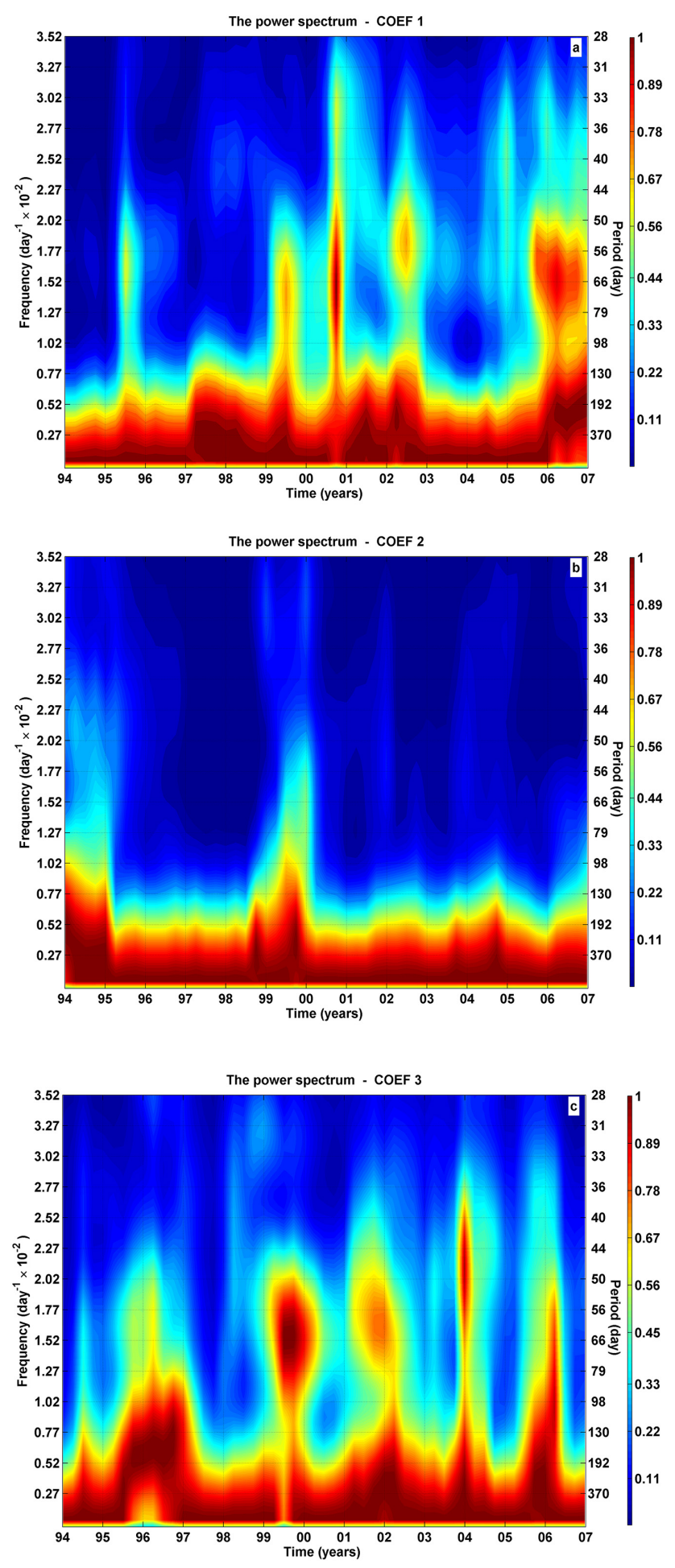

Fig. 1. Normalized time-dependent frequency spectra of empirical orthogonal function coefficients of the SLA. (a-c) Spectra of coefficients $1-3$, respectively. Left and right vertical scales indicate frequencies and periods, respectively (adapted from loannone et al., 2011). 

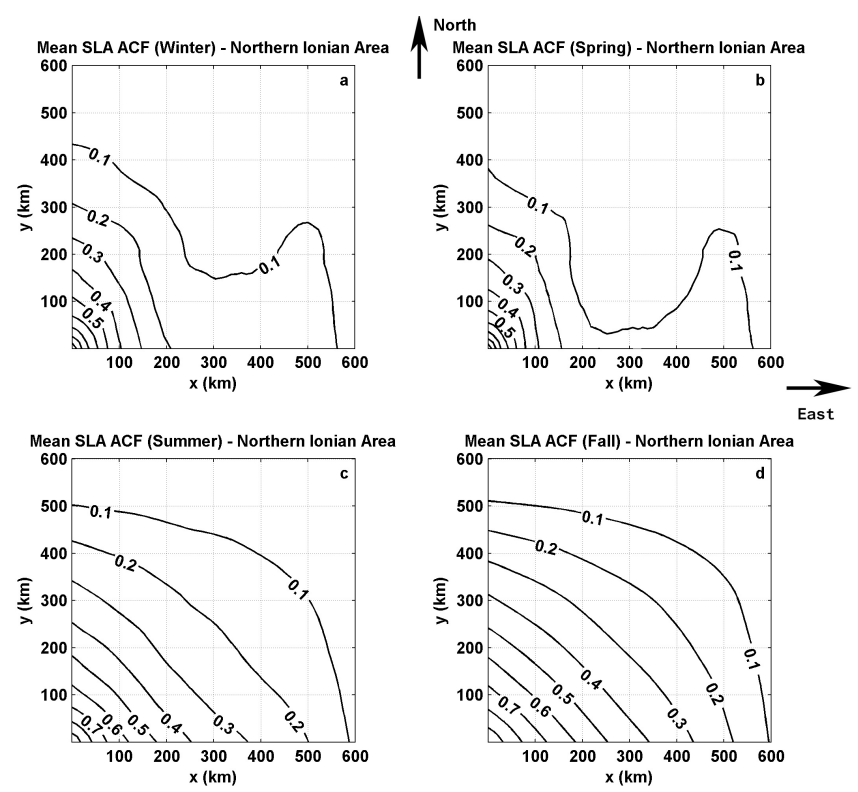

Fig. 2. Contours of the SSH autocorrelation function over the Ionian Sea in the period 1993-2007 averaged over the different seasons. (a) Winter; (b) spring; (c) summer; (d) fall (adapted from Ioannone et al., 2011).

timescales (annual and inter-annual) the circulation is essentially determined by baroclinic components. This implies that, in order to maintain the long-term circulation, energy transferred from the wind to the barotropic component has to be transferred from the barotropic component to baroclinic ones. In order to clarify this mechanism an analysis of the way different modes interact with each other is necessary.

3. Mediterranean overturning circulation and deep mixing rates

Throughout the world ocean, stratification is maintained by mixing in the deep layers that, counteracting upwelling processes, provide the counterflow of dense water necessary for restoring the stability of the water column. In the Mediterranean, although scales of the horizontal circulation have been intensively investigated during POEM and PRIMO, the relationship between the intensity of the Mediterranean overturning circulation and deep mixing rates is not yet understood. Indeed, mixing is generally believed to occur through tidal dissipation over shelf breaks and/or breaking of internal gravity waves. In the Mediterranean, energy associated with these processes is too low compared to the energy required for maintaining the overturning circulation.
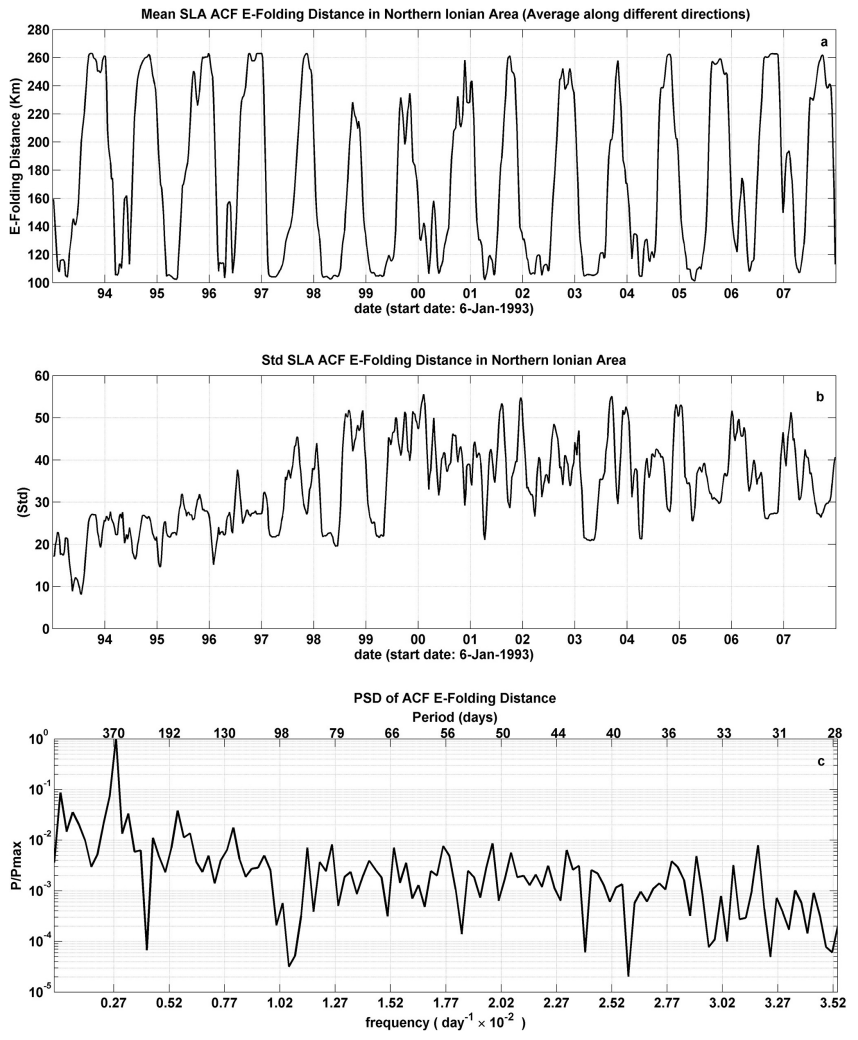

Fig. 3. Temporal variability and frequency spectra of the correlation length scale of the SSH over the Ionian in the period 1993-2007. The correlation length is computed as the average of 17 e-folding distances obtained by fitting the SSH autocorrelation with a Gaussian along 17 different radial directions. (a) Average over 17 radial directions between 0 and $90^{\circ}$; (b) standard deviation of the mean of Fig. 5a; (c) power spectrum of Fig. 5a (adapted from Ioannone et al., 2011).

\subsection{Differences and similarities between circulation, forcing and water mass conversion in the WMed and EMed and interactions between the basins}

\subsubsection{Present knowledge}

The Western and Eastern Mediterranean (WMed, EMed) are connected by the Strait of Sicily (sill depth $500 \mathrm{~m}$ ). Forcing is dominated by exchange with the Atlantic Ocean through the Strait of Gibraltar in the west (sill depth about $300 \mathrm{~m}$ ) and, to a lesser degree, also with the Black Sea through the Strait of Dardanelles in the northeast. There are also a number of straits and channels that connect both the WMed and EMed with the marginal seas. They play a crucial role in determining the water mass exchanges and related properties (Astraldi et al., 1999). The other factor is atmospheric forcing, primarily in the form of net evaporation. Local climate variability exists due to both the different impacts of large-scale teleconnection patterns (NAO, EA/WR, etc.) in the WMed and EMed (Krichak and Alpert, 2005; Josey et al., 2010) and the 


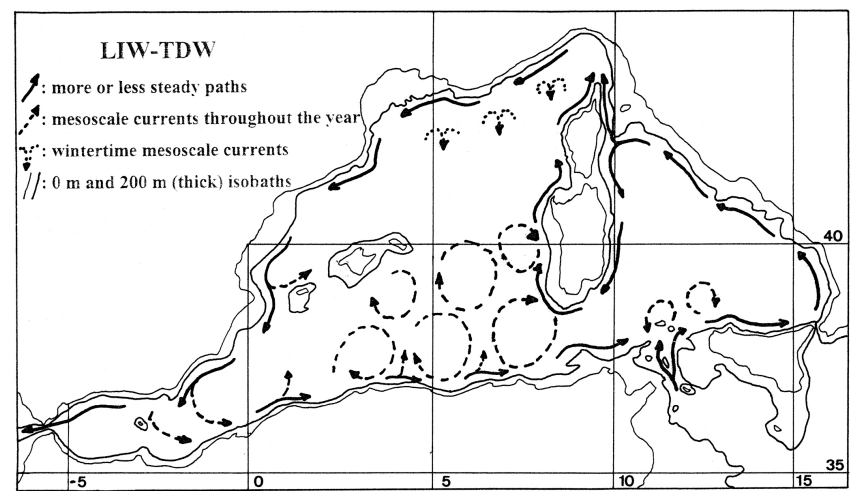

Fig. 4. Western Mediterranean circulation in the upper layer. In the northern part of the WMed, the westward rim current is permanently well defined, even if affected by seasonal variability. This AW flow is a recirculating branch that detaches AW from southern latitudes in the southwestern area of Sicily (Millot and Taupier-Letage, 2005). In the southern part of the WMed the Algerian Current is unstable and generates (anticyclonic) meanders and eddies of $\sim 50-100 \mathrm{~km}$ (up to 200) in diameter. These eddies can detach from the Algerian current and propagate into the interior of the Algerian and Tyrrhenian basins. The pattern of Fig. 4 has recently been extended to the entire Mediterranean by Millot and Taupier-Letage (2005), who have inferred it from SST imagery. In the EMed, however, and especially in the Levantine Basin (or Levantine Sub-Basin, LSB, as in Menna et al., 2012), the AW is topped by the more saline Levantine surface waters during most of the year and the use of SST imagery to infer circulation patterns is rather controversial.

regional characteristics (Xoplaki et al., 2003, 2004). The induced eastward salinity increase in the upper waters results in two kinds of thermohaline cells.

The open conveyor belt consists of an upper layer eastward flow of low-salinity Atlantic Water (AW) and a subsurface westward spreading of the warm and saline Levantine Intermediate Water (LIW) in 200-400 m (i.e., at depths shallower than the Sicily and Gibraltar Strait sills; Schroeder et al., 2012) formed in the Levantine Basin, enriched sporadically by Cretan Intermediate Water (CIW) formed in the Cretan Sea. This Eastern Mediterranean Intermediate Water (EIW) enters the WMed, where part of it participates in the DWF processes. A further ingredient in the EIW is the Western (formerly Winter) Intermediate Water (WIW), cooler and fresher than the LIW, formed in the WMed (Send et al., 1999). The main volume of the EIW along with the WIW exit at depth at Gibraltar. The parts of the Intermediate Waters that cannot outflow directly through the Channel of Sicily and the Strait of Gibraltar continue recirculating in both Mediterranean basins (Millot, 2013).

Secondly, there exist internal or quasi-closed thermohaline cells in both Mediterranean basins, driven by deep water formation processes in the northern regions of the seas. These deep waters are partly involved in the Sicily and Gibraltar overflows. The WMDW is formed in the open region of the

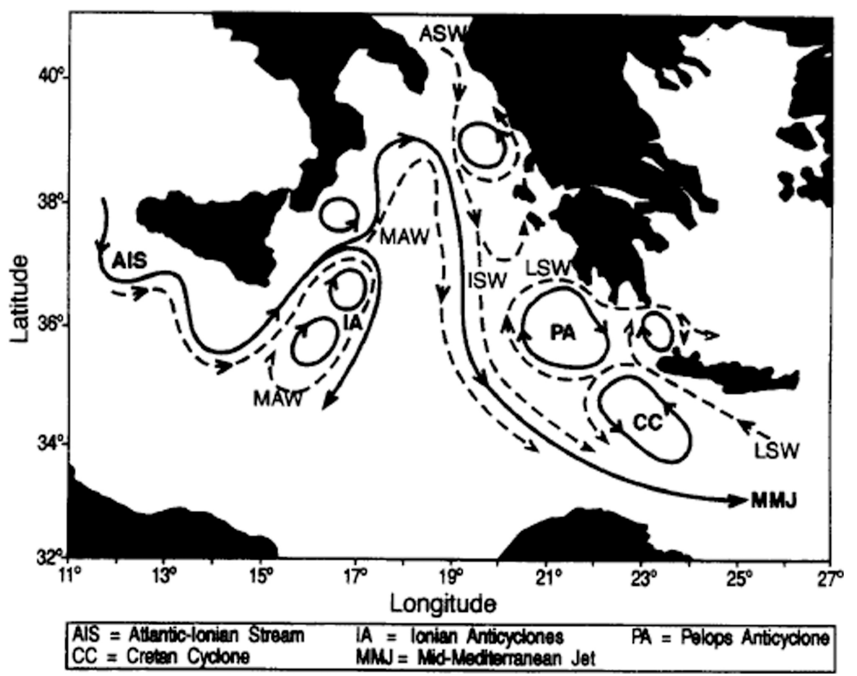

Fig. 5a. Schematic of the upper thermohaline circulation and water mass pathways in the central Mediterranean. Dashed lines mark water mass pathways. Solid lines denote permanent dynamic features, i.e., currents and sub-basin gyres, for which names are given in the table.

NW Mediterranean, while the EMDW originates in marginal seas, regularly mostly in the Adriatic but also in the Aegean and, sporadically, in the NW Levantine (Kontoyiannis et al., 1999).

A marked difference exists in the bathymetry between the two basins. A highly structured bathymetry characterizes the EMed compared to the WMed, which has a virtually flat bottom east and south of the Balearic Islands. This contributes to the differences in the circulation, especially the depth, of the two basins. In the WMed the eastward flow of AW is concentrated in the southern part of the basin, along the continental slope, i.e., the Algerian Current (Fig. 4, adapted from Millot, 1985, 1999).

Figure 5 shows the circulation pattern for the EMed, specifically Fig. 5a for the Ionian Sea (adapted from Malanotte-Rizzoli et al., 1997) and Fig. 5b for the LSB (adapted from Menna et al., 2012). The anticyclonic pattern of AW depicted in Fig. 5a synthesizes the hydrographic data set collected during POEM-Phase I, especially during 1987. It corresponds to the anticyclonic circulation mode of the recently discovered Bimodal Oscillation System (BIOS) (Gačić et al., 2010, 2011). During the anticyclonic mode there is increased spreading of the AW northeastward, thus freshening the northern Ionian Sea (see Sect. 3.1).

For the LSB, there has been an ongoing controversy regarding the pathway of surface waters propagating eastward from the Ionian Sea. Two pictures have been proposed and contrasted. The first one was proposed by Millot and TaupierLetage (2005), Alhammoud et al. (2005), and Hamad et al. (2005, 2006), and is similar to the WMed pattern of Fig. 4, based again on SST imagery. The assumed instabilities of 


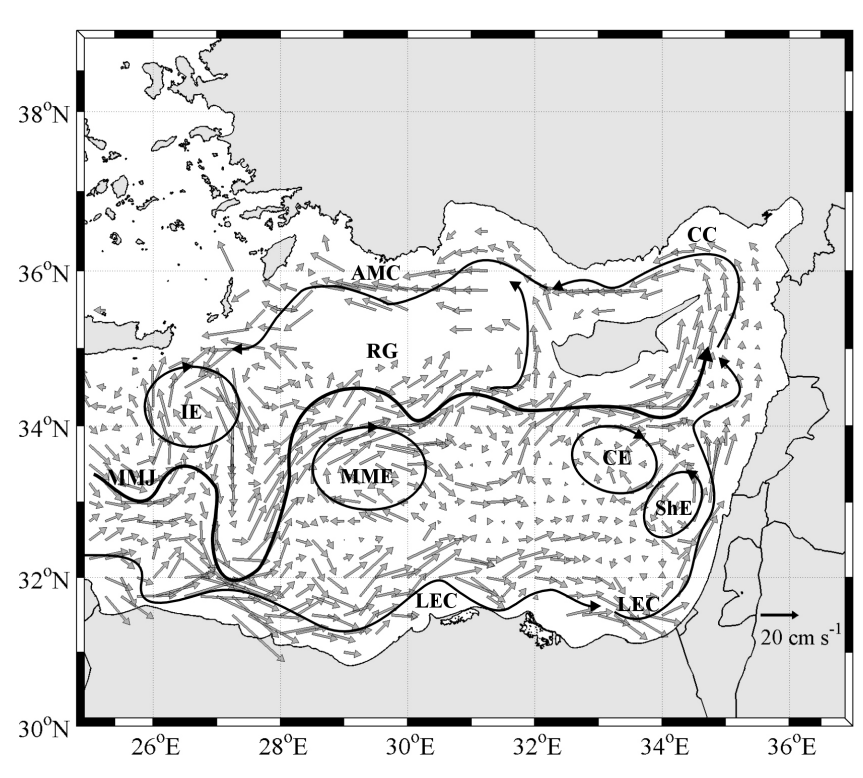

\begin{tabular}{|c|c|c|c|c|}
\hline $\begin{array}{c}\text { RG: } \\
\text { Rhodes Gyre }\end{array}$ & $\begin{array}{c}\text { CE: } \\
\text { Cyprus Eddy }\end{array}$ & $\begin{array}{c}\text { IE: } \\
\text { Ierapetra Eddy }\end{array}$ & $\begin{array}{c}\text { LEC: } \\
\text { Libyo-Egyptian Current }\end{array}$ & $\begin{array}{c}\text { AMC: } \\
\text { Asian Minor current }\end{array}$ \\
\hline $\begin{array}{c}\text { MME: } \\
\text { Mersa Matruh Eddy }\end{array}$ & $\begin{array}{c}\text { ShE: } \\
\text { Shikmona Eddy }\end{array}$ & $\begin{array}{c}\text { CC: } \\
\text { Cilician Current }\end{array}$ & $\begin{array}{c}\text { MMJ: } \\
\text { Mid Mediterranean Jet }\end{array}$ & \\
\hline
\end{tabular}

Fig. 5b. Mean absolute geostrophic velocities in the period 19922010 (dark grey). Black lines emphasize the main currents and subbasin eddies for which names are given in the table.

the Libyo-Egyptian current are responsible for the generation of anticyclonic eddies propagating the AW into the LSB interior. This picture is in sharp contrast to the picture originally proposed by the POEM group (1992), in which the surface/sub-surface waters carry the AW into the Levantine as an open sea central eastward current. This continues as the Mid Mediterranean Jet (MMJ) splitting into several branches (Robinson et al., 1991, 2001; Robinson and Golnaraghi, 1994; Malanotte-Rizzoli et al., 1997, 1999; Malanotte-Rizzoli and the LIWEX group, 2003). Furthermore, observational work comprising several oceanographic surveys carried out in the CYCLOPS experiment (Zodiatis et al., 2005) and the recent works by Schroeder et al. (2012) and especially Menna et al. (2012) demonstrate unambiguously the existence of the MMJ. Figure 5b, reproduced from Menna et al. (2012, their Fig. 5b) is based on the analysis of 18 years of drifter data and satellite-derived sea level anomalies. It clearly shows the major currents and eddies of the LSB, thus confirming and refining the old POEM pattern. The reader is referred to Menna et al. (2012) for a detailed description of the AW flow, the major eddies characterizing the region, and the mechanism of periodic generation of the Shikmona eddy (see also Brenner, 1993).

The classical view that the thermohaline circulation of the Mediterranean was quasi-stable has more recently been overruled. During the late 1980s to the early 1990s the Aegean
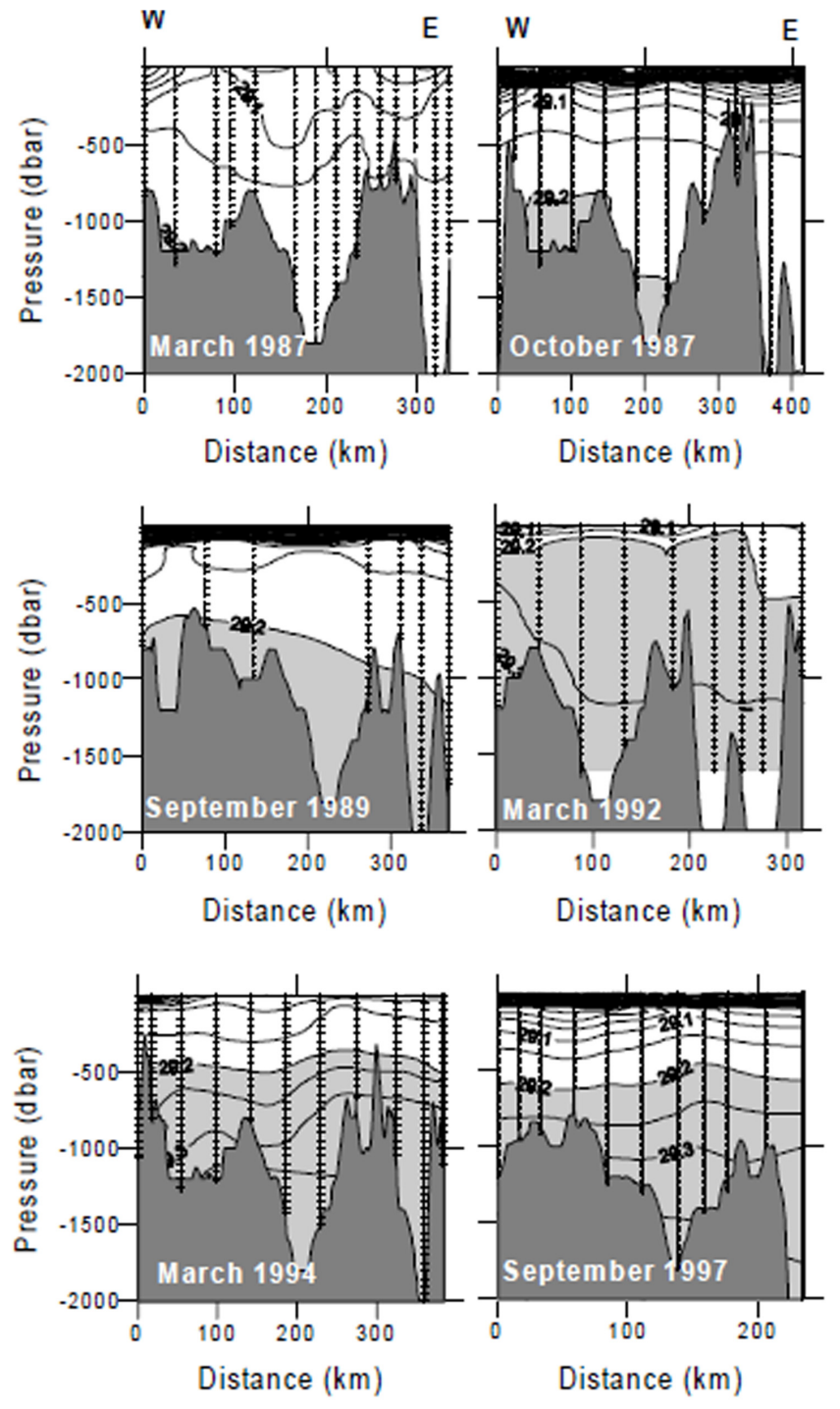

Fig. 6. West-east $\sigma_{\theta}$ cross-sections in the Cretan Sea showing the evolution of the $29.2 \mathrm{~kg} \mathrm{~m}^{-3}$ surface during the decade 1987-1997.

deep water formation took over from the Adriatic (Fig. 6, adapted from Theocharis et al., 1999a, b).

Huge amounts of very dense waters characterized by enhanced salinity and temperature were released for a few years, forming the Eastern Mediterranean Transient (EMT; Roether et al., 1996, 2007; Theocharis et al., 1999, 2002a), significantly influencing the thermohaline structure and stratification of the entire EMed Basin (Fig. 7, adapted from Roether et al., 1996).

A specialty is that the Aegean dense-water outflow feeds into the Hellenic Trench region before being transferred into the EMed at large. However, deep water formation in the Aegean has been reported for the 1970s (Lascaratos et al., 1999; Theocharis et al., 2002b; Beuvier et al., 2010), but it is not known if the Aegean dense water observed in the deep layers of the EMed was enough to produce a substantial change in the deep thermohaline cell as in the 1990s. 

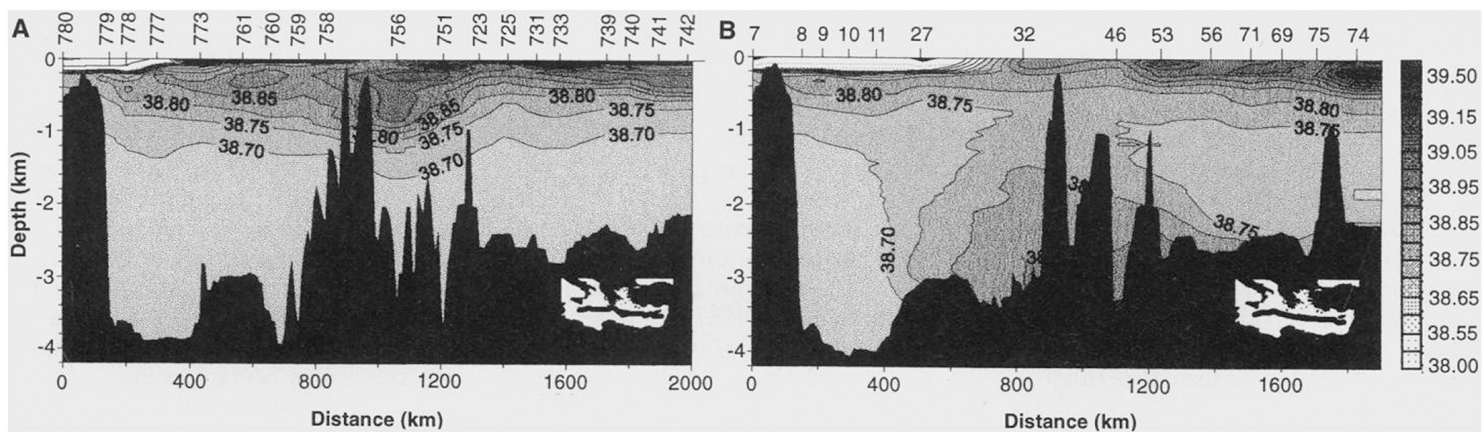

Fig. 7. Salinity isolines on sections across the Ionian Basin (see inset maps) for Meteor cruises M5/6 (1987) (A) and M31/1 (1995) (B) stations are at the top.

Recently it was also suggested that the EMT could be a recurrent phenomenon (Borzelli et al., 2009; Pisacane et al., 2006). EMT-induced changes have been communicated through the Sicily Strait to the WMed (Fig. 8, adapted from Schroeder et al., 2006), with the role of the Tyrrhenian becoming enhanced for some years (Gasparini et al., 1995; Roether and Lupton, 2011).

More specifically, in the Tyrrhenian Sea, the WMDW and the overflow from the Eastern Mediterranean mix, lifting the former component to allow it to take part in the Sicily Strait outflow (Millot and Taupier-Letage, 2005), and, at the same time, forming a deep salinity source for the WMDW. Indeed, a significant warming and salinification of the whole water column has been observed also in the Western Mediterranean, comparable to the EMT, both in terms of intensity and observed effects (Schroeder et al., 2008). This event of high production of anomalously warm and salty new deep water during the winters of 2004/2005 and 2005/2006 (Fig. 9, adapted from Schroeder et al., 2008) is now known as the Western Mediterranean Transition (WMT) (Schroeder et al., 2008; Herrmann et al., 2010).

Currently, thus, the subsurface distributions of temperature and salinity, as well as of most other properties in the entire Mediterranean, are far from a steady state. Moreover, the changes observed in the circulation during the last decades, such as the reversals in the Ionian circulation (Gačić et al., 2011; Borzelli et al., 2009) and the transport of the EMT effects westwards (Gasparini et al., 2005) dictate a more thorough study on water mass spreading pathways and their variability and on water mass conversion, as well as temporal and spatial variability in the marginal seas of the EMed (Adriatic/Aegean). Only if these items have been resolved will it be possible to come up with quantitative answers on the geochemistry and ecology of the Mediterranean Sea.

In the last two decades there has existed an increased effort for the development of observational systems in the Mediterranean in the framework of programs or initiatives such as Med-GOOS, MFSTEP (Mediterranean forecasting system), ECOOP (European Coastal/Shelf seas operational observing and forecasting), MYOCEAN/GMES (Global Monitoring and Environmental Security) and EUROARGO. These observational systems are designed to transmit real-time data to operational centers with the ultimate goal of producing accurate model predictions. Recent developments in numerical modeling that assimilate available in situ observations are a promising step towards more reliable ocean predictions and long-term reanalysis simulations in the Mediterranean within the scope of operational oceanography (Adani et al., 2011; Dobricic et al., 2007, 2010; Pinardi and Coppini, 2010; Nilsson et al., 2011).

There is furthermore a need for clarification of the role of the characteristic atmospheric circulation patterns (west vs. east), also in the context of large climatic variations and trends that are associated with variability of the circulation and with deep water formation events (Josey et al., 2010; Kontoyiannis et al., 2012).

\subsubsection{Unresolved issues}

1. Long-term variability

A principal concern is to improve the understanding of the long-term variability and evolution of the Mediterranean circulation. A special item that must urgently be amended is scarce data in the southern part of the EMed in consequence of the political situation in the past.

\section{Influence of lateral forcing}

One need is to monitor the path and characteristics of the AW after it enters the Mediterranean at Gibraltar and after passing the Sicily Channel, to find the causes of its path variability and its contribution in water mass transformations. Furthermore, one needs to monitor the characteristics of the overflows at the Gibraltar and Sicily straits and to relate their variability to that observed in both Mediterranean basins. Finally, the interaction between subsurface Eastern and Western Mediterranean waters must be clarified further. 


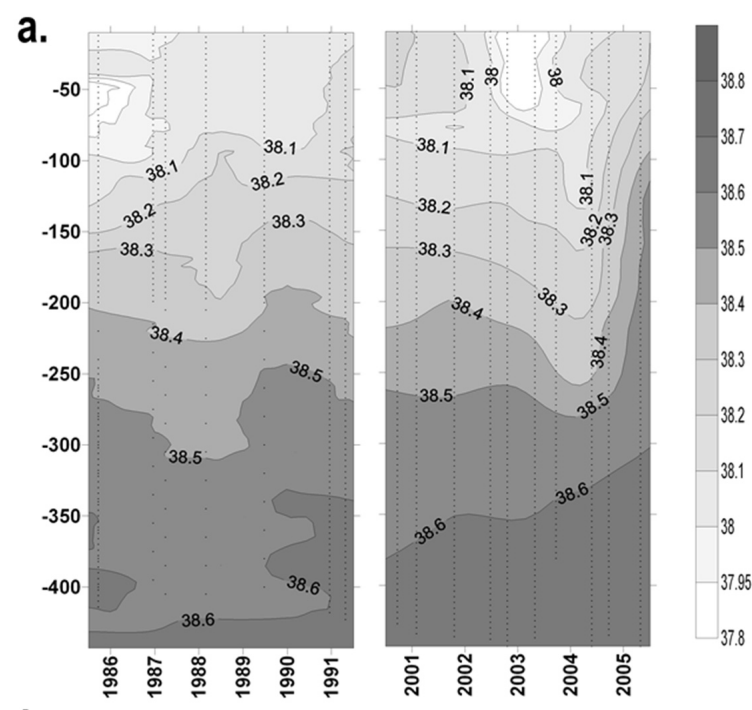

b.
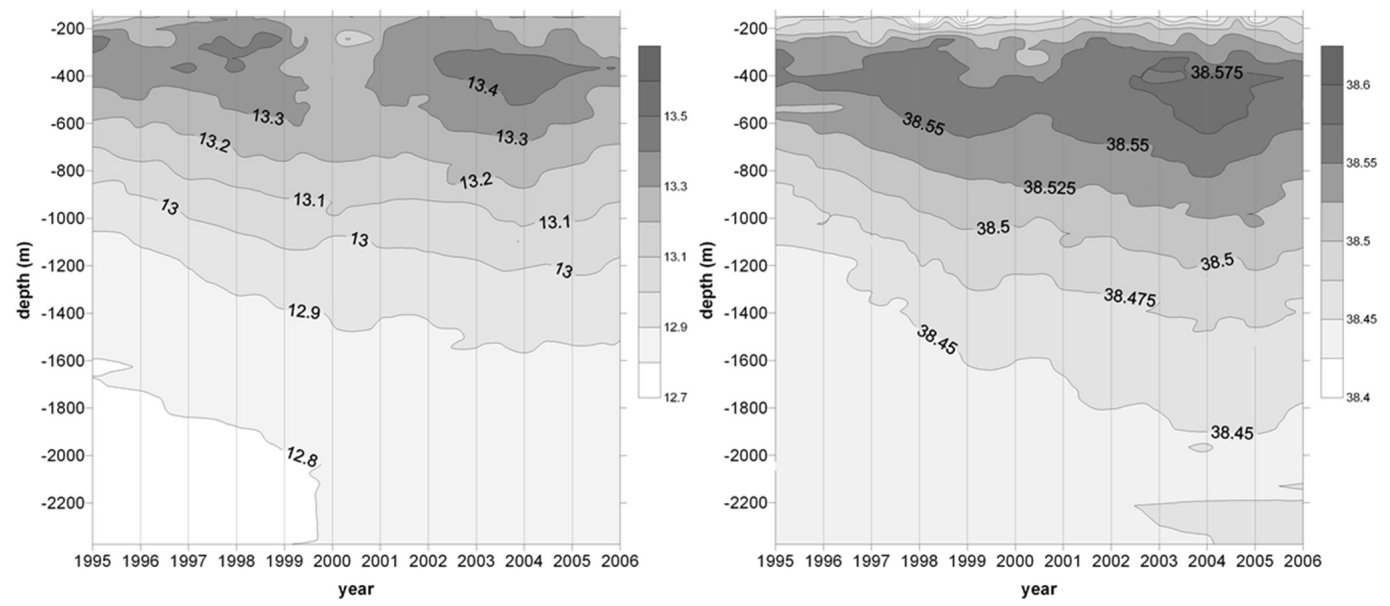

Fig. 8. (a) Temporal evolution of salinity in the Corsica Channel; (b) temporal evolution of potential temperature and salinity at the DYFAMED site showing the propagation of the EMT towards the WMed.

\section{Sub-basin and mesoscale variability}

Additionally, we need to improve our understanding of the eddies, their nature (permanent/transient) and lifetimes and their role in water mass transport and distribution that have different influences in each sub-basin.

\section{EMT and its influence in the WMed}

A further subject is the changes relevant to the EMT since the 1990s and the corresponding changes in the WMed, and the related variability over decadal or longer timescales in the entire Mediterranean, also in relation to the ongoing climatic changes (IPCC report). This analysis is straightforward for water properties based on historical hydrographic data after the early $50 \mathrm{~s}$, but the question of the past circulation patterns is more difficult, so that one has to employ model simulations.
5. Joint observational strategies and modeling studies

Apart from the existing European observational systems mentioned above, field observations from ships are of great value because they provide unique information with respect to the circulation and the thermohaline processes. One strategy in this direction would be to reapply past multi-ship multi-national hydrographe surveys, but these surveys will have to (1) be on a decadal timescale jointly for both Mediterranean basins, (2) extend to the near-Africa areas and (3) employ presently available technology on direct current measurements (ADCPs, LADCPs) so as to produce near-synoptic realizations of the 3-D surface-to-bottom mass and flow fields. These observations will provide indisputable pictures of the Mediterranean circulation that can not be achieved by 

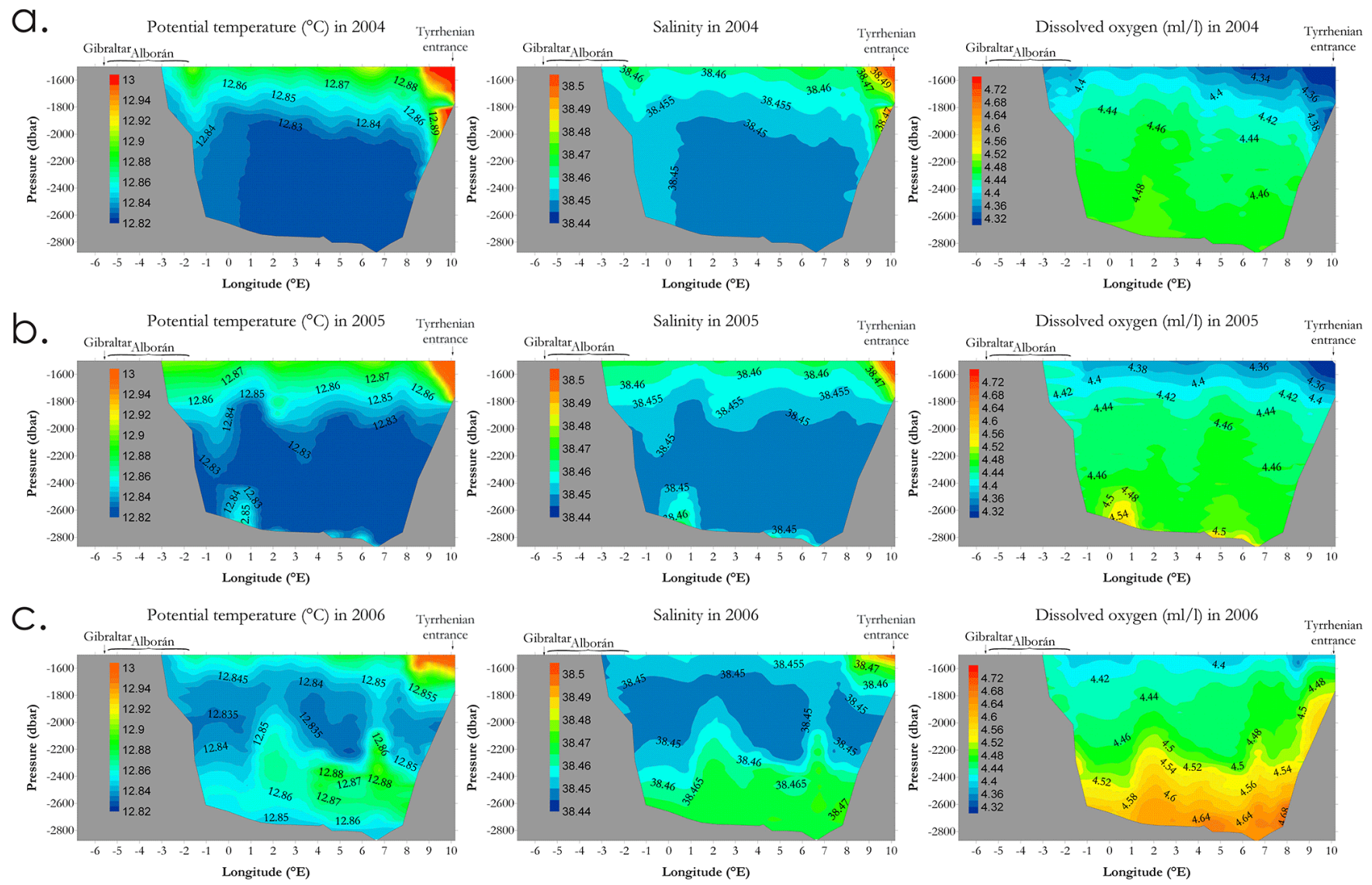

Fig. 9. Vertical $\theta, \mathrm{S}$ and $\mathrm{O}_{2}$ distributions below $1500 \mathrm{~m}$ depth along transects in the WMed showing the evolution of the WMT.

the operational observing systems. The other direction would be to continue monitoring certain parameters at key locations, such as straits and water formation areas. It is of importance to continue the effort towards an ocean-atmosphere interaction direction, which combines models with data, with schemes assimilating all different parameters of direct field measurements, from temperature and salinity to flow velocities throughout the water column.

\subsection{Forcings and variability in the stock of nutrients of the Mediterranean Basin}

\subsubsection{Present knowledge}

In this section we use the term biogeochemical in a restrictive sense, focusing only on the distributions of nutrients and the key processes affecting them. Based on nutrient concentrations, the western and the eastern Mediterranean are classified as oligotrophic or extremely oligotrophic. However, the trophic regimes of the basin cannot be characterized only by the low nutrient concentrations of Mediterranean waters. Atmospheric deposition, riverine inputs, exceptional crossshelf transports and exchanges with the Black Sea suggest a less extreme lack of nutrient availability in the photic zone, with a quick utilization and channeling through the food web (e.g., Thingstad et al., 2005).

Estimates of atmospheric fluxes are generally based on a few stations located around the perimetry of the basin (e.g., Guerzoni et al., 1999; Markaki et al., 2008) or, in the case of Saharan dust deposition, inferred from remote-sensing observations (e.g., Volpe et al., 2009). Despite the obvious uncertainties, most of the estimates support the view that atmospheric contributions provide an amount of nutrients to the photic zone comparable to other sources. Krom et al. (2004) presented a detailed nutrient budget for the eastern Mediterranean and showed that atmospheric input of dissolved inorganic nitrogen (DIN) and dissolved inorganic phosphorus (DIP) may account for $61 \%$ and $28 \%$ of the total budget of nitrogen $(\mathrm{N})$ and phosphorus $(\mathrm{P})$, respectively. This contribution is the most difficult to track in surface concentrations due to the low values of instantaneous fluxes and rapid uptake. A parallel uncertainty exists for cross-shelf fluxes due to extreme and hard-to-monitor events . The importance of external sources as compared to internal stocks and the rapid turnover of the basin is also at the origin of the nonRedfieldian N:P ratio in the stocks. N:P ratio in the atmospheric deposition, in dissolved or soluble inorganic forms (Ridame et al., 2003), is considered the natural candidate 
for explaining the anomalous high $\mathrm{N}: \mathrm{P}$ ratio typical of the Mediterranean. Indeed, it displays an eastwardly increasing trend, from about $20: 1-24: 1$ in the western basin to $28: 1$ in the eastern one (Markaki et al., 2008).

In the Mediterranean, river loads, even relatively important ones, have limited shelves (with the noticeable exception of the Po and West Adriatic rivers) and release their nutrient content directly into the open ocean. They also display a $\mathrm{N}$ : P ratio higher than Redfield, especially after the reduction in phosphorus utilization on land. Despite this evidence the relative weight of the different processes is still elusive.

The internal stock is homogenized by general circulation processes, such as the recurrent meandering of the northern current over the Provencal-Catalan shelf, that facilitate the export of nutrients from the coastal region offshore. Irregular bathymetric features near the coastal region, such as canyons, further enhance the export of water properties and suspended material offshore, contributing to an efficient transfer of coastal signals to the open ocean (e.g., Gomez Gesteira et al., 2003; de Madron et al., 2011).

All the external inputs contribute to mitigate, or to compensate for, the imbalance in the phosphate and nitrate budget estimated at Gibraltar (surface waters with low nutrient concentration, about 3-411 MN, enter the Alboran Sea in the upper layer of $-200 \mathrm{~m}$, while roughly twice as much exits in the lower layer). On the other hand, the large differences in water fluxes at the Gibraltar Strait $(0.81 \mathrm{~Sv}$ in, 0.76 out, CANIGO group) and the exchanges at the Sicily Channel (around $1.2 \mathrm{~Sv}$ ) suggest that in the western Mediterranean a relevant recirculation (with an associated supply of nutrients) must take place between the intermediate and upper layers, even if wind-driven upwellings are relatively small and not permanent. This is testified to by the relatively steady concentration of the nutrients in the deep layers of the Mediterranean.

\subsubsection{Unresolved issues}

1. Understanding the functioning of the Gibraltar valve

The Mediterranean is connected to the Atlantic through a shallow sill at Gibraltar, which is expected to decrease the turnover of tracers passing through the Gibraltar Strait. Despite its small section the strait is still responsible for the largest flux of water and elements into the basin. In the last decade observations have become more systematic and data are, therefore, increasing (e.g., Huertas et al., 2012). However, what is crucial is the net flux, which, as mentioned above, is significantly negative. Budget estimates have existed since the pioneering age of Mediterranean oceanography (e.g., McGill, 1961), but they generally assume a steady state. A dynamical reconstruction of the exchange with the Atlantic is still lacking. An analysis of pluriannual or long-term variations in fluxes, which may depend on the reorganization of
Mediterranean and Central Atlantic circulation, impacting on Mediterranean stocks, is not available. A robust estimate of the role of entrainment and mixing among different water masses because of the peculiar functioning of the Strait has only recently been made (e.g., Huertas et al., 2012; Bruno et al., 2013), but should be better refined. Models have also provided important insight, e.g., Sannino et al. (2009), but, to date, no single term of the nutrient budget of the basin is really solid, which is striking considering the size and the closeness of the basin. A better understanding of the functioning of the Gibraltar valve at different timescales (from decadal to centennial) is a necessary step for analyzing the Mediterranean internal variability and changes in nutrient stocks.

2. Turnover rates and exchanges between Mediterranean sub-basins

The turnover rates of Mediterranean nutrient stocks in different basins depend not only on advective processes and exchanges through the straits, but also on water mass transformation rates and biogeochemical processes. Constraining the physical drivers with classical approaches based on passive tracers and modeling would allow one to determine the coupling between surface biology and internal remineralization, which would also help in building scenarios of future trends in the basin. Furthermore, biogeochemical processes in filaments, fronts and eddies may be very important in coupling the surface and deep layers.

\section{Timescales of internal variability}

To assess the scales of internal variability a careful analysis of possible longer term oscillations/trends is required. Existing databases, even in presently reviewed forms, display high internal noise and dispersion of data. Despite this an updated assessment of pluri-decadal trends in nutrient concentrations for the eastern and western Mediterranean must be carried out starting from the existing database.

4. Data on stable isotopes

Stable isotopes have been recently used to differentiate the different atmospheric inputs in the eastern basin. Less is known for the western basin and, overall, the data available are still too few. ${ }^{15} \mathrm{~N}$ has also been used to infer trophic levels of copepods or top predators (e.g., Koppelman et al., 2009), still without covering the whole basin. Future surveys should consider those parameters, especially to approach the problem of the external vs. internal contribution of elements to the basin production. 


\section{Silicon dynamics}

De Madron et al. (2011) noted that decrease in terrestrial inputs may decrease the Si content of the basin. Ribera d'Alcala et al. (2003) pointed out that balancing the silicon budget in the Mediterranean is difficult with the existing data. The silicon distribution in the Mediterranean shows a different gradient with respect to nitrogen and phosphorus, indicating that a better representation of the silicon sources is necessary to quantify its variability in the open sea. In addition, there are sediment trap data that show a large proportion of biogenic silica, in contrast to the low primary production (at least in the eastern basin).

6. Mutual feedbacks between biogeochemical functioning and community structure

These feedbacks display differences between the subbasins of the Mediterranean that need to be addressed better (e.g., Moutin et al., 2012). Furthermore, the functioning of the biological pump should be investigated, combining estimates of $p \mathrm{CO}_{2}$, satellite PP, Chia data and POC fluxes measured by sediment traps at various depths along with the role of community structure (D'Ortenzio and Ribera d'Alcala, 2009).

7. Biogeochemical processes in intermediate and deep layers

These processes should be analyzed in relation to the higher respiration rates and the very low values of dissolved organic carbon (DOC, Santinelli et al., 2010).

\subsection{Modeling and assessing ecosystems in the Mediterranean Sea}

\subsubsection{Present knowledge}

The objective of this section is to identify some research priorities in physical-biological interactions limited to basinwide seasonal-to-decadal scales, in order to be consistent with the overarching objectives of this article. The interested reader can refer for the climatic scale to a comprehensive review of functioning and responses of Mediterranean marine biogeochemical cycles and ecosystems to key natural and anthropogenic drivers, recently published by the MerMex Group (2012). To elicit the nonlinear impact of dynamical variability on the ecosystem on the above-mentioned scales, basic questions, opportunities offered by innovative observational networks, and scientific challanges in numerical models are discussed to underpin the emerging research themes in a crosscutting perspective. A holistic approach has been followed in this section, prioritizing those themes that have been neglected up to now both for conceptual and practical reasons. The key questions have been set, retaining the "Mediterranean flavor", i.e., the specificity that makes this basin unique and vulnerable. The peculiarity of the Mediterranean Sea however has indeed been recognized but still not understood in its full complexity.

The whole Mediterranean Sea was characterized as a single bio-province by Longhurst (1998) by using an intermittent, variable-quality data set produced by CZCS. This conclusion has been questioned more recently by other papers based on different approaches: in situ data (Bianchi and Morri, 2000), remotely sensed surface chlorophyll (D'Ortenzio and Ribera d'Alcala, 2009), and decadal simulation of hydrodynamical-biogeochemical models (Lazzari et al., 2012). In this last paper an analysis of the dynamics of the physical-biogeochemical seasonal cycle has been produced, showing contrasting behaviors according with the different forcing. In Fig. 10 the opposite responses of the ecosystems to the seasonal cycles are represented using a sub-basin-integrated Longhurst diagrams (see the caption for details): in the NWMed (left plate) deep convection plays a major role in delaying the spring bloom by a month, while, to the other extreme, the model predicts a deepening of mixed layer depth (MLD), relatively high daily irradiance even in winter and a concomitant gentle increase in primary production and autotrophic biomass. Thus, two dominant regimes have been identified: "bloom" and "no bloom". In fact, despite being smaller, the WMed displays a larger number of trophic regimes than the eastern basin, which is known to be oligotrophic with the exception of the shallower part of the Adriatic Sea (D'Ortenzio and Ribera d'Alcala, 2009).

This is largely due to the interplay between physical and biological processes (inverse estuarine thermohaline circulation, biological pump, limited river loads, ubiquitous atmospheric inputs, etc.), the different forcings and their modulation by the morphology of boundaries, which may in turn produce a different internal dynamics (Crispi et al., 1998). Interesting responses to the interplay between primary and secondary producers have been identified in the case of episodic nutrient inputs. Paradigmatic is the impact of atmospheric input, which has long been recognized as a major source of nutrients in the Mediterranean surface waters. The response of the planktonic community to this episodic input in the case of nutrient-depleted surface water has proved elusive: during the CYCLOPS experiments, as a response to an artificial additional phospate addition, the total chlorophyll declined in the surface waters and there was an increase in bacterial production and, lately, copepod egg abundance. Thus the nutrient supply to the higher trophic levels may have taken place by phosphorus uptake in heterotrophic bacteria and by "tunnelling" to copepod through the heterotrophic nanoflagellate predation (Thingstad et al., 2005). This pathway may partially explain the relatively high carry capacity of the eastern basin compared with its primary productivity.

The link between differences in multiannual through multi-decadal variability in the internal dynamics of the two basins and the biotic dynamics is still an unexplored trait of the Mediterranean Sea. This issue deserves even more 


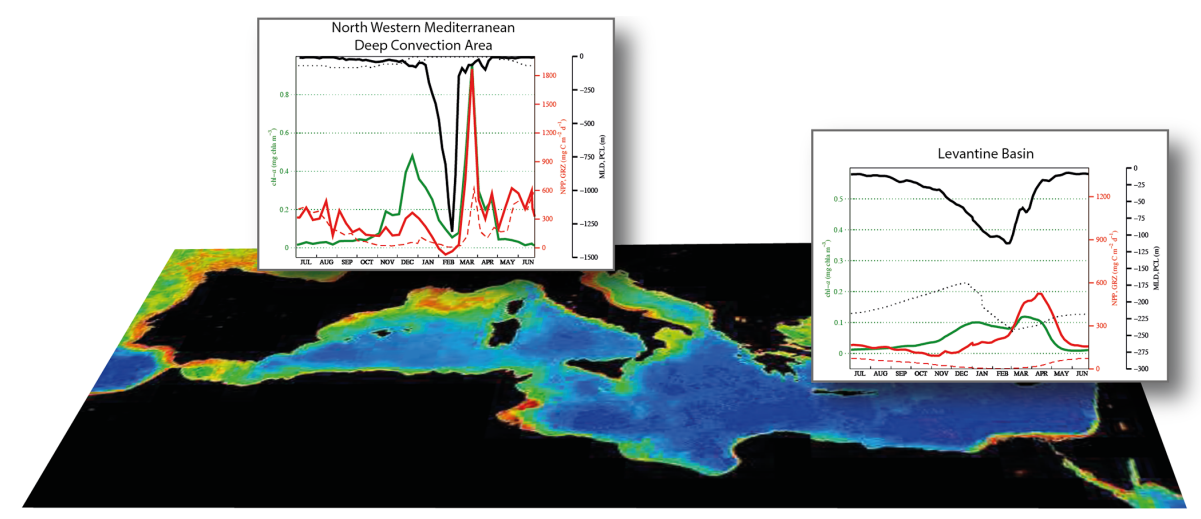

Fig. 10. Seasonal cycles of two contrasting ecosystem dynamics. The seasonal cycles of Chi-a concentration (green), MLD (black), net primary production (red solid), phosphocline (green dotted) and grazers (red dotted) are been modeled for the deep NWMed convection area (left) and for the Levantine Basin (right). The first reproduces very well the post-convection bloom (as seen in the Chi-a satellite images), while the latter follows a semi-tropical dynamics. Note that the vertical scales have been adjusted to accommodate the different intensities in the responses (after Lazzari et al., 2012, modified).

attention considering the recent finding of multiannual oscillations in the eastern Mediterranean (Gačić et al., 2011; Roether et al., 1996). On the other end of the drivers of changes, uncontrolled anthropic activities such as overfishing are impacting top predators of high commercial values. The expected impact on the food web is not confined to the upper trophic levels, but also influences the whole food chain (Parsons and Lalli, 2002). The biomass continuously supplied by primary producers was once channelled towards the top predators; now it is supposed increasingly to feed jellyfish growth (more generally the macro-zooplankton). "If jellyfish prevail, they are a further blow to fish populations, as they prey upon the prey of fish larvae (crustacean plankton) and on the larvae themselves, acting as both competitors and predators of fish" (Boero et al., 2008). The understanding of this potential regime shift should also be connected with the above dynamic variability and the introduction of non-indigenous species.

This fact, in turn, highlights that processes occurring in the basin should be approached through their appropriate space and timescales, spanning from the synoptical to the decadal (and longer) variability. The need to investigate the impacts of the internal and forced variability on longer timescales in the Mediterranean community structures and composition requires better, qualified, problem-oriented models and model systems (Arhonditsis and Brett, 2004).

The considerable efforts made up to now in trying to model the vertical dynamics and circulation processes and their impact on biogeochemical cycles on basin scale started approximately 20 years ago. A number of 3-D models were developed on the basin scale using a simplified food web (NPD) (Crise et al., 1998; Crispi et al., 1998) to study/simulate the east-west gradient in nutrient limitation and DCM depth, as well as the impact of the general circulation on the ecosystem dynamics. Many subregional studies have been carried out with intermediate complexity biogeochemical-coupled models in both the WMed and EMed, in particular in the NWMed (see Herrmann et al., 2013 and the references reported therein), the Adriatic Sea (Polimene et al., 2006; Cossarini et al., 2012) and the Alboran and Levantine basins. Despite its local validity, the regional approach to modeling is generally not useful for sub-basin intercomparison because of the forcing mismatches and the lack of spatio-temporal synopticity. In addition, even if the open boundary conditions derive from a coarser model, the solution is boundary condition dependent (in particular if the flushing timescale $L_{\text {basin }} / U_{\mathrm{OBC}}$ is less than the internal adjustment time to local forcing). In this case sub-regional simulations largely mimic the coarse model solutions on scales longer than the seasonal one.

More complex 1-D (water column) configurations based on the ERSEM and BFM (Fig. 11) model were used to study the ecosystem functioning in more detail, although mostly on the regional scale, addressing the dynamics of the microbial loop, the bacterial dynamic and primary production (Allen et al., 1998; Anderson and Turley, 2003; Polimene et al., 2007; Lazzari et al., 2012). A significant effort has focused on the data assimilation of biophysical parameters into an ecosystem model of the eastern Mediterranean (Triantafyllou et al., 2005, 2007).

Only recently have food web models and ecological network analysis applications been developed for Mediterranean marine ecosystems. Because of the intrinsic formulation of this class of models, the studies have focused on data-rich areas of the basin (Coll and Libralato, 2011). Very few studies (if any) are available for the southern side of the Mediterranean Sea. Few comparisons of trophic networks from different Mediterranean sub-basins have been published (Coll et al., 2008; Barausse and Palmieri, 2013), even if they can be proved essential in understanding the differences in 


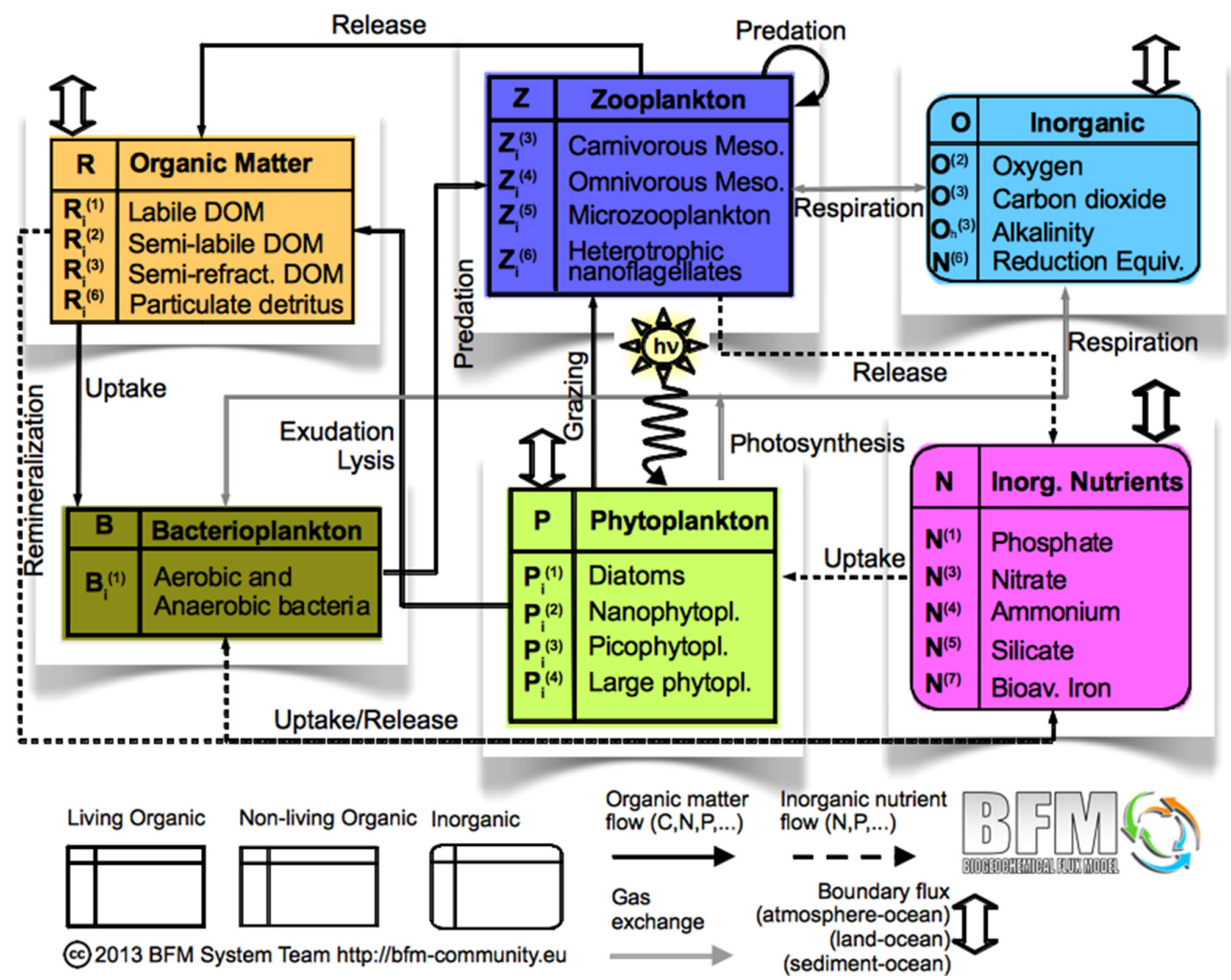

Fig. 11. State-of-the-art biogeochemical model schematics. The biogeochemical flux model is used extensively in Mediterranean biogeochemical studies. It describes the trophic interactions of the marine ecosystems by describing the cycles of the organic and inorganic carbon as well as the macro-nutrients. Major features are the plastic intracellular $\mathrm{N}: \mathrm{P}: \mathrm{Si}: \mathrm{C}: \mathrm{Chl} a$ ratios and the explicit description of the microbial loop.

the functioning of Mediterranean ecosystems. Such ecosystem models, if properly validated, can also provide a management tool for exploitation of renewable resources (Coll and Libralalto, 2012) and constitute a component of end-toend implementation of the marine ecosystems (Libralato and Solidoro, 2009). Experiments in producing decadal-scale reanalyses provided by state-of-the-art biogeochemical models coupled with data-assimilation schemes are carried out in the framework of some ongoing EC FP7 projects (MyOCEAN2, $\mathrm{OpEc}$ ) in order to be able to describe the dominant modes of variability of the Mediterranean ecosystem(s).

In recent years, substantial improvements in the scienceto-policy interface in the marine sector have been achieved, driven by practical requirements such as the ecosystem approach to the management of natural resources. This crosscutting approach also includes a socio-economical adaptive component to be connected in a seamless way to the ecosystem models. This approach is the backbone of ongoing projects aimed at connecting marine science findings with socio-economical models and management tools (e.g., the EC FP7 PERSEUS project).

\subsubsection{Unresolved issues}

The necessarily brief summary of the state of the art in ecosystem studies in relation to the physical forcing can generate many open questions. In the following, a selection of key questions focuses on basic understanding and modeling of the Mediterranean marine ecosystem to scales from synoptic to decadal.

1. Non-indigenous species (NIS)

The Mediterranean ecosystem structure(s) is(are) clearly influenced by the overall physical/chemical processes and exchanges active in the basin that favored the immigration of many species of Atlantic origin that dominate the Mediterranean communities and the invasion of alien species from either Gibraltar, Suez, and anthropogenic transport (Galil et al., 2007; Galil, 2000). The short time needed by several new non-indigenous species to colonize vast areas of the Mediterranean Sea hints at the presence of favorable conditions that may contribute to NIS success related to resources, natural enemies and the physical environment (Shea and Chesson, 2002). The foreseen temperature and salinity positive trends summed to the 
anthropogenic pressures create conditions to observe and understand the evolution of NIS in a changing ocean. The relative importance of resources, enemies and environment in an evolutionary perspective has to be investigated, and their impacts on the interactions between them (resource and escape opportunity, interaction between natural enemies and competition in the native range of the invader and the invaded community, community maturity and invasion resilience). The Mediterranean can be an ideal natural laboratory for improved understanding of coexistence mechanisms in an evolving marine realm.

\section{Mesopelagic community structure}

It has long been recognized that the dissolved oxygen vertical structure in the Mediterranean shows only a slightly pronounced oxygen minimum layer (if any) compared with other bio-provinces (i.e., the equatorial Pacific) (McGill, 1961). This highlights a relatively small export likely due to the peculiar community structure and composition. In addition, possible ventilation spots can occur in anticyclonic structures. This, in turn, further reduces the concentration of macronutrients in the ocean interiors, which suggests that the community efficiently recycles most of the nutrients in the surface layer. Conversely, dissolved organic carbon exhibits a well-shaped minimum with values comparable with those typical of the oceans (Santinelli et al., 2006). The mesopelagic trophic regime and respiration dynamics therefore deserve specific studies in light of these peculiar conditions.

\section{Habitat mapping}

The Regional Activity Centre for Specially Protected Areas showed that $39 \%$ of habitats and associated species considered in the list are scarcely covered by scientific knowledge and that the quantitative information about the geographical distribution of selected habitats and associated species is largely unbalanced toward the shallow western Mediterranean Sea (UNEP-MAP-RAC/SPA, 2006). There is a need to improve the classification protocols and the inventories of marine habitats (Fraschetti et al., 2011) in a novel perspective of continuously evolving ocean conditions. The classification would also include dynamical processes and rather new concepts such as ecological coherence and connectivity to allow better estimates of biodiversity distribution, and to reverse habitat loss rates through the systematic implementation of proper measures and instruments.

\section{Mesoscale impact on primary producers}

The mesoscale has a typical length shorter than the major oceans (about 15-20 km according to Pinardi and Masetti, 2000), but the coherent structures found in the satellite images are roughly three to four times the Rossby internal deformation radius, since twodimensional geostrophic turbulence is evolving toward larger scales. Large, long-lasting anticyclonic eddies are regularly generated in the Algerian Current, most probably because of the baroclinic instability of this current flowing along the African coast. A number of large, recurrent, continuously evolving structures connected by jets and separated by fronts (Robinson and Golnaraghi, 1994) have been observed in the surface waters of both sub-basins. In recent years the mesoscale activity in the Mediterranean has been a matter of scientific discussion, and is not the subject of this section. What is worth noting here is that the response in the surface chlorophyll images is not clearly connected to the vorticity polarity, so the simple equivalence cyclone (anticyclone) $=$ more(less) nutrient supply in the surface layer $=$ more(less) primary production seems not to hold in general. More intriguingly, during the stratified season no $\mathrm{Chl} a$ features are evident in the EMed. Since mesoscale, as tracked by the SSt and SSHA satellite-borne sensors, is ubiquitous, this unexpected result may be related to the well-known E-W nutricline slant. Alternatively (or in combination), a different penetration of the mixed layer, possibly modified by baroclinic processes, can be confined in the proximity of the surface, being unable to puncture the (deep) nutricline. This in turn can be responsible for the different responses in the standing crops and primary production of the two subbasins. The origin of the differences in this response has still to be investigated thoroughly.

5. Impact of decadal variability on the western Mediterranean food web

While recent analyses hint at a relevant role of interannual variability in the EMed (10-20\% of the seasonal cycle), existing data show that the seasonal cycle is the dominant component of variation. However, recent 50year Mediterranean climatology provides evidence of consistent temperature changes in the WMed and the North Atlantic, explained by similarities in the atmospheric heat flux anomalies strongly correlated with NAO (Rixen et al., 2005). Conversely, the copepod community composition and abundance (even with a clear seasonal cycle) exhibits in the Ionian Sea a reduced variability on the interannual scale showing a remarkable resilience to the interannual variability. More generally, an assessment of the long-term atmospheric variability impact on the food web has still to be made.

6. Multiple stressor impacts on Mediterranean marine ecosystem functioning

Global increases in atmospheric $\mathrm{CO}_{2}$ and temperature are associated with changes in ocean chemistry 
and circulation, altering light, $\mathrm{pH}$ and nutrient regimes. Resulting changes in phytoplankton community structure are expected to have a cascading effect on primary and export production, food web dynamics and the structure of the marine food web as well as the biogeochemical cycling of carbon and bio-limiting elements in the sea. A review of the current literature indicates that cell size and elemental stoichiometry often respond predictably to abiotic conditions and follow biophysical rules that link environmental conditions to growth rates, and growth rates to food web interactions, and consequently to the biogeochemical cycling of elements. This suggests that cell size and elemental stoichiometry must be monitored to allow modeling and tracking changes in phytoplankton community structure in response to climate change. In turn, these changes are expected to have further impacts on phytoplankton community structure through as yet poorly understood secondary processes associated with trophic dynamics (Finkel et al., 2010).

7. Modeling and assessing the budgets of the relevant ocean variables for Mediterranean sub-basins

The Mediterranean physiography as well as its circulation dynamics are composed of a limited number sub-basins connected by straits. In their interior, subbasins have internal (in some ways independent) dynamics, whereas the impact of the other sub-basins is ruled by the exchanges at the connecting straits. In this context, the Mediterranean nutrient dynamics as depicted with full-blown 3-D coupled BGC hydrodynamical models can be represented as averaged 1$\mathrm{D}$ or $0-\mathrm{D}$ variable vectors, each representing a subbasin interconnected by laterally averaged fluxes. This simplified analysis should allow the testing of scenarios (i.e., modifications of boxes' internal functioning, changing fluxes at the connecting boundaries, steady state vs. interannual/decadal variability, connections/feedbacks/linkages with climate alteration), directly focusing on the impact of the internal vs. external forcing on the nutrients, and spatio-temporal repartition between sub-basins.

\section{Observational needs and perspectives}

The issues unresolved above often require closely interconnected state-of-the-art observational capacity and cutting edge technologies. Here some basic requirements are spelled out, in terms of observations, data management and modeling. Autonomous observational techniques profiting from the advancement of observational techniques should be adopted extensively because they provide new relevant information on distributions and internal dynamics of the mesopelagic and bathypelagic ecosystems at high space and time resolution. The integration with advanced technologies (metagenomics, automated image analysis and recognition, innovative acoustic measurements) on autonomous vehicles such as AUV is still a challenge, but will lead in the near future to a totally different approach to observing ocean interiors. There is a need for a network of sustained truly multidisciplinary deep sea observatories able to complement the "diffuse" and often problem-/projectdependent observing initiatives and experiments. The data integration and harmonization of observing stategies lead to the further development of a sustained ocean observing system prioritizing the Mediterranean at European level and taking advantage of what has been developed and consolidated within EuroGOOS and, in particular, MONGOOS. There is a need for a sustained pan-Mediterranean cyber-infrastructure based on existing components (MyOCEAN, SeaDataNet, national initiatives) to link, qualify, preserve and disseminate the observations to facilitate the data and metadata interoperability in the framework of the GEO and GEOSS programs. An open and free data policy should be adopted by all the major actors in Mediterranean marine research acknowledging the EC INSPIRE directive, in order to enable easy access to data and their reuse.

3 Relative importance of external forcing functions (wind stress, heat/moisture fluxes, forcing through straits) vs. internal variability

\subsection{The role of salinity decadal oscillations in triggering the thermohaline circulation and the Mediterranean conveyor belt}

\subsubsection{Present knowledge}

The Mediterranean Sea open circulation cell is driven by the salinity differences between the inflowing low-salinity Atlantic Water (AW) and the highly saline Eastern Mediterranean waters, mainly the Levantine Intermediate Water (LIW). The salinity differences established between the two water masses are maintained due to the prevalence of evaporation over precipitation. Deep closed circulation cells are driven by the air-sea heat losses at specific locations, resulting in vertical convection and dense-water formation. This average circulation pattern is subject to interannual and decadal variability due to both external (meteorological) and internal forcings. Temporal variability of the closed circulation cells is primarily determined by the intensity of the dense-water formation, which in turn depends on the air-sea heat fluxes and the preconditioning. Deep circulation was thought for a long time to be invariable, and based on that the residence time of the Eastern Mediterranean was estimated at about 100 years. Recent long-term simulations gave 
evidence that the alteration of the two sources of dense waters (Adriatic and Aegean Seas) in the EMed could be a recurrent phenomenon, connected to salinity out-of-phase decadal oscillations between the two basins (Borzelli et al., 2009), given the necessary intense local atmospheric forcing. The salt content in each formation site, along with the intensity of the atmospheric forcing, determines the depth of the convection and thus the density of the newly produced water. In the early 70 s a high-salinity event was documented in the Levantine and Aegean, but with lower formation rates and thus without a significant signature of Aegean dense water in the adjacent sub-basins (Beuvier et al., 2010). Theocharis et al. (2002) noted that the 70s episode was evident in all three basins, Levantine, Ionian and Aegean, with a maximum signal in the Levantine. The total volume of the produced waters was lower than that produced during the EMT, thus its effect vanished quickly.

In the mid-1990s, experimental evidence on the Eastern Mediterranean Transient (EMT) was presented and it was shown that the abyssal circulation is not in a steady state but can be subject to episodic sudden changes (Roether et al., 1996). The EMT involves the passage of the Eastern Mediterranean dense-water formation site from the Adriatic to the Aegean. This then resulted in important changes in the abyssal circulation of the entire basin. Changes were evidenced over the upper part of the water column as well. Generally, the most prominent variations in the upper layer circulation have taken place in the northwestern Ionian, where they manifested as the circulation reversal in 1997 reinforced by the EMT. In addition, evidence of two other events in 1987 and 2006 (Gačić et al., 2011) was presented. These reversals of the upper-layer circulation pattern in the Ionian denominated Bimodal Oscillation System (BiOS) (Gačić et al., 2010) determine the salt redistribution between the Adriatic and the Levantine/Cretan seas (Fig. 12, adapted from Gačić et al., 2010). This is due to a preferential pathway of the relatively fresh AW; in the cyclonic circulation pattern in the Ionian the AW pathway is towards the Levantine/Cretan seas, while during the Ionian anticyclonic circulation mode the northern Ionian and the southern Adriatic are subject to freshening due to the increased spreading of the AW northeastward.

Therefore, the salt content and buoyancy in the upper layers of the Adriatic and the Levantine/Aegean are out of phase, suggesting that one or the other sub-basin is more prone to the convective mixing. This suggests that the EMT, i.e., the Cretan Sea undertaking the role of the main densewater source for the Eastern Mediterranean, is potentially a recurrent phenomenon if the winter air-sea heat losses are strong enough. Important decadal variability in the thermohaline properties and the deep circulation were evidenced in the Western Mediterranean as well. Again, salinity forcing seems to play an important role, since on decadal scale there is important building-up of the highly saline water spreading over the entire bottom layer and increasing continuously in

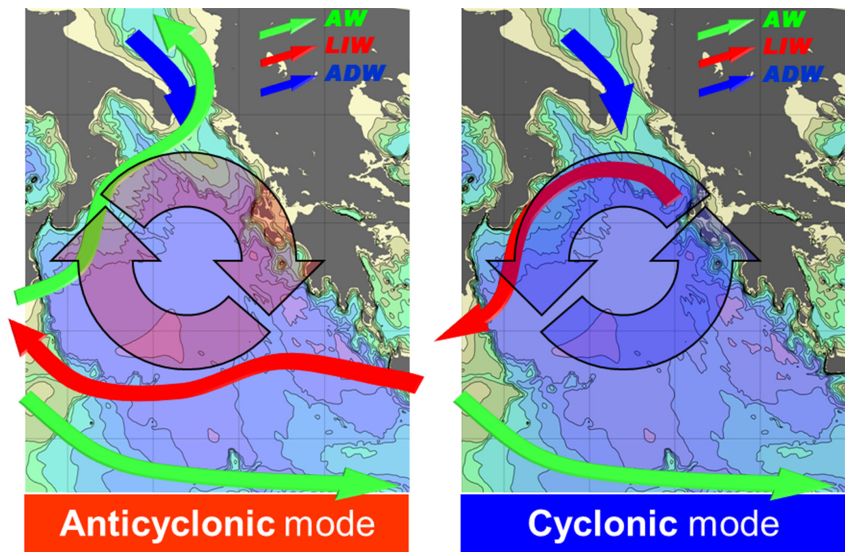

Fig. 12. Schematic presentation of the BiOS decadal inversions of the Ionian circulation and pathways of the principal water masses.

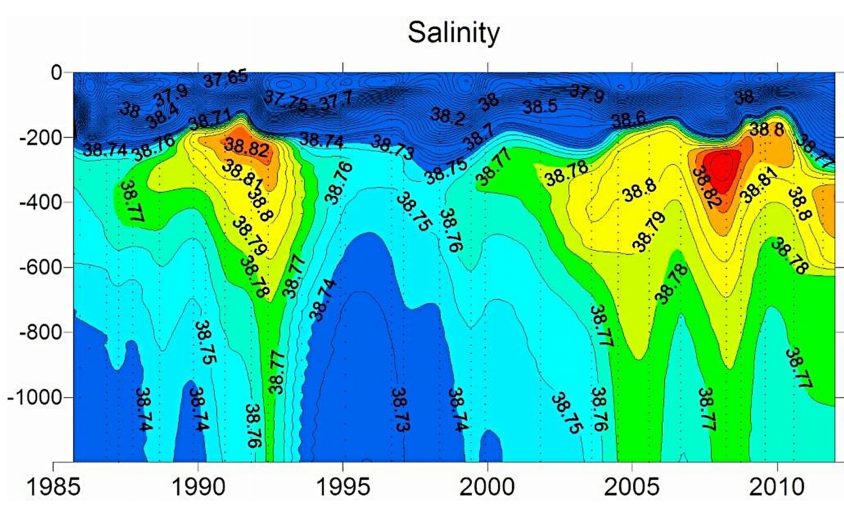

Fig. 13. Time-depth diagram of the salinity variations in the Sicily Channel. Two episodes of the salinity maximum at the depth of the LIW are evident in the early 1990s and in the second half of the 2000s associated with BiOS and impacting the WMDW and Western Mediterranean Transition pre-conditioning (modified from Gačić et al., 2013).

thickness from 2004 up to the present day. The phenomenon is called the Western Mediterranean Transition and can presumably be connected to the inflow of the LIW of varying salinity from the Eastern Mediterranean (Schroeder et al., 2009). In fact, it has been shown recently (Gačić et al., 2013) that this salinity increase can be explained by up to $60 \%$ by the advective input of the highly saline LIW and thus related to $\mathrm{BiOS}$ and circulation reversals in the Ionian subbasin (Fig. 13). The replenishment of the deep basin is by newly formed Western Mediterranean Deep Water that, depending on its density, can either uplift old resident waters or lay above them, leaving in any case a cold signature in the temperature series (Garcia-Lafuente et al., 2009). This mechanism then determines interannual variability of thermohaline properties of the outflowing Mediterranean waters, possibly changing their impact on the global conveyor belt. 
The Mediterranean outflow is a constant source of warm and salty intermediate water, and it has even been suggested that it influences the Atlantic Meridional Overturning Circulation (Candela, 2001). Thus, understanding the interannual and long-term variability of the Mediterranean Sea appears to have a broader significance than previously thought (Millot, 2007).

\subsubsection{Unresolved issues}

1. Completion of a more reliable data set for studies of long-term variability in the Mediterranean

During the last few years considerable effort has been put into identifying past changes in the water mass characteristics of the Mediterranean Sea from historical hydrographic records related to salinity oscillations. The investigation of this long-term variability by using historical databases such as MEDARMEDATLAS has been proven to be inadequate due to spatial inhomogeneity of data and high noise levels (Schroeder et al., 2012). Important efforts have been made to construct new and extend existing data sets (SeaDataNet, EMODNET, MyOcean) that pass screening quality control procedures, but cannot resolve the inefficiencies of past measurements and spatial inhomogeneity. Long-term reanalysis simulations that assimilate in situ measurements and exploit the significant amount of information from observational systems in the Mediterranean are an important step towards reliable reconstructions for "short-term" climatic analysis. Moreover, studies of DWF and circulation on decadal and interdecadal scales must take into account the variability of the inflowing $\mathrm{AW}$ and in particular its observed increasing salt content (Lauzier and Sindlinger, 2009).

2. Relative importance of internal processes and external large-scale climatic forcing

The salinity oscillations show a prevailing decadal timescale modulated by internal mechanisms, but could also be influenced by atmospheric forcing. This is especially related to the fact that the deep closed circulation cells are subject to the air-sea heat fluxes. The large-scale atmospheric circulations such as the NAO (North Atlantic Oscillation), which largely determines Mediterranean winter climatic conditions (Xoplaki et al., 2003) and EA (East Atlantic) and plays an important role over most of the region (Krichak et al., 2002; Josey, 2010), also exhibits variability on decadal timescales. Therefore, it is important to investigate the combined effects and relative importance of internal processes and external forcing.
3. Decadal and interdecadal variability studies in the Mediterranean as a whole

The intensity of the EMT compared to similar past events is a major issue. Both the increase in salinity and the huge amount of dense waters $(8 \mathrm{~Sv}$ years, Roether et al., 2007) produced in the Aegean were exceptional. Further study is needed to clarify whether the EMT can be attributed to coincidence of the salinity preconditioning of the area with intense atmospheric forcing. Diagnostic long-term simulations give evidence of internal modes of variability even on interdecadal timescales (Pisacane et al., 2006). It is important to find out whether the Mediterranean as a whole exhibits internal variability modes, similar to or inferred by the decadal oscillations evidenced in the EMed.

4. Studies of long-term trends

It is of great interest to study the variability and trends in the EMED in response to changes and improve knowledge of the functioning of internal feedback mechanisms and related processes.

5. Biogeochemical responses in the Mediterranean to circulation changes

Finally, biogeochemical responses in both the Eastern and Western Mediterranean to circulation changes on the decadal scale should be addressed in more detail (Civitarese et al., 2010).

\subsection{Residence times and ventilation of water masses in the Mediterranean Sea: implications for dynamical and biogeochemical processes}

\subsubsection{Present knowledge}

Water mass characteristics, structure and distribution in the Mediterranean, as well as the associated circulation patterns, are complex and show significant variability and sensitivity. This can be attributed to the complex topography of the basin, the diversity of the mixing processes involved, the variability of atmospheric forcing on various timescales and the variety of water mass formation processes present in the basin. Regional and local observational efforts and modeling studies of the Mediterranean and its sub-basins reveal a complete picture of the water mass structure and evolution. Even in the same sub-basin and nearby depressions, water mass characteristics and tracer concentrations of the deep waters present a remarkable diversity, as can be seen in Fig. 14, depicting the spatial and temporal variability in the Aegean Sea (Gertman et al., 2006; Zervakis et al., 2000; Vervatis et al., 2011). At the same time, significant and sometimes abrupt changes are encountered in the deep and intermediate layers (Roether et al., 1996; Schroeder et al., 2010). An example 

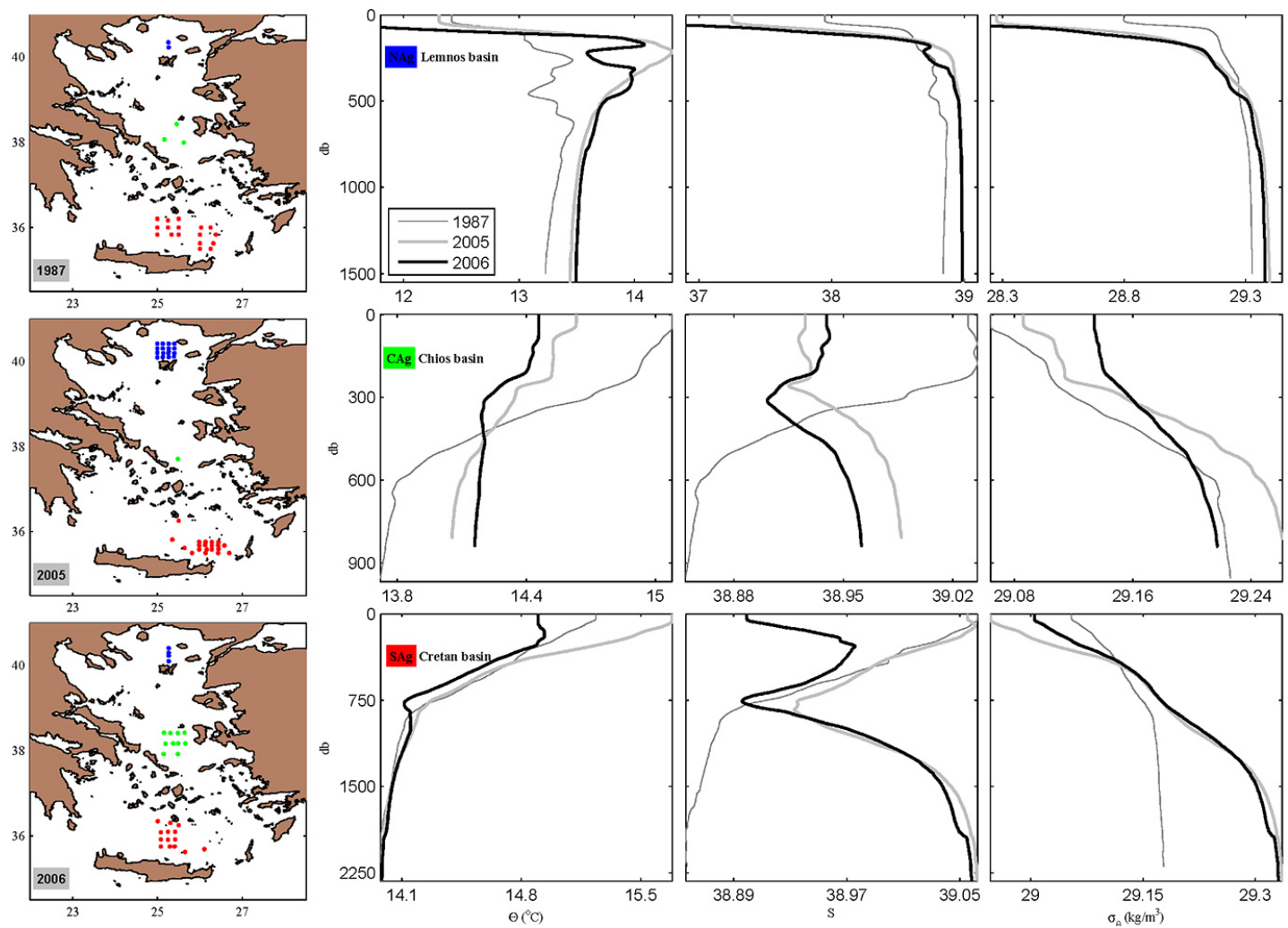

Fig. 14. Map panels: Aegean Sea winter hydrographic stations for the years 1987 (pre-EMT), 2005 and 2006 (post-EMT); North Aegean (NAg): blue dots at the Lemnos basin; Central Aegean (CAg): green dots at the Chios basin; South Aegean (SAg): red dots at the centraleastern Cretan basin. Profile panels: averaged profiles of $Q\left({ }^{\circ} \mathrm{C}\right), S$ and $\sigma_{\theta}\left(\mathrm{kg} \mathrm{m}^{-3}\right)$, for all three major sub-basins; adapted from Vervatis et al. (2011).

of the abrupt change in the heat and salt content of the deep layers in the Western Mediterranean is illustrated in Fig. 15.

If we want to understand the dynamical and biogeochemical functioning of the Mediterranean Sea, we need to construct a clear picture of the water mass structure and characteristics, monitor their variability and relate it to internal and external forcing mechanisms. Evaluation of the renewal timescales and the associated processes of the Mediterranean water masses is crucial for understanding the variability of the thermohaline circulation and its response to the atmospheric variability. Progress in our understanding and quantification of these processes will also enhance the investigation of biogeochemical cycles on basin-wide or regional/local scales. Using a variety of observational and modeling approaches, the evaluation of residence times and the investigation of aging processes of the various water masses can be achieved.

\subsubsection{Unresolved issues}

1. Investigation of spatial and temporal variability of deep water masses in the Mediterranean Sea, using historical data and modeling reanalysis
A series of research projects was devoted to constructing oceanographic databases on the global and regional scales (e.g., SESAME, SeaDataNet, EMODNET, MyOcean). Today a wealth of data exists that can be used to analyze the spatio-temporal variability of physical and biogeochemical parameters in the Mediterranean Sea. Modeling techniques and computer power have been greatly improved during the last decades, enabling an ever increasing accuracy of results that can be applied on the Mediterranean and subbasin scales for the investigation of long-term variability. The contribution of operational oceanography in the Mediterranean Sea was important, developing and implementing new and advanced modeling tools and techniques in the Mediterranean Sea in the framework of research projects and initiatives at the Mediterranean and European levels (e.g., MFSPP, MFSTEP, ECOOP, MERSEA, MyOcean, MOON/MONGOOS). Blending the two approaches through data assimilation procedures can produce useful results for filling spatio-temporal gaps. It is important that additional quality control of existing data collections for, in particular, biogeochemical parameters is performed 

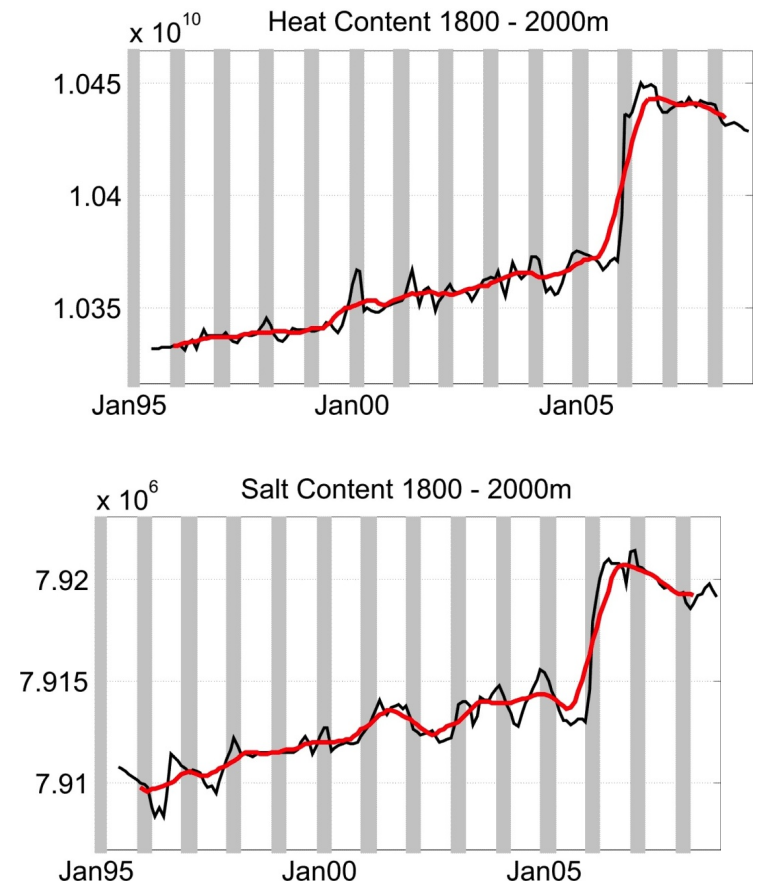

Fig. 15. (a) Temporal evolution of heat content $\left(\mathrm{J} \mathrm{m}^{-2}\right)$ of the 1800-2000 m layer at the Dynamique des Flux Atmosphériques en Méditerranée (DYFAMED) site in each $200 \mathrm{~m}$ layer from 0 to $2000 \mathrm{~m}$ (black line, observed; red line, moving average over 13 months). Shaded regions indicate the "convection period" (December-March); (b) same as (a) except for salt content $\left(10^{3} \mathrm{~kg} \mathrm{~m}^{-2}\right)$; (adapted from Schroeder et al., 2010).

to ensure that the data sets are internally consistent and that measurement biases are removed so that temporal trends can be estimated correctly.

2. Investigation of ventilation processes in water masses and monitoring of spatio-temporal variability

Based on past observations, numerical model techniques and a strategy for observational processorientated campaigns, renewal patterns and mixing processes that affect the characteristics and ventilation of the water masses can be revealed and explained. Places like deep depressions, straits and water-mass formation areas are key sites for understanding renewal processes. Monitoring of the spatio-temporal variability can also take advantage of national and international observational networks, among which the HydroChanges CIESM program deserves special mention (http://www.ciesm.org/marine/programs/ hydrochanges.htm).

3. Estimation of residence times of water masses

The overall observational and modeling strategy should target the estimation of the residence time of the various water masses in the Mediterranean Sea.
Simpler and more elaborate techniques (box models, GCMs, etc.) can both be applied. In this way, the effects of residence time and renewal processes on the physical and biogeochemical cycles can be better understood. Regular measurement of transient tracers in the Mediterranean Sea is an important and valuable tool for monitoring ventilation processes and any spatio-temporal changes in ventilation.

\section{Attribution of renewal processes}

All the above should be related to the investigation of the relative importance of external forcing and internal modes of variability. The imprint of these on the deep-water masses is very significant in understanding the dynamical and biogeochemical functioning of the Mediterranean Sea.

\subsection{Paleo-climate and past physical/biogeochemical changes in the Mediterranean}

\subsubsection{Present knowledge}

The investigation of marine archives (like sediment cores) provides new and relevant evidence of physical and biogeochemical processes, which drove the dynamics of the Mediterranean basin, in terms of response to regional/global climate, exchanges with the Atlantic Ocean and internal processes on the sub-basin scale. This backward glance could extend our potential for understanding the deeper physical forces that presently drive the 3-D circulation system of the basin and regulate its relationships with the climate system.

So far the existing paleoclimate records provide data sets for different environmental indices, including microfaunal abundances (planktonic and benthic foraminifera), microfloral abundances (coccolithophores, dinocysts), and pollen. The analysis of stable isotopes and biomarkers/alkenones indicates rich and interesting dynamics in the eastern and western Mediterranean sub-basins in the past.

Despite the large amount of existing data, comparison between different records is problematic as archives are characterized mainly by different time resolutions and spatial distributions, while data collection is characterized by different methodological approaches. This lack of a systematic comparison between the paleoceanographic records inhibits an overall climatic consideration, which is an important step towards improving our understanding of the physical climate and its variability in response to natural and anthropogenic forcing.

A detailed study of the last 20 kyrs of Mediterranean sea dynamics was focused on selected time intervals like the transition from the last glacial maximum (LGM, $\sim 20 \mathrm{kyr} \mathrm{BP}$ ) to the Holocene, a distinctive cooling between 13 and 11.7 kyr BP (Younger Dryas), a rather mild climatic period between 10 and $6 \mathrm{kyr} \mathrm{BP}$, a warm and wet period within the Mid Holocene, followed by the abrupt climatic 
deterioration observed all over the Northern Hemisphere at $4.2 \mathrm{kyr}$ BP and several cooling and warming events during the last 2 kyrs.

As an example of climatic reconstruction, the Eastern Mediterranean circulation experienced a major phase of reduced thermohaline ventilation, causing anoxic sediment (sapropel) deposition between $\sim 10$ and $6 \mathrm{ka} \mathrm{BP}$ (Holocene climatic optimum and S1 deposition). A remarkable interruption, centred at $8.2 \mathrm{ka} \mathrm{BP}$ and reflecting an invigorated thermohaline circulation, occurred during this event in both the Adriatic and Aegean seas, with repopulation of deep-sea sediments by benthic foraminifera that had been absent before and after because of the anoxia (De Rijk et al., 1999). The $8.2 \mathrm{ka}$ BP cooling event was found to be part of a repetitive sequence of rapid climate shifts (Bond et al., 1997) that can also be recognized in the Mediterranean Sea (Incarbona et al., 2008). The close association of these climatic shifts with abrupt changes in bottom water oxygenation and organic-rich matter (sapropel) deposition makes them uniquely suitable for the investigation of the changes in climatic forcing that caused thermohaline shutdowns/restarts.

Climatic reconstruction of the time interval during the last $20 \mathrm{kyr}$, however, is not simple. This is because regional factors, associated with the hydrologic, chemical-physical and climatic features of the Mediterranean, largely determine climatic variability (Cacho et al., 2002; Rohling et al., 2002). Moreover, despite the fact that the deep waters of the Mediterranean are currently well ventilated (Bethoux et al., 1999), the presence of sapropels in the eastern Mediterranean indicates that this mechanism has been absent several times in the past. Over the past million years, relatively small changes in the Mediterranean water budget have had a profound impact on the thermohaline circulation of the basin. Many studies have addressed the relationship between enhanced freshwater input into the basin at times of summer insolation maxima in the Northern Hemisphere and the formation of sapropels (Fig. 16); enhanced burial of organic carbon in sediments was likely initiated by the influx of low-salinity waters that slowed or halted the convective overturning in the eastern Mediterranean and reduced deep-water oxygenation (Rohling et al., 2002).

In the western Mediterranean, there is no record of sapropel deposits, but organic-rich, nonlaminated layer (ORL) deposit records are available. Although these cannot be considered to be true sapropels, some paleoceanographic studies dated and correlated eastern Mediterranean sapropels (Rohling, 1994) with ORL in the western Mediterranean (Perez-Folgado et al., 2004).

As the Mediterranean enhances the paleoceanographic and paleoclimatic signals, the basin can be used as a laboratory for climate change. This is the time to establish a paleoceanographic comparison between the eastern and western sides of the Mediterranean and evaluate paleoproductivity trends related to paleoclimatic events.
Although the analysis of proxy records to study the climate of the past is important, it provides only partial information regarding the state of the past ocean and the processes that regulated it. To complete our knowledge, model simulations are necessary. The modeling experiments have first to be validated with observations and can then be used to study the fully realistic, three-dimensional ocean dynamics.

The use of simple box models can clarify some mechanisms underlying the variability in the circulation of the Mediterranean. These simple models, which include Stommel's pioneering box model (Stommel, 1961), are useful for studying the multiple states of the Mediterranean Thermohaline Circulation (THC) in the different basins as well as the oscillations between them (e.g., the Bimodal Oscillating System, Gačić et al., 2010). An example of such a box model for the Eastern Mediterranean THC showing the shift in the deep water formation cell from the Adriatic to the Aegean seas has recently been proposed by Ashkenazy et al. (2012). These models, although not realistic, provide a conceptual view of the dynamics and the mechanisms underlying its variability. On the other end, hypotheses made by using simple models can be verified by using more complex ocean global circulation models and proxy data.

\subsubsection{Unresolved issues}

1. Impact of the Atlantic circulation on the Mediterranean THC

No investigation exists about how the changes in the Atlantic waters inflowing at Gibraltar affect the Mediterranean thermohaline circulation as opposed to changes in surface heat fluxes.

2. Analysis of the limiting factors of the past interaction between North Atlantic and Mediterranean THC

A proto-modern circulation was established in the Mediterranean when the eastern connection with the Indian Ocean was interrupted $\sim 18$ million years ago (Sprovieri et al., 2007). Thereafter, the Gibraltar sill regulated the Mediterranean circulation. In a broad sense, the North Atlantic and the Mediterranean can be seen as one connected system, whose internal dynamics is modulated by the exchanges at Gibraltar (Artale et al., 2006).

3. Investigation of the nonlinear behavior of the Mediterranean circulation

The present state-of-the-art numerical climate models are able to provide reasonable simulations of the present climate but are unable to reproduce the rapid transitions from one climate state, such as glacial climate, to another such as the present state. These transitions are inherently nonlinear and involve the competition and interactions between external forcing, such as 


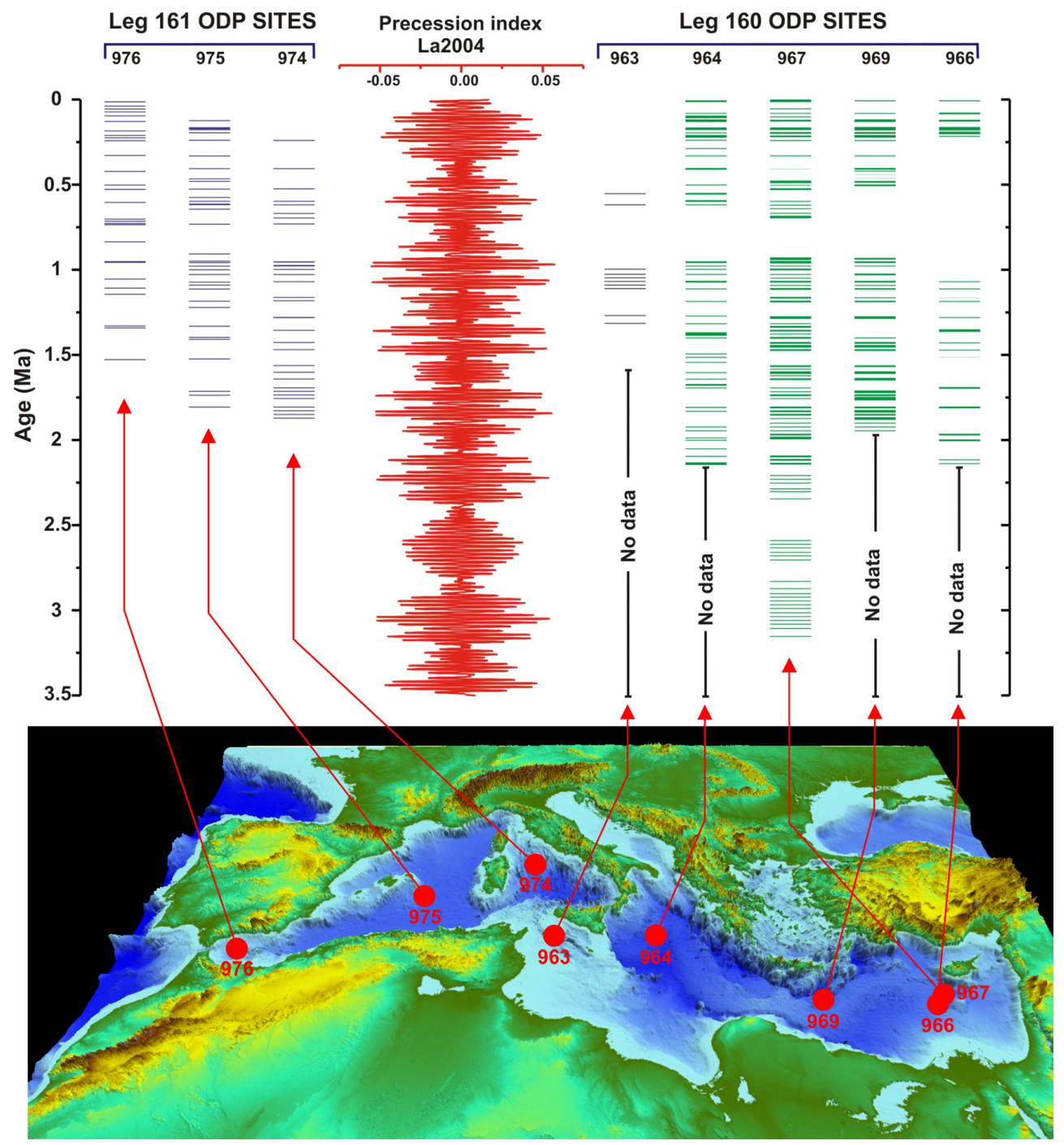

Fig. 16. Plot of sapropels and organic-rich layers (ORLs) collected in the Mediterranean Sea over the last 3.5 million years by the Ocean Drilling Program (ODP), legs 160 and 161. The chronology of sapropel layers from the central-eastern Mediterranean Sea (ODP sites 963, 964, 966, 967 and 969) follows Howell et al. (1998) and Emeis et al. (2000). The chronology of ORLs from the western Mediterranean Sea (ODP sites 974, 975 and 976) follows Murat (1999). The precession index of the same time slice is also shown (Laskar et al., 2004). Inset below: the bathymetric map of the Mediterranean Sea and the location of the ODP sites.

wind stress and heat-moisture fluxes, and internal dynamical mechanisms such as BIOS (Gačić et al., 2010; see also Sect. 3.4).

4. Study of the patterns of climate change of the Northern Hemisphere influencing Mediterranean climates

The available evidence suggests that forced changes in dynamical modes of variability in the global ocean, such as the North Atlantic Oscillation (NAO), El Nino-Southern Oscillation (ENSO) and the Atlantic Multi-decadal Oscillation (AMO) play a key role in the patterns of climate variability in the Mediterranean region, and investigations are needed for remote times (see also Sect. 3.4).

\subsection{Short-term and climatic variability in the SST and mixed layer heat budget over the Mediterranean and effects on the circulation and biota surface concentrations}

\subsubsection{Present knowledge}

Instrumental records of increasing duration and spatial coverage as well as modeling efforts have documented substantial Mediterranean variability on timescales ranging from one day or less to decades and longer. Part of this variability can be related to known forcing mechanisms, but in many cases the relationship between observed variability and forcing has not been fully understood. Variability in the strength 


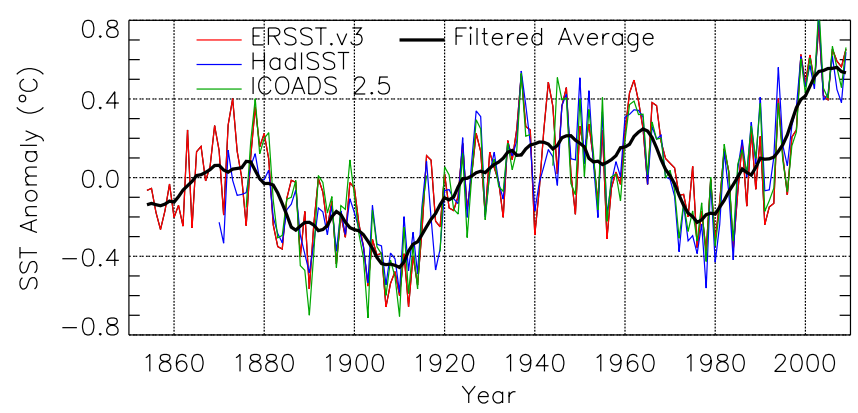

Fig. 17. Mediterranean annual SST anomaly (with respect to the 1971-2000 average) from 1854 to 2008. The red line shows ERSST.v3, the blue line HadISST, and the green line ICOADS 2.5. The solid black line represents the filtered average of the three data sets (from Marullo et al., 2011, American Meteorological Society; used with permission).

and location of local fluxes of heat, moisture and momentum are reflected in changes in the surface fields. Among these fields, the sea surface temperature (SST) is the more extensively measured surface parameter and, since it responds directly to the atmosphere-ocean interactions, represents a candidate for investigating the space-time surface variability of the Mediterranean system. Satellite SST data have been available, at least twice a day, since 1982 . They have been used in a variety of studies to investigate the surface variability of the Mediterranean from the annual and interannual timescales (Borzelli and Ligi, 1999a, b; Marullo et al., 2007; Notarstefano et al., 2008; Borzelli, 2008; Borzelli et al., 2009) to the daily SST cycle (Marullo et al., 2011). The Group for High Resolution SST (GHRSST) supports these research activities by providing high-quality sea surface temperature data for applications in short, medium and decadal/climate timescales in an efficient manner through international collaboration and scientific innovation.

Marullo et al. (2011) used lagged-correlation analysis, the multitaper method (MTM) and singular spectral analysis (SSA) to reveal the presence of a significant oscillation with a period of about 70 years (Fig. 17), which is close to the Atlantic Multi-decadal Oscillation (AMO) period.

They found that, during winter, the Mediterranean SST and the North Atlantic Oscillation (NAO) vary coherently over periods longer than about 40 years, with a confidence limit between $90 \%$ and $95 \%$. Over periods longer than 85100 years, Mediterranean SST and AMO vary coherently with a confidence limit that exceeds $95-99 \%$ (Fig. 18).

From the above analysis the question arises whether the Mediterranean Sea can be considered a component of the entire North Atlantic climate system, taking part in the deterministic mechanism proposed by Dima and Lohamnn (2007) and based on the interaction between atmosphere, ocean and ice. Furthermore, the system composed of the North Atlantic, the Mediterranean Sea/Gibraltar Strait (Artale et al., 2006) and the Arctic Sea/Fram Strait might work as a unique oceanographic entity, with the physical processes within the straits determining the exchange of the fresh and salty waters between the marginal seas and the open ocean (Sannino et al., 2009). The analysis of the Mediterranean SST variability alone, however, cannot provide a full answer to whether the forcing of the observed multi-decadal signal has an atmospheric origin or whether it is determined by changes in the Mediterranean Thermohaline Cell (THC).

Coupled ocean-atmosphere models could contribute to answering this question and to investigating the origin of the Mediterranean multi-decadal oscillation, separating the contributions of the atmosphere and the Mediterranean THC.

A very important link exists between SST and the heat content of the surface mixed layer with the phytoplankton distribution. The variability of the mixed layer temperature is governed by the heat equation that includes horizontal advection of the mean and eddy components and the entrainment at the base of the mixed layer. The heat equation is forced by the heat budget at the air-sea interface minus the short-wave radiation (SWR) not absorbed within the mixed layer. The portion of SWR absorbed within the mixed layer depends on the value of a diffuse attenuation coefficient for solar light. Several formulations are available to estimate the latter one, such as the one proposed by Foltz et al. (2003). The diffuse attenuation coefficient depends on the environmental conditions, being a measure of the water turbidity caused by the presence of suspended sediments and/or biological components. For the open sea, phytoplankton is the main factor determining this coefficient. Morel et al. (2007) proposed an empirical equation to determine its value from chlorophyll concentrations, obtaining a relationship that directly links the chlorophyill concentration to the percentage of absorbed solar radiation in the mixed layer. As an example of such a calculation, consider a typical April condition in the northwest Mediterranean when the mean mixed-layer depth is typically between 15 and $30 \mathrm{~m}$, with a mean incoming SWR of $200 \mathrm{~W} \mathrm{~m}^{-2}$ and chlorophyll concentrations ranging from 1 to $0.1 \mathrm{mg} \mathrm{m}^{-3}$ inside and outside the most productive area. The SWR contribution to the mixed-layer heating would be 180 and $160 \mathrm{~W} \mathrm{~m}^{-2}$ for the two regions, respectively (D'Ortenzio et al., 2005). This example emphasizes the importance of evaluating the effect of biota concentrations in determining the mixed-layer thermodynamics.

\subsubsection{Unresolved issues}

1. Understanding the relation between multi-decadal SST oscillations and Mediterranean thermohaline cell variability

The SST being the more extensively measured surface parameter of the ocean, many works have investigated its decadal or multi-decadal variability based solely on this parameter, supposing that some complex relation exists between the SST variability and the changes in 

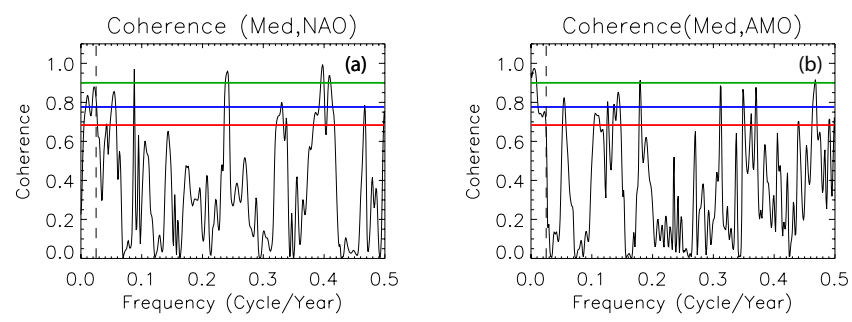

Fig. 18. Magnitude squared coherence estimation between (a) Mediterranean SST and NAO, and (b) Mediterranean SST and AMO. Green, blue, and yellow lines represent the $90 \%, 95 \%$, and $99 \%$ confidence limits, respectively (modified from Marullo et al., 2011, American Meteorological Society; used with permission).

the thermohaline cell or the heat content of the mixed layer over the same timescales.

The physical relation between SST and ocean interior dynamics exists, but unfortunately that relation is not as simple as replacing one with the other in the time series analysis obtaining the same trends or oscillations. We believe that future investigations should be devoted to understanding the extent to which an advanced use of combined surface data with numerical simulations will be able to describe the 3-D upper ocean with sufficient space and time resolution. A better understanding of the relation between the surface field and the 3-D structure of the ocean in the Mediterranean Sea will contribute to investigating to which extent feedback between changes in the Mediterranean thermohaline and multi-decadal variability of the SST exist.

2. Relation between multi-decadal Atlantic indices variability and Mediterranean SST oscillations

Since Atlantic indices have been found to vary coherently over multi-decadal timescales with oscillations of the Mediterranean SST field, it would be very stimulating to investigate whether this statistical evidence can be related to some physical, likely nonlinear, process that drives the interaction between the two dynamical systems. Recently, Francombe et al. (2010) proposed that the multi-decadal variability of the North Atlantic is dominated by two main time scales (20-30 and 50-70 years). The first oscillation has an ocean-internal origin, while the second should be more related to atmospheric forcing. Considering the absence of lag between the AMO and the 70-year Mediterranean SST oscillation, the hypothesis of an atmospheric origin also for the Mediterranean 70-year signal can be considered reasonable. Actually, available information does not allow a definitive answer to the question of whether the forcing of the observed multi-decadal signal has an atmospheric origin or whether there is some contribution due to the
Mediterranean THC or to the interaction with the Atlantic Ocean.

\section{Bio-feedbacks in the Mediterranean Sea}

Bio-optical feedbacks among phytoplankton and upper ocean dynamics represent a promising field of investigation also for the Mediterranean Sea. The presence of phytoplankton in the ocean modifies the penetration of light and impacts the physical properties of the upper water column, modulating the spatial and temporal variability of the heat content in the mixed layer. In this context the use of coupled physical-biogeochemistry models gives us the opportunity to study the loop of effects between biology and physics. The direct inclusion of the optical properties of the upper ocean, modulated by the phytoplankton concentration, can contribute to understanding the way these bio-feedbacks work in the oligotrophic Mediterranean conditions and variation induced by spring blooms and transition between coastal case II and open ocean case I waters.

\subsection{The carbonate system in the Mediterranean}

\subsubsection{Present knowledge}

The characteristics of the Mediterranean Sea are such that it has the potential to sequester large amounts of anthropogenic $\mathrm{CO}_{2}$ and $\mathrm{C}_{\mathrm{ant}}$ (e.g., Álvarez et al., 2013). The buffer capacity of the Mediterranean Sea is particularly high due to the high alkalinity and temperatures throughout the water column. Furthermore, the active deep overturning circulation is effective in transporting the atmospheric imprint on the carbon cycle to the interior of the Mediterranean Sea. In fact, the column inventories of $\mathrm{C}_{\mathrm{ant}}$ are higher in the Mediterranean than anywhere else in the world ocean (Schneider et al., 2010), and the $C_{\text {ant }}$ storage in the Mediterranean is a significant portion of the global anthropogenic emissions of $\mathrm{CO}_{2}$. However, the carbon observations in the Mediterranean are so scarce that it is difficult to quantify the sink of anthropogenic carbon in the Mediterranean accurately, and to quantify changes in the carbon cycle (Fig. 19).

This is manifested among other features as a shift in deep water formation from the Adriatic to the Aegean seas, and back again, the Adriatic being more important for deep water formation. The deep water formed from these two sources has different properties of salinity and the last few decades have seen dramatic changes in the circulation of the Mediterranean Sea's temperature and different biogeochemical signatures. Very little is known about how the recent changes in the Mediterranean overturning circulation have affected the storage rate of carbon and particularly $\mathrm{C}_{\mathrm{ant}}$.

Lateral exchanges of carbon to surrounding seas are significant (e.g., Ait-Ameur and Goyet, 2006; Huertas et al., 2009; Schneider et al., 2010; Flecha et al., 2012), although they are subject to large temporal variability and thus not 

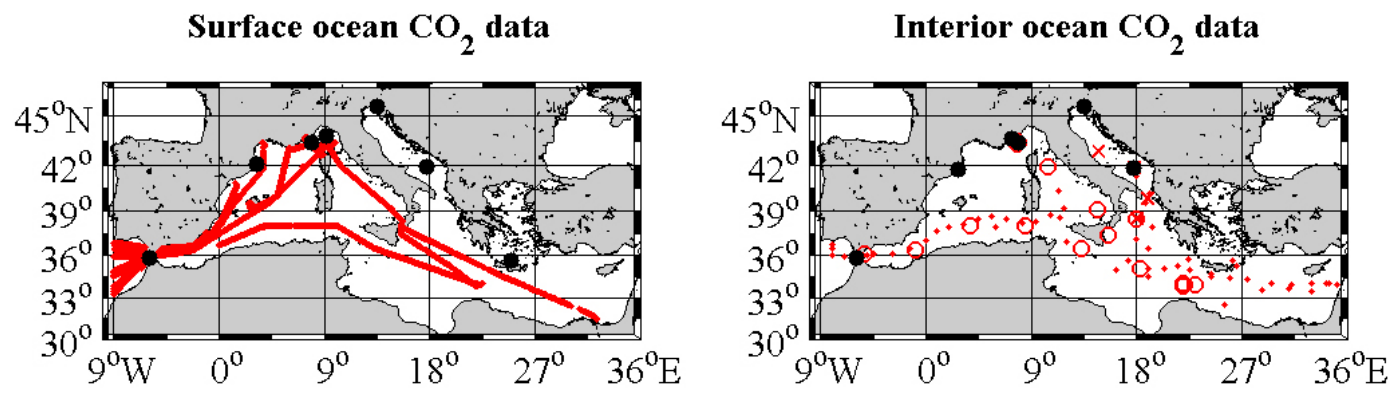

Fig. 19. Mediterranean Sea $\mathrm{CO}_{2}$ data available in public databases. Left panel: $p \mathrm{CO}_{2}$ data (surface ocean) from the SOCATv2 database (red dots), and time-series stations with $\mathrm{pCO}_{2}$ data (black dots). Right panel: DIC data from the interior ocean; red dots Meteor cruises M51 and M84/3 in 2001 and 2011, red crosses MATER cruises from 1997 and 1998, red circles the PROSOPE cruise, black dots the time-series stations. The data from all time-series stations are not publicly available at this stage.

well constrained, similar to different methods for calculating $\mathrm{C}_{\text {ant }}$ in the Mediterranean Overflow Water (MOW), which lead to different magnitudes and even direction of the net flux through the Strait of Gibraltar. In particular, it seems that the TrOCA method overestimates the $\mathrm{C}_{\text {ant }}$ concentration in the MOW, leading to too large an export of $\mathrm{C}_{\mathrm{ant}}$ from the Mediterranean to the Atlantic.

The increasing inorganic carbon content of the Mediterranean Sea leads to changes in the carbonate system, such that the concentration of the carbonate ion decreases and the $\mathrm{pH}$ decreases. In a recent study the sensitivity of the Mediterranean seawater to increasing $p \mathrm{CO}_{2}$ concentrations is discussed in detail (Álvarez et al., 2013). Even though the pH of the Mediterranean is high in comparison to the world ocean, it is possible that these changes in the carbonate system can impact the ability of certain well-adapted groups of marine organisms (e.g., coccolithophores) to thrive. Decreasing $\mathrm{pH}$ leads to changes in chemical equilibrium in, for instance, trace metals and nutrients. The effects of these changes on the Mediterranean ecosystem are as yet poorly understood and an active field of research. Changes in the community structure as a direct effect of the changing carbonate system are conceivable.

\subsubsection{Unresolved issues}

1. Characterization of carbon distributions

It is important to characterize the distributions and controls of natural and anthropogenic carbon (both organic and inorganic) distributions in the interior of the Mediterranean Sea better in order to understand any trends and variability. This includes (a) characterization of key areas for $\mathrm{CO}_{2}$ penetration in the Mediterranean Sea, (b) evaluation of the role of the intermediate and deep water formation areas, and (c) evaluation of the impact of shelf events (flood, storms, shelf-water formation).
2. Temporal and spatial variability of the interior carbonate system

The carbonate system is evidently not in a steady state due to increased influx across the air-sea interface, for instance. This motivates monitoring of the temporal variability of the interior carbonate system and determination of how this relates to increasing atmospheric $\mathrm{CO}_{2}$ concentrations and changing climate, i.e., to the relation between anthropogenic and natural forcing. Observations of the interior ocean carbonate system are necessary on a regular basis in selected hydrographic sections and hotspots. This concept has been presented in some detail in the latest CIESM monograph (CIESM, 2012), which proposes a program called MED-SHIP (MEDiterranean Ship-based Hydrographic Investigation Program) for repeat hydrography in the Mediterranean Sea. Currently, shipbased observations are the only means of obtaining reliable carbonate data of the interior ocean of sufficiently high accuracy for determining temporal variability. This is particularly true for the regions of the Mediterranean Sea deeper than the Gulf of Lion, as $2000 \mathrm{~m}$ is the maximum depth of the present-day Argo floats. The MED-SHIP concept relevant for interior carbon data is based on zonal and meridional sections in the Mediterranean Sea repeated at regular intervals. This could be the cornerstone in an observational program for interior ocean carbon in the Mediterranean Sea. Furthermore, information from sensors mounted on gliders, floats and moorings is invaluable for the understanding of the temporal and spatial variability. Development of other sensors is rapid and any observational program needs to take advantage of additional sensors for a better understanding of the total carbonate system.

3. Air-sea fluxes of $\mathrm{CO}_{2}$

The variability of air-sea flux of $\mathrm{CO}_{2}$ in the Mediterranean Sea is poorly constrained and needs to be 
understood better on various temporal (seasonal to annual to decadal) and spatial (local to sub-basin to basin) scales. Similarly, variability of surface ocean carbon will need to be connected to variability of the interior ocean carbon. Regular observations of surface $p \mathrm{CO}_{2}$ (partial pressure of $\mathrm{CO}_{2}$ ) on commercial vessels (cargo ships and ferries) that regularly cross the oceans is a well proven and useful concept. However, only a limited number of surface $p \mathrm{CO}_{2}$ observations are available for the Mediterranean Sea, although time series like the DYFAMED site south of France provide important long-term information. Installation and operation of $p \mathrm{CO}_{2}$ systems on a number of commercial vessels would be very useful for understanding the airsea flux of $\mathrm{CO}_{2}$ and its spatial and temporal variability. Ideally, these measurements should be coupled with measurements of additional biogeochemical variables concurrently, to help establish the forcings in the $\mathrm{CO}_{2}$ variability. It is also important that an additional variable of the carbonate system, such as alkalinity, DIC or $\mathrm{pH}$, is monitored simultaneously in order to understand the whole carbonate system.

\section{Lateral carbon fluxes}

The poorly constrained lateral flux of carbon (natural and anthropogenic) to and from the Mediterranean Sea through the Strait of Gibraltar and the Bosphorus Strait system is highly variable and an integral component of the Mediterranean carbonate system. It is important to monitor the variability of the $\mathrm{CO}_{2}$ system and ancillary data by means of repeat fixed stations or moorings (using biogeochemical sensors) in hotspot regions such as water mass formation areas (such as the Gulf of Lion and the northern Adriatic Sea), the Strait of Gibraltar and the Bosphorus Strait.

5. Monitoring the change and impact of decreasing $\mathrm{pH}$

The effect of increasing DIC concentration, leading to decreasing carbonate ion concentration and decreasing $\mathrm{pH}$ in Mediterranean ecosystems, is largely unresolved and needs to be monitored, for instance with current $\mathrm{pH}$ sensors for surface $\mathrm{pH}$ changes, in addition to monitoring of changes in the carbonate system itself in the Mediterranean Sea. The understanding of processes responsible for observed trends and variability is important and is probably best undertaken with the help of modeling schemes, data assimilations and/or inversion methods. Observations and modeling efforts need to go hand in hand and will benefit from close cooperation between the modeling and observational communities.
6. Anthropogenic $\mathrm{CO}_{2}$ inference methods tailored to the Mediterranean Sea

Calculations of the anthropogenic $\mathrm{CO}_{2}$ penetration in the Mediterranean Sea using the existing, but limited, historical data record and the existing calculation techniques need to be performed. This should be coupled to the investigation of a new scheme for the calculation of anthropogenic $\mathrm{CO}_{2}$, appropriate for the Mediterranean Sea.

\section{Shelf-deep sea interactions and exchanges of physical/biogeochemical properties and how they affect the sub-basin circulation and property distribution}

\subsection{Filament and eddy formation and its effects on biogeochemical processes}

\subsubsection{Present knowledge}

Frontal zones, filaments and eddies (FZFE hereafter, ranging from mesoscale $(10-100 \mathrm{~km})$ to submesoscale $(1-10 \mathrm{~km})$ dimensions) are dynamical features with sharp gradients having a large effect on circulation and on the distribution of heat, salt and matter in the ocean (Robinson, 1983; McGillicuddy et al., 1998). It has been shown that they are important routes of the energy cascade and dissipation in the ocean, and the transport of mass, energy, chemical compounds and biota among water masses by turbulent advection and mixing. Their characteristics and distributions play a major role on the basin scale and in the local energetics and circulation. They contribute to shaping the spatio-temporal distribution of biogeochemical variables by creating physical boundaries (separating distinct areas of completely different properties from the surroundings in the open sea) and by modulating the seasonal evolution (inducing, for example, sporadic events). In the coastal areas, they can transport land-based coastal and continental shelf natural and anthropogenic components to the open sea and vice versa. Often these dynamic features, created or destroyed by atmospheric interactions as well as internal instability mechanisms, interact with each other, going down even to the small scales of sub-mesoscale filaments and streamers only captured in high-resolution simulations and by satellite observations. Through energy cascading mechanisms of geophysical turbulence some features disintegrate or dissipate, while other small-scale features can coalesce to become coherent structures that persist for extended periods.

The challenges of characterizing the FZFE processes imply precise and high-resolution observations in addition to a multi-sensor approach on several spatial/temporal scales. Thermal NOAA/AVHRR satellite images were used to identify sites of highest frequency in cold filaments in the Mediterranean Sea (Bignami et al., 2008) and transport 
patterns were studied using satelite altimetry and Lagrangian numerical analysis in the open sea (d'Ovidio et al., 2004). This methodology was adapted to the coastal area using in situ observations to correct for the uncertainties connected to satelite altimetry data close to shore (Nencioli et al., 2011). Ruiz et al. (2009a, b) reported the first attempt to combine high-resolution $(\sim 0.5 \mathrm{~km})$ hydrographic observations using glider technology and altimetry measurements to quantify vertical exchanges in an area with intense horizontal density gradients. The study was designed to be coincident with an OSTM/Jason-2 passage in the eastern Alboran Sea. Using the quasi geostrophic dynamics (Hoskins et al., 1978), they reported vertical velocities of about $1 \mathrm{mday}^{-1}$, partially explaining an observed subduction of chlorophyll. Niewiadomska et al. (2009) used gliders equipped with optical biogeochemical sensors to detect upwards and downward motions not easily detected by direct measurements. More recently, Navarro et al. (2011) analyzed the coupled patterns of variability between satellite altimetry and chlorophyll data in the Alboran Sea. They demonstrated that the pelagic ecosystem in the Alboran Sea is controlled by the inverse barometer effect (first mode). They also showed that the distribution of chlorophyll-rich and poor areas can be explained by the second mode.

In the Balearic Basin, mesoscale eddies have been found to modify not only the local dynamics but also the large-scale patterns, as shown by Pascual et al. (2002) in a detailed study of the blocking effect of a large anti-cyclonic eddy, as well as a clear influence of the basin circulation on the phytoplankton biomass (Jordi et al., 2009). The (sub)meso-scale activity of boundary currents around the shelf break leads to strong patchiness of the nutrient and primary production distributions in the Gulf of Lion (Diaz et al., 2000). Bouffard et al. (2010) developed innovative strategies to characterize horizontal ocean flows, specifically in terms of current velocity associated with filaments, eddies or shelf-slope flow modifications close to the coast. These methodologies were applied to a series of glider missions carried out almost simultaneously and well co-localized along the satellite tracks, as part of a pilot initiative lead by IMEDEA (CSICUIB). In this context, Pascual et al. (2010) showed that the high-resolution hydrographic fields from the gliders combined with coastal altimetry revealed the presence of permanent and non-permanent signals, such as relatively intense eddies. Moreover, the almost synoptic view from altimetry and SST images during the glider missions provided a more detailed picture of regional small-scale features. Since January 2011, a new sustained observational program in the Balearic channels has been conducted by IMEDEA (CSICUIB) and SOCIB, the new Balearic Islands Coastal Observing and Forecasting System (Tintoré et al., 2012). This monitoring program consists of repeated transects between Mallorca, Ibiza and Denia. During 2011, 7 glider missions were successfully carried out in the Ibiza Channel, reporting an unprecedented spatial and temporal variability in transports
(Heslop et al., 2011) compared to the literature values (Pinot et al., 2002). These new findings will have relevant consequences for improving our understanding of local ecosystem changes, as it is known that the variability of Atlantic Water through the Balearic channels is critical for the understanding of bluefin tuna spawning south of the Balearic Islands (Alemany et al., 2010). Another important observational/modeling program is MOOSE, the Mediterranean Ocean Observing System for the Environment, developed during recent years and now fully operational in the LiguroProvencal basin (mio.pytheas.univ-amu.fr/moose/). MOOSE addresses not only continental inputs, mesoscale processes, biogeochemical cycles, biodiversity, and air-sea interactions in the northwestern gyre, but also has a modeling/data assimilation component.

Multi-scale interactions are especially relevant for the eastern Mediterranean, where coherent eddies either reinforce or block seasonal circulations, divert or entrain water masses of contrasting properties, and indirectly contribute to inter-basin transports (Feliks and Itzikowitz, 1987; Malanotte-Rizzoli et al., 1999; Zodiatis et al., 2005). In the Levantine Basin fast current systems known as the Mid Mediterranean Jet and the Asia Minor Current (Robinson et al., 1991, 2001) bear the energy that can sustain unstable FZFEs or evolve into long-lived features such as the IeraPetra, Antalya and Shikmona eddies. Interaction between various eddies along the Asia Minor Current has often been observed in great detail (Onken and Yüce, 2000; Hamad et al., 2005, 2006). Modified Atlantic Water propagating from the west and the Levantine Intermediate Water created through convection events are entrained and transported by these eddies and jets and exchanged by FZFE interactions (Özsoy et al., 1989, 1991, 1993; Sur et al., 1992; Lascaratos and Nittis, 1998). Analysis of drifter data and satellite altimetry (Gerin et al., 2009; Menna et al., 2012) has expanded the knowledge of the mesoscale features. They showed the branching of the surface water entering through the Sicily Channel into the Ionian and the Levantine, the eastward flow along the Libyan and Egyptian slopes, and a cyclonic circuit along the Middle East and Turkish slopes. This flow is perturbed locally and temporally by instabilities of the current, wind and topography. The along-slope and offshore currents generate recurrently (western Egyptian coast, Ierapetra, Mersa-Matruh, southwest of Cyprus, Israel-Lebanon coast, Latakia) or persistent (Rhodes Gyre) eddies. Highly variable and energetic currents are observed between the Ierapetra and Mersa-Matruh regions, as a result of the interaction of the Mid Mediterranean Jet meandering in between and interacting with the eddies generated by the instability of the coastal current.

These interactions also affect the horizontal and vertical distributions of chemical parameters and plankton composition, as shown by conventional in situ sampling and analysis (for example, Özsoy et al., 1993; Ediger et al., 1999, 2005; Salihoğlu et al., 1990; Bingel et al., 1993; Yılmaz 

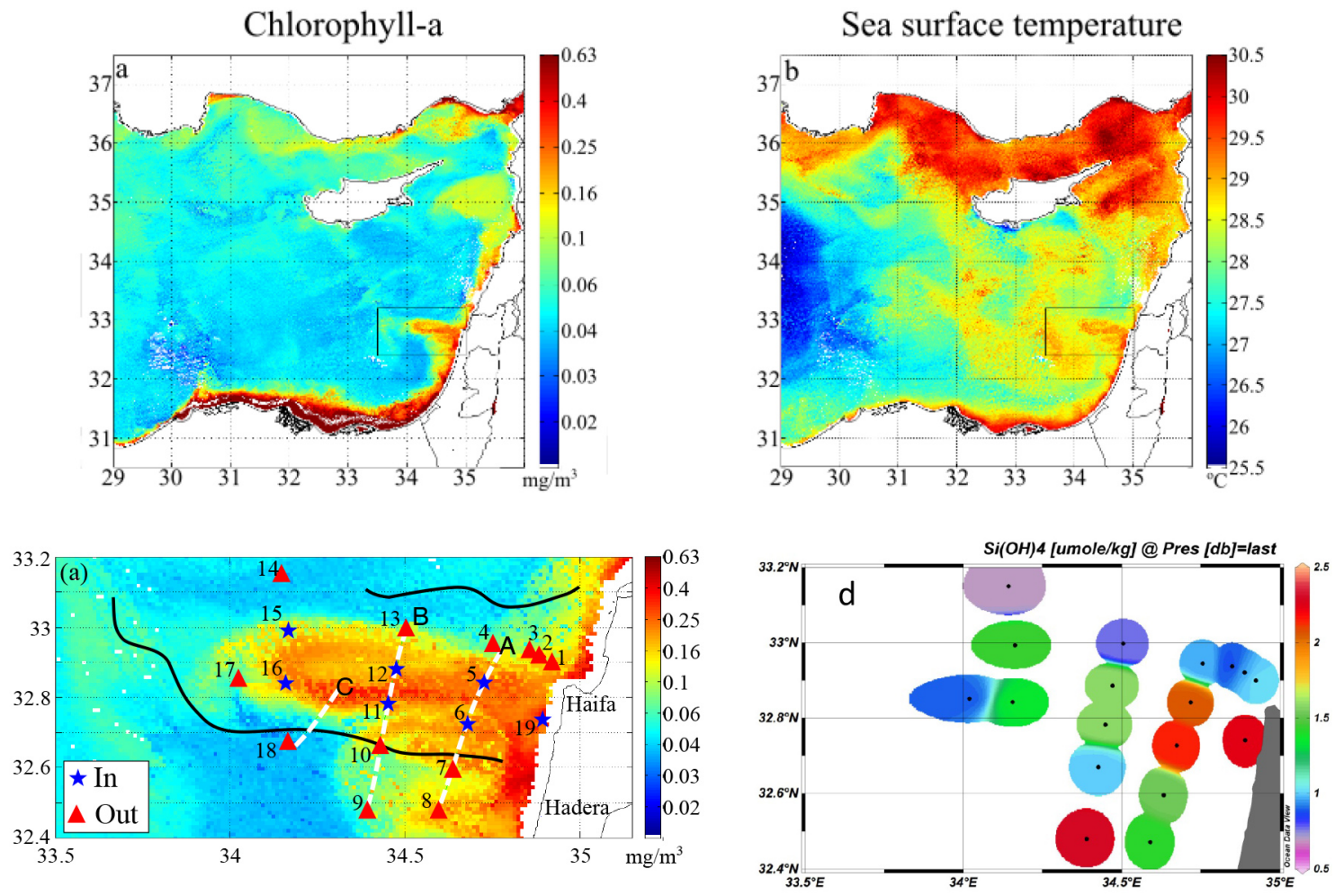

Fig. 20. Satellite images of chlorophyll $a$ (upper panel) and sea surface temperature (middle panel) showing a filament protruding from the Israeli coast, easternmost Levantine Basin, in August 2011. The concentration of silicic acid measured at the surface (lower panel) was higher at the stations inside the filament than outside it. Modified from Efrati et al. (2013).

and Tuğrul, 1998; Krom et al., 1993). The surface and deep chlorophyll maxima formed near the base of the euphotic zone depend on light and biochemical variability imposed by FZFEs (Y1lmaz et al., 1994; Yacobi et al., 1995; Ediger et al., 1996, 2005). In some Mediterranean areas FZFEs affect the distribution of plankton biomass and community composition either directly, due to the physical characteristics (e.g., salinity and temperature boundaries, convergence or divergence processes), or indirectly, through the influence on the chemical parameters (Fiala et al., 1994; Van Wambeke et al., 2004; Riandey et al., 2005; Siokou-Frangou et al., 2009, among others). Recently, relatively high concentrations of biogenic silica were found in some areas, perhaps related to the presence of eddies (Crombet et al., 2011). High silica in a filament stretching from the coast to the open sea in the Levantine Basin were reported as well (Efrati et al., 2013) (Fig. 20). A combination of near-real-time multi-satellite observations, a circulation model and in situ high-resolution sampling within the COSEM project (http://isramar.ocean. org.il/isramar2009/cosem/) showed that the filament was a semi-enclosed system, bounded within the mixed layer and separated from ambient waters by transport barriers induced by horizontal stirring. The physical-biogeochemical properties significantly differed from those of the waters surrounding it, with a volume flux on the order of $0.1 \mathrm{~Sv}$.

\subsubsection{Unresolved issues}

1. Importance of frontal zones, filaments and eddies (FZFE) for the Mediterranean Sea circulation

Although the existence of FZFE in the Mediterranean Sea has been documented, it is still unclear how important they are to the local and overall circulations. The unresolved issues that need to be addressed are (a) FZFE formation and decay and what the relative contributions to these processes of atmospheric forcing, topography and interaction between different features are; (b) investigation of the formation/decay timescales; (c) examination of the differences in these processes between the coastal and open sea regions; (d) FZFE role in the basin-wide and local energy budgets and how the multi-scale interactions transfer and partition energy; (e) FZFE areas are usually identified from their surface signature, which does not provide information about how deep they are. The penetration depth may be seasonal and area dependent and a function of the strength and character of the physical forcing causing the FZFEs. 
2. Importance of FZFEs for the chemical and biological distribution and the biogeochemistry

It has been shown that mesoscale and FZFEs affect the chemical and biological distribution in the water body as well as biogeochemical processes. However, it is still unclear if FZFEs are important features in the Mediterranean as a whole or are only of localized importance. The relative contributions of the FZFEs and the large-scale forcing mechanisms to the spatiotemporal distribution of chemical/biological parameters are not known. The unresolved issues that need to be addressed are (a) how the FZFEs affect the chemical and biological parameter distribution in the entire Mediterranean Sea; (b) determination of properties other than chlorophyll $a$ that can be used to trace FZFEs remotely in the surface layer; (c) the extent to which chemical compounds can be used as passive tracers to track processes associated with FZFE; (d) the FZFEs may cause patchiness in the biomass distribution and, if so, areas need to be identified that are more likely to have this patchiness; (e) the FTFEs may change the estimated primary production and bridge the apparently high yield of fisheries compared to the low primary production (Estrada, 1996); (f) the FTFE contribution may affect the calculation of nutrient and carbon budgets in the Mediterranean; (g) thin layers of plankton in the Mediterranean may be found similar to those found elsewhere in frontal areas (Sullivan et al., 2010).

\section{Integration of measurements from different platforms}

The study of these highly dynamic and space-/timedependent FTFEs needs to integrate a multi-platform, multi-sensor approach, including a range of novel instrumentation for in situ and remote sensing observations, together with modeling efforts. As an example, gliders allow high-resolution oceanographic monitoring by autonomously collecting high-quality observations in three dimensions, and provide useful contributions to the understanding of mesoscale dynamics and multidisciplinary interactions (e.g., Hodges and Fratantoni, 2009). However, isolated measurements from fleets of gliders are not sufficient, as glider measurements remain scarce, both in space and time, for many small-scale processes. The combination of glider data with information from other platforms (satellite, ships cruises, high-frequency radar and buoys) will support the investigation of unresolved issues stated above. In addition, observational data should be integrated with satellite images and numerical analysis. Investigation of the transport patterns needs to be expanded using satelite altimetry and Lagrangian numerical analysis. Studies were performed in the open sea, also in the Mediterranean (d'Ovidio et al., 2004). Recently, this methodology was adapted to the coastal

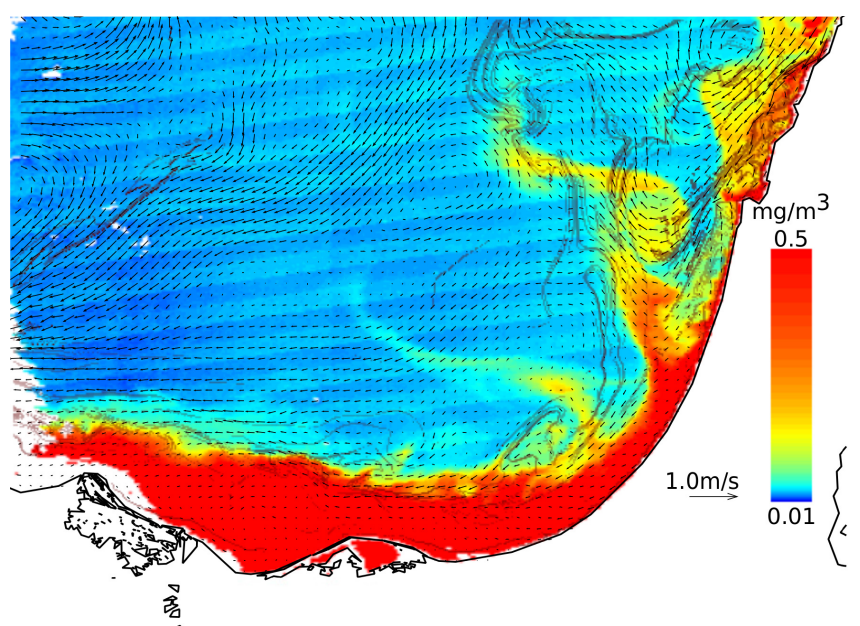

Fig. 21. Satellite image of chlorophyll (29 April 2013) showing filaments protruding from the coast at the southeastern Levantine Basin. Superimposed on the image are the currents and the Lagrangian analysis of passive tracer circulation. The satellite image was obtained from the MyOcean project and the currents and Lagrangian analysis from Israel's Marine Data Center (http://isramar.ocean.org.il/isramar2009/cosem/fsle.aspx).

area using in situ observations to correct for the uncertainties connected to satellite altimetry data close to shore (Nencioli et al., 2011). A semi-operational tool is being operated along the southeastern coast of the Levantine Basin (Fig. 21). These patterns are important for predicting the distribution and transfer of characteristics and matter between areas.

\subsection{On the role of surface forcing in the shelf-slope circulation}

\subsubsection{Present knowledge}

The Mediterranean Sea is a region in which air-sea interaction plays a crucial role in shaping both the atmospheric and oceanic circulation. For the sea, the main components of the surface forcing are the wind stress, the surface heat flux, the direct surface fresh water flux (evaporation minus precipitation), and the terrestrial-based water flux in the form of runoff and river discharges. While early modeling studies of the Mediterranean used relatively coarse horizontal grid resolutions of $\sim 25 \mathrm{~km}$ (e.g., Roussenov et al., 1995; Zavatarelli and Mellor, 1995), more recent studies have used higher resolution grids that are nearly eddy resolving (e.g., $\sim 10 \mathrm{~km}$ in Beuvier et al., 2010$)$ and even eddy resolving $(\sim 7 \mathrm{~km}$ in Tonani et al., 2008). Other studies of sub-basins (e.g., Lascaratos and Nittis, 1998) have also used eddy-resolving grids $(\sim 5 \mathrm{~km})$ for process studies such as LIW formation. These studies show that a model with a reasonable spatial resolution is able to reproduce circulation features of the basin scale, sub-basin scale and mesoscale, in agreement with the small 
Rossby radius of deformation for this sea. However, the common feature of these and other studies is that the surface forcing fields have been extracted from large-scale climatological or reanalysis data sets in which the horizontal resolution is at best on the order of $50-100 \mathrm{~km}$. In most of these studies, the temporal resolution of the forcing was also relatively coarse (daily or longer means), with the exception of Tonani et al. (2008), who used 6-hourly data. While these studies have led to significant progress in understanding the circulation of the Mediterranean, it is clear that in most cases the models and the associated forcing are not able to resolve the fine details of the shelf and slope regions adequately, which are relatively narrow (typical width of a few tens of kilometers or less). One promising direction to improve this is the use of high-resolution shelf models (1-2 km resolution) for local circulation and process studies. Such models have been implemented within the framework of the operational ocean forecasting systems developed over the past 5-8 years for the Mediterranean (MFS, MOON, MyOcean, and MONGOOS; www.moon-oceanforecasting.eu) for daily forecasting. Some of these models have already been used to investigate the local circulation (e.g., Jordi et al., 2006).

Chelton et al. (2004) have discussed the importance of small-scale features in ocean winds, as well as the influences of the coastal and island orography on the wind stress curl and divergence as observed from the $25-\mathrm{km}$ horizontal resolution of the wind stress from the Quickscatt radiometer. Such features, even on smaller scales (of about $1 \mathrm{~km}$ ), are of great importance for the Mediterranean Sea and its adjacent basins, where orography and coastal geometry influence the wind pattern. For example, the effects of these smallscale variations have long been recognized in controlling the wind-driven circulation in the Adriatic Sea. Recent studies of the role of Bora wind events forcing the circulation in the northern Adriatic have demonstrated the importance of sufficiently high resolution in the observations (Lee et al., 2005) and models (Cushman-Roisin and Korotenko, 2007) for understanding the sea's response to the fine-scale atmospheric forcing. These studies also demonstrate the complex interaction that can occur in the shelf zone due to the combined effects of wind forcing and river discharge. Development of the operational ocean forecasting systems for the Mediterranean has led to the implementation of high spatial resolution $(\sim 10 \mathrm{~km})$ and high-frequency ( $3 \mathrm{~h}$ or less) surface forcing to drive the short-term forecasts. This could provide the basis for producing a high-resolution surface forcing reanalysis for further detailed investigations of the shelf and slope circulation and process studies.

Other processes previously discussed in terms of the interaction of the shelf-slope circulation with the open sea are also highly dependent upon the surface forcing. The formation of dense water by cooling and/or evaporation on the broad, shallow northern shelf (generally shallower than $50 \mathrm{~m}$ ) occurs when cold, dry air flows down from the Dinaric Alps during the winter. The resulting intense cooling (as much as $\left.1000 \mathrm{~W} \mathrm{~m}^{-2}\right)$ produces dense water $\left(11^{\circ} \mathrm{C}\right.$, $38.5 \mathrm{psu}$ ), which spills over the shelf edge and then flows southward along the Italian coast as a gravity current. In the South Adriatic Pit it mixes with the Levantine Intermediate Water (LIW) and eventually exits into the Ionian Sea through the Otranto Strait, both as a shelf vein or a slope vein mixed within the Adriatic Deep Water (Zoccolotti and Salusti, 1987; Manca et al., 2002). Bignami et al. (1990) observed the cascading dense waters at the Bari canyon in October 1987 and estimated the transit time from its formation in the north to its arrival in the Bari canyon to be 4-5 months. Such dense-water formation events are episodic and their small spatial scales make them difficult to observe. Based on data from 1981, 1987 and 1999, Vilibić and Supić (2005) found that the reduction in river discharges in the months preceding dense-water generation is a precondition for NAdDW formation. The reduced river discharge may also permit LIW to penetrate the northern Adriatic and bring highly saline water masses that when cooled sufficiently can form very dense water that is capable of cascading into the interior. Sustained cooling by severe Bora outbreaks from November to January are necessary to cool the water column and form the dense NAdDW. In addition to the convective mixing driven by airsea heat loss and evaporation, the tidal mixing at the bottom as well as mixing from wind-driven waves may also play a role in triggering the cascading process.

In other basins of the Mediterranean a strong rim current usually flows along the bathymetry near the shelf break or over the slope. In the western Mediterranean this is manifested by the Algerian Current, which meanders and often generates coastal eddies due to baroclinic instability (Millot, 1985), while the Balearic Basin in the northwestern Mediterranean is characterized by frontal dynamics and shelf-slope exchanges in terms of mesoscale eddies and filaments (e.g., Bouffard et al., 2010). In the eastern Mediterranean the Libyo-Egyptian Current may generate mesoscale eddies that modify the pathway of Atlantic Water, dispatching it offshore (Gerin et al., 2009), or it may meander and form long-lived sub-basin scale features (Menna et al., 2012). Along the eastern boundary of the Levantine Basin, the northward flowing shelf-break current (Rosentraub and Brenner, 2007) also meanders, generating coastal eddies that drift out to the open sea, and occasionally it separates from the shelf break (Brenner, 2003). All of these current systems are an integral part of the general circulation of the Mediterranean Sea and play an important role in shelf-open sea interaction. The contribution of the high-resolution and high-frequency surface forcing to these processes is not well understood and warrants further investigation.

\subsubsection{Unresolved issues}

1. Remote-sensing and shelf-slope in situ measurements of the surface forcing 
While it is clear that high spatial and temporal resolution surface forcing is important for properly simulating the ocean response in terms of mesoscale dynamics in the various basins and sub-basins of the Mediterranean Sea, it is also crucial for understanding the fundamental processes of the shelf and slope zone circulation. Remotely sensed winds on a continuous basis (with no interruptions due to the termination of the satellite mission) with at least a daily time step would be a valuable source of information on the synoptic wind patterns over the Mediterranean. This kind of data should be complemented with data from a coastal network that should fill the gap near land (15-30 km, Bourassa et al., 2010) where the satellite remotely sensed winds are not available. Moreover, there is a need for atmospheric forcing with adequate temporal resolution from in situ observations at platforms such as buoys, moorings, or drifters, located in the offshore regions, especially where wind-driven eddy/gyre systems are observed. Ideally, the remotely sensed wind data should be integrated with the data from autonomous self-recording and transmitting platforms with meteorological sensors moored in the regions of the shelf-slope interaction. Such instruments can provide the local meteorological conditions that cannot be remotely sensed with a sufficient temporal detail and duration. Close cooperation should be established with the operational ocean forecasting community.

2. Dedicated observations for specific process studies

A similar approach should also be applied to regions where other important oceanic phenomena occur as a response to the local forcing, or dense-water formation (the Gulf of Lion, the southern Adriatic, and the southern Aegean). For example, Vilibić and Supić (2005) suggest that the importance of the preconditioning phase in NAdDW formation needs to be studied by examining the specific years in which NAdDW formation has been observed and documented. They also suggest investigating the precise location(s) of NAdDW formation and spreading in the northern Adriatic using more realistic, high-resolution surface forcing based on observational data and model simulations. The same conclusion was reached by Signell et al. (2005) when assessing the relevance of highresolution meteorological models in the Adriatic.

\section{High-resolution surface forcing reanalysis}

The use of high-resolution regional atmospheric models for downscaling of the surface forcing is a promising approach (e.g., Cushman-Roisin and Korotenko, 2007; Beuvier et al., 2010). High-resolution atmospheric fields $(\sim 10 \mathrm{~km})$ are routinely provided to the operational ocean forecasting models of MONGOOS to drive the daily, short-term forecasts. The logical next step would be to develop a high-resolution, multidecadal, regional surface forcing reanalysis data set. In this respect, close cooperation with the operational ocean forecasting community is paramount, since the atmospheric analyses and forecasts are produced daily. However, in order to make long-term surface forcing data sets useful, consistency of the data must be ensured using a reanalysis approach.

\subsection{Interactions between the shelf-slope circulation and open sea in the Mediterranean}

\subsubsection{Present knowledge}

Most of the Mediterranean Sea is characterized by relatively narrow shelf-slope zones so that throughout much of the basin the open sea is in close proximity to the coastal region. Notable exceptions are the northern Adriatic and Aegean seas, where the shelf is relatively wide but laterally confined. In many locations a prominent jet flows along the bathymetry near the shelf break or over the slope (Poulain et al., 2012). Often it meanders and generates eddies or filaments, thereby leading to a net cross shelf flow. Another process that leads to cross shelf flow is dense shelf water cascading (DSWC), in which dense water formed by cooling and evaporation over the relatively shallow continental shelf spills over the shelf edge and sinks as a bottom-trapped gravity current. Such processes are important for the shelf-open sea exchange of dissolved and suspended material and therefore may affect the ecosystem.

The circulation in the Alboran Basin is characterized by the intense inflow/outflow regime due to the exchange of water between the Atlantic and the Mediterranean through the Strait of Gibraltar. Atlantic Water entering the Mediterranean in the upper layer forms the intense Atlantic Jet. This jet meanders and forms the quasi-permanent West Alboran Gyre (e.g., Baldacci et al., 2001) and an intermittent Eastern Alboran Gyre (EAG). The eastern boundary of the EAG is defined by the Almería-Oran front (e.g., Ruiz et al., 2009a) and marks the start of the Algerian Current (AC) (Millot, 1985). As the AC progresses eastward, it forms baroclinically unstable meanders that can evolve into coastal eddies. Only anticyclonic eddies are long lived (Puillat et al., 2002; Isern-Fontanet et al., 2006). They usually propagate along the bathymetry, can detach from the current and become opensea eddies (Millot and Taupier-Letage, 2005, and references therein). Some eddies are quasi-permanent and can divert the AW flow offshore as far as south of the Balearic Islands (Millot and Taupier-Letage, 2005).

The northern current in the Ligurian-Provençal Basin in the northwestern Mediterranean is the dominant feature. The flow is strongest during winter, with significant mesoscale variability, and weakens during summer (Millot and TaupierLetage, 2005). In the Balearic Basin it splits into two 
branches, one recirculating into the Balearic Current (e.g., Ruiz et al., 2009a) and the other continuing south through the Ibiza Channel (Pinot et al., 2002). The Balearic Basin is also characterized by shelf-slope exchange due to mesoscale eddies (Pinot et al., 2002; Bouffard et al., 2010), filaments, and shelf-slope flow modifications (Wang et al., 1988; La Violette et al., 1990). The bathymetry plays a key role in controlling the transport between the northern and southern regions (Astraldi et al., 1999) and may enhance sub-mesoscale activity (Bouffard et al., 2012).

The Atlantic Ionian Stream (AIS) enters the eastern Mediterranean through the Strait of Sicily and usually follows the southern coast of Italy and the western coast of Greece (Robinson and Golnaraghi, 1994). Recent studies (e.g., Borzelli et al., 2009; Gačić et al., 2010) have shown that during certain periods the AIS can follow a more southerly pathway when the overall northwestern Ionian circulation switches from anticylonic to cyclonic. According to the POEM results (e.g., Robinson and Golnaraghi, 1994; Malanotte-Rizzoli et al., 1999) the AIS continues primarily as the eastward flowing Mid Mediterranean Jet that meanders through the center of the Levantine Basin. The POEM results also hinted that it may feed into an eastward flowing shelf-break jet that is part of the general, basinwide rim current. Studies based on SST and surface drifters suggest that this Libyo-Egyptian Current, LEC (Alhammoud et al., 2005; Hamad et al., 2005; Millot and Taupier-Letage, 2005), generates baroclinically unstable mesoscale eddies that transport AW offshore (Gerin et al., 2009). However, other recent studies based on subsurface drifters and satellite altimetry (Poulain et al., 2012; Menna et al., 2012) have shown that the LEC is persistent and stable and forms several stable, sub-basin scale eddies. This current continues eastward, turns northward following the coasts of Israel and Lebanon, and then turns westward following the coast of Turkey as the Asia Minor Current (Öszoy et al., 1993). Based on extensive in situ current measurements, Rosentraub and Brenner (2007) found that over the shelf and slope of Israel, the flow throughout most of the year is directed northward with strong currents that may reach $50 \mathrm{~cm} \mathrm{~s}^{-1}$ or more in both winter and summer. Further to the north, this current can form long-lived eddies through interaction with the MMJ (Menna et al., 2012), which may also lead to shelf open sea exchange. In the near-bottom layer at the shelf break, Rosentraub and Brenner (2007) found evidence of a net seaward, cross-shelf flow.

Understanding DSWC's interaction with the bottom morphology is also of paramount relevance. These energetic cascades, lasting up to a few weeks, are considered one of the main drivers at the oceanic margins. During DSWC events, cold, dense shelf waters spill over the shelf edge and flow along topographic features as a bottom-trapped gravity current. Upon reaching the level of neutral density they spread laterally. Of the 61 confirmed cases of dense-water cascades around the globe (e.g., Ivanov et al., 2004), three occurred in the Mediterranean. Over the broad northern Adriatic shelf the North Adriatic Dense Water (NAdDW) forms in the area exposed to the cold, dry Bora winds during the winter. One branch of NAdDW flows southward with a vein-like shape reaching the shelf break, while a second branch enters the Jabuka pit, from where the spillover can reach the Bari Canyon and the South Adriatic Pit. The cascading water is diluted by entrainment of ambient water masses. While DSWC in the northern Adriatic or at the northern side of the Cretan arc does not play a direct role in the exchange with the open sea, it is nevertheless important, since this process is crucial for the formation of the dense deep water that eventually fills the Eastern Mediterranean. Over the Gulf of Lions shelf DSWC does not occur every year, but when it does, it can reach the bottom (Dufau-Julliand et al., 2004; Palanques et al., 2009; Pascaual et al., 2010, and references therein) and can be an important source of deep water along with that formed by open sea convection.

\subsubsection{Unresolved issues}

1. Meandering coastal currents, fronts, and eddies

The establishment of ocean observing networks, especially over the shelf, is being adopted as an important component of marine strategy by many countries with economically significant coastal areas. These new facilities are delivering new insights into coastal and open ocean variability. They also contribute to a more science-based and sustainable management of the coastal area. In the western Mediterranean, MOOSE (Mediterranean Ocean Observing Site for Environment) and SOCIB (Balearic Islands Coastal Observing and Forecasting System) are two examples of such networks. SOCIB addresses multidisciplinary research into mesoscale and frontal dynamics as a key element in the physical and ecosystem variability (Tintoré et al., 2012). It includes multi-platform observations and modeling services distributed through an integrated system. Such information, when used in synergy with satellite observations, will be particularly helpful for societal benefits, and for a better understanding of 3-D biogeochemical (Lévy et al., 2009) and energy transfers (Lapeyre and Klein, 2006) occurring at meso- and submeso-scales. Similar networks should be established at other select locations in the eastern Mediterranean in order to provide continuous, long-term measurements. Field campaigns to investigate specific aspects of the jet and frontal dynamics should be planned, and very high-resolution models for specific shelf regions should be developed or refined as necessary.

\section{Dense shelf water cascading}

Dense-water formation is primarily a local phenomenon and therefore amenable to study by local 
observations and models. Present models do not have sufficient resolution to capture the small-scale processes responsible for dense-water formation and entrainment. Water mass preconditioning is crucial to dense-water formation and should be studied. In particular, turbulent mixing in the water column, driven by surface cooling and by tidal and storm-driven mixing near the bottom, is the key to homogenizing the shallow shelf waters so that they can be subsequently cooled. These must be further clarified through process-oriented studies combining ad hoc field campaigns to sample the state of the shelf water and the implementation of very high-resolution models that include more accurate parameterization of turbulent mixing.

Implementation of very high-resolution shelf models and data assimilation systems

Present high-resolution shelf models used for the operational ocean forecasting systems within the framework of MONGOOS typically have a horizontal resolution of $\sim 1-2 \mathrm{~km}$ (e.g., Brenner et al., 2007; Zodiatis et al., 2008; Guarnieri et al., 2010), which is barely adequate for resolving the narrow shelf circulation regime. Similarly, the data typically collected as part of the operational systems provide reasonable coverage of the open sea but are more limited in the shelf zone. In order to investigate shelf-open sea interaction further, the models' horizontal and vertical resolutions must be refined further and the domains must extend far enough into the open sea. Non-hydrostatic models may also be necessary. An example of the potential advantage of higher resolution models is shown in Fig. 22, which compares the daily mean currents in the southeastern corner of the Mediterranean based on the MyOcean reanalysis (resolution of $\sim 6.9 \mathrm{~km}$ ), in the left panel, with the downscaled field produced by a model that has a resolution of $\sim 1.7 \mathrm{~km}$, in the right panel. The shelf break current in the high-resolution field is more sharply defined and stronger than in the coarser resolution field. Similarly, smaller-scale eddies appearing over the shelf in the downscaled field are absent in the coarse resolution field. Data routinely collected within the framework of the operational forecasting systems should be used for baseline studies and should be combined with data collected during dedicated field campaigns and the very high-resolution models through a data assimilation system. The experience and systems developed within the framework of operational forecasting in the Mediterranean will be invaluable here.

\section{Additional advances in model development}

In addition to refining the models' resolutions, several new parameterizations should be developed and
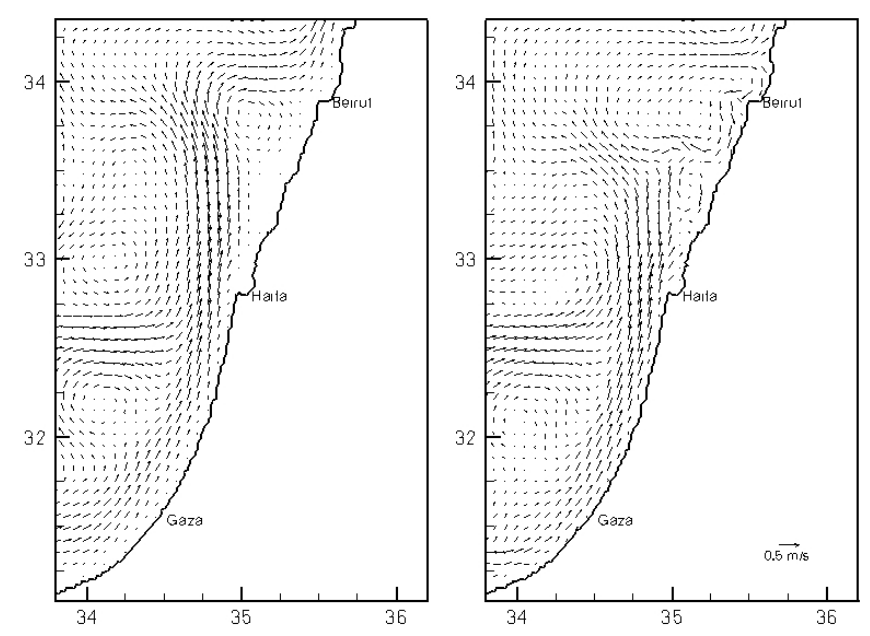

Fig. 22. Comparison of the daily mean near-surface $(10 \mathrm{~m})$ currents on 20 July 2008 from the MyOcean reanalysis, resolution $\sim 6.9 \mathrm{~km}$ (left panel), with the downscaled field produced by a highresolution, $\sim 1.7 \mathrm{~km}$, model (right panel).

implemented. Specifically, second moment closure (SMC) models of turbulent mixing (e.g., Kantha and Clayson, 2007) have enabled more accurate simulations of oceanic mixing processes, although there is still room for improvement. Recently, Kantha and Carniel (2009) refined turbulence models of stably stratified flows to allow mixing at all values of the gradient Richardson number. Non-local mixing models are the key to accurate depiction of mixing processes dominated by convection, prevalent during dense-water formation. Furthermore, parameterization of dense gravity currents for inclusion in larger-scale models is of interest, as are the effects of wind waves on mixing in shallow areas of dense-water formation, using a coupled hydrodynamic model-wave model. To the extent possible these model advances should draw on the experience of the operational forecasting community.

\section{Conclusions}

The most important novel results that have emerged in the investigation of the Mediterranean Sea during recent decades can be summarized in a few focal points. First and foremost, the appearance and discovery in the early 90 s of the Eastern Mediterranean Transient (EMT) has marked a remarkable transition in the understanding of the large-scale thermohaline circulation of the eastern basin. The EMT is manifested in the shift in deep water formation through deep winter convection processes from the southern Adriatic Sea to the Aegean and, later, back again to the Adriatic. This phenomenon led to a greater in-depth outlook for 
the western basin, where a similar phenomenon, evidenced in the early 2000s, was called the Western Mediterranean Transition (WMT). The WMT involved events of high production of anomalously warm and salty new deep water in the winters of 2004/2005 and 2005/2006. The intriguing possibility is that events of such a type had multiple occurrences in the past and might be the manifestation of multiple equilibria of the closed thermohaline circulations of the two basins. Such events may have very profound consequences for biogeochemical properties such as, as an important example, the carbonate system of the Mediterranean. The characteristics of the sea are such that it has the potential to sequester large amounts of anthropogenic $\mathrm{CO}_{2}$ and $\mathrm{C}_{\text {ant }}$. This high buffer capacity is due to the high alkalinity and temperatures throughout the water column.

Still, very little is known about how the recent changes in the thermohaline overturning circulations have affected the storage rate of $\mathrm{C}_{\mathrm{ant}}$.

A second major novel result has been the recent finding of multiannual oscillations again in the eastern basin, which manifest themselves as reversals in the Ionian upper-layer circulation. The first event occurred in the late 80 s, with a reversal from a cyclonic to an anticyclonic circulation. In 1997 an opposite inversion occurred, with the return to a cyclonic pattern. These inversions of the Ionian circulation may have profound effects on the dynamics of the eastern basin ecosystems. In fact, the merging of the whole Mediterranean Sea into a single bio-province, as proposed in some studies, is rather questionable. The western basin, even though smaller, displays a larger number of trophic regimes than the eastern one, with the exception of the limited Adriatic sea area. The link between differences in multiannual through pluridecadal variability in the internal dynamics of the two basins and the biotic dynamics is still unexplored, and this issue deserves even more attention in view of the newly discovered multiannual oscillations.

Finally, historical hydrographic observations as well as recent observations prove that the Mediterrenean Sea is getting saltier, and this is particularly true for the western basin. The crucial question is whether this increase is due to gradual changes or to singular, shorter events. Furthermore, it is not clear if this increased saltiness of the western basin is due to a progressive increase in surface evaporation with downward diffusion of saltier water or through advection of saltier waters, for instance from the eastern basin. Again, such changes in the water mass properties have profound consequences for biogeochemical properties and processes.

Modeling techniques and computer power have been greatly improved during the last decades, enabling an ever increasing accuracy of results that can be applied on the Mediterranean and sub-basin scales for the investigation of long-term variability. The contribution of operational oceanography in the Mediterranean Sea is important, developing and implementing new and advanced modeling tools and techniques in the Mediterranean Sea in the framework of research projects and initiatives at the Mediterranean and European levels (e.g., MFSPP, MFSTEP, ECOOP, MERSEA, MyOcean, MOON/MONGOOS). Blending the two approaches through data assimilation procedures can produce useful results for filling spatio-temporal gaps

These are just a few highlights from the richness of novel, recent results presented in the various sections that have emerged from the investigations carried out during recent decades. More importantly, each section of this paper poses new questions and addresses unresolved issues. The hope is that these questions will produce new challenges and excite new discussions in the interdisciplinary Mediterranean community, which will lead to even more exciting collaborative research and subsequent discoveries.

Acknowledgements. We wish to thank Mario Hoppema for his excellent handling of the manuscript as topic editor throughout the successive phases of the review process and for his excellent comments and suggestions at the various stages of the revisions.

Edited by: M. Hoppema

\section{References}

Adani, M., Dobricic, S., and Pinardi, N.: Quality assessment of a 1985-2007 Mediterranean Sea reanalysis, J. Atmos. Ocean. Technol., 28, 569-589, 2011.

Ait-Ameur, N. and Goyet, C.: Distribution and transport of natural and anthropogenic $\mathrm{CO}_{2}$ in the Gulf of Cadiz, Deep-Sea Res. Pt. I, 53, 1329-1343, 2006.

Alemany, F., Quintanilla, L., Velez-Belchí, P., García, A., Cortés, D., Rodríguez, J. M., Fernández de Puelles, M. L., González-Pola, C., and López-Jurado, J. L.: Characterization of the spawning habitat of Atlantic bluefin tuna and related species in the Balearic Sea (western Mediterranean), Prog. Oceanogr., 86, 21-38, 2010.

Alhammoud, B., Beranger, K., Mortier, L., Crepon, M., and Dekeyser, I.: Surface circulation of the Levantine Basin: comparison of model results with observations, Prog. Oceanogr., 66, 299-320, 2005.

Allen, J. I., Blackford, J. C., and Radford, P. J.: A 1-D vertically resolved modelling study of the ecosystem dynamics of the middle and southern Adriatic sea, J. Marine Syst., 18, 265-286, 1998.

Allen, J. T., Smeed, D. A., Tintoré, J., and Ruiz, S.: Mesoscale subduction at the Almeria-Oran front, Part 1: Agesotrophic flow, J. Marine Syst., 30, 263-285, doi:10.1016/S0924-7963(01)000628, 2001.

Anderson, T. R. and Turley, C. M.: Low bacterial growth efficiency in the oligotrophic eastern Mediterranean Sea: a modelling analysis, J. Plankton Res., 25, 1011-1019, 2003.

Arhonditsis, G. B. and Brett, M. T.: Evaluation of the current state of mechanistic aquatic biogeochemical modeling, Marine Ecol. Prog. Ser., 271, 13-26, 2004.

Artale, V., Calmanti, S., Malanotte-Rizzoli, P., Pisacane, G., Rupolo, V., and Tsimplis, M.: The Atlantic and Mediterranean Sea as connected systems, in: Mediterranean Climate Variability, 
edited by: Lionello, P., Malanotte-Rizzoli, P., and Boscolo, R., Elsevier, 283-323, 2006.

Ashkenazy, Y., Stone, P. H., and Malanotte-Rizzoli, P.: Box modelling of the Eastern Mediterranean Sea, Physica A, 391, 15191531, 2012.

Astraldi, M., Balopoulos, E., Candela, J., Font, J., Gacic, M., Gasparini, G. P., Manca, B., Theocharis, A., and Tintore, J.: The role of straits and channels in understanding the characteristics of Mediterranean circulation, Prog. Oceanogr., 44, 65-108, 1999.

Baldacci, A., Corsini, G., Grasso, R., Manzella, G., Allen, J. T., Cipollini, P., Guymer, T. H., and Snaith, H. M.: A study of the Alboran Sea mesoscale system by means of empirical orthogonal function decomposition of satellite data, J. Marine Syst., 29, 293-311, doi:10.1016/S0924-7963(01)00021-5, 2001.

Barausse, A. and Palmierim L.: A Comparative Analysis of Trophic Structure and Functioning in Large- Scale Mediterranean Marine Ecosystems, in: The Mediterranean Sea, its history and present challenges, edited by: Goffredo, S. and Dubinsky, Z., 678 pp., Springer, 2013.

Barron, C. N. and Kara, A. B.: Satellite based daily SSTs over the global ocean, Geophys. Res. Lett., 33, L15603, doi:10.1029/2006GL026356, 2006.

Bethoux, J. P., Gentili, B., Morin, P., Nicolas, E., Pierre, C., and Ruiz-Pino, D.: The Mediterranean Sea: a miniature ocean for climatic and environmental studies and a key for the climatic functioning of the North Atlantic, Prog. Oceanogr., 44, 131-146, 1999.

Beuvier, J., Sevault, F., Hermann, M., Kontoyiannis, H., Ludwig, W., Rixen, M., Stanev, E., Béranger, K., and Somot, S.: Modelling the Mediterranean Sea inter annual variability during 1961-2000: focus on the Eastern Mediterranean Transient (EMT), J. Geophys. Res., 115, C08017, doi:10.1029/2009JC005950, 2010.

Bianchi, C. N. and Morri, C.: Marine biodiversity of the Mediterranean Sea: situation, problems and prospects for future research, Mar. Pollut. Bull., 40, 367-376, 2000.

Bignami, F., Mattietti, G., Rotundi, A., and Salusti, E.: On a Suigimoto-Whitehead effect in the Mediterranean Sea: sinking and mixing of a bottom current in the Bari Canyon, southern Adriatic Sea, Deep-Sea Res., 37, 657-665, 1990.

Bignami, F., Böhm, E., D’Acunzo, E., D'Archino, R., and Salusti, E.: On the dynamics of surface cold filaments in the Mediterranean Sea, J. Marine Syst., 74, 429-442, 2008.

Bingel, F., Özsoy, E., and Ünluata, Ü.: A review of the state of the fisheries and the environment of the northeastern Mediterranean (Northern levantine Basin), General Fisheries Council for the Mediterranean,No 65, 74 pp,Rome, FAO, 1993.

Boero, F., Bouillon, J., Gravili, C., Miglietta, M. P., Parsons, T., and Piraino, S.: Gelatinous plankton: irregularities rule the world (sometimes), Mar. Ecol.-Prog. Ser., 356, 299-312, 2008.

Bond, G., Showers, W., Cheseby, M., Lotti, R., Almasi, P., deMenocal, P., Priore, P., Cullen, H., Hajdas, I., and Bonani, G.: A pervasive millennial-scale cycle in North Atlantic Holocene and glacial climates, Science, 278, 1257-1266, 1997.

Borzelli, G. L. E.: Scales and variability of the sea surface temperature distribution in the Adriatic Sea, J. Geophys. Res., 113, C11S01, doi:10.1029/2007JC004396, 2008.
Borzelli, G. and Ligi, R.: Empirical orthogonal function analysis of sst image series: a physical interpretation, J. Atmos. Ocean. Tech., 16, 682-690, 1999a.

Borzelli, G. and Ligi, R.: Autocorrelation scales of the SST distribution and water masses stratification in the channel of Sicily, J. Atmos. Ocean. Tech., 16, 776-781, 1999b.

Borzelli, G. L. E., Gačić, M., Cardin, V., and Civitarese, G.: Eastern Mediterranean Transient and reversal of the Ionian Sea circulation, Geophys. Res. Lett., 36, L15108, doi:10.1029/2009GL039261, 2009.

Bouffard, J., Pascual, A., Ruiz, S., Faugère, Y., and Tintoré, J.: Coastal and mesoscale dynamics characterization using altimetry and gliders: a case study in the Balearic Sea, J. Geophys. Res., 115, C10029, doi:10.1029/2009JC006087, 2010.

Bouffard, J., Renault, L., Ruiz, S., Pascual, A., Dufau, C., and Tintoré, J.: Sub-surface small scale eddy dynamics from multisensor observations and modelling, Progr. Oceanogr., 106, 6279, 2012.

Bourassa, M., Stoffelen, A., Bonekamp, H., Chang, P., Chelton, D. B., Courtney, J., Edson, R., Figa, J., He, Y., Hersbach, H.,Hilburn, K., Jelenak, Z., Kelly, K. A., Knabb, R., Lee, T., Lindstrom, E. J., Liu, W. T., Long, D. G., Perrie, W., Portabella, M., Powell, M., Rodriguez, E., Smith, D. K., Swail, V., and Wentz, F. J.: Remotely sensed winds and wind stresses for marine forecasting and ocean modeling, in: Proceedings of OceanObs'09: Sustained Ocean Observations and Information for Society, vol. 2, edited by: Hall, J., Harrison, D. E., and Stammer, D., ESA Publication WPP-306, doi:10.5270/OceanObs09.cwp.08, Venice, Italy, 21-25 September 2009, 2010.

Brenner, S.: Long-term evolution and dynamics of a persistent warm core eddy in the Eastern Mediterranean Sea, Deep-Sea Res. Pt. II, 40, 1193-1206, 1993.

Brenner, S.: High-resolution nested model simulations of the climatological circulation in the southeastern Mediterranean Sea, Ann. Geophys., 21, 267-280, doi:10.5194/angeo-21-267-2003, 2003.

Brenner, S., Gertman, I., and Murashkovsky, A.: Preoperational ocean forecasting in the southeastern Mediterranean: model implementation, evaluation, and the selection of atmospheric forcing, J. Marine Syst., 65, 268-287, doi:10.1016/j.jmarsys.2005.11.018, 2007.

Bruno, M., Chioua, J., Romero, J., Vazquez, A., Macias, D., Dastis, C., Ramirez-Romero, E., Echevarria, F., Reyes, J., and Garcia, C. M.: The importance of submesoscale processes for the exchange of properties through the Strait of Gibraltar, Progr. Oceanogr., 116, 66-79, 2013.

Cacho, I., Grimalt, J. O., and Canals, M.: Response of the Western Mediterranean Sea to rapid climatic variability during the last 50000 years: a molecular biomarker approach, J. Marine Syst., 33, 253-272, 2002.

Canals, M., Puig, P., de Madron, X. D., Heussner, S., Palanques, A., and Fabres, J.: Flushing submarine canyons, Nature, 444, 355357, doi:10.1038/nature05271, 2006.

Candela, J.: Mediterranean water and the global circulation, in: Ocean Circulation and Climate: Observing and Modeling the Global Ocean, edited by: Siedler, G., Church, J., and Gould, J., Academic Press, 419-429, 2001. 
Chelton, D. B., Schlax, M. G., Freilich, M. H., and Millif, R. H.: Satellite measurements reveal persistent small-scale features in ocean winds, Science, 303, 978-983, 2004.

CIESM: Dynamics of Mediterranean deep waters, No 38, CIESM Workshop Monographs, edited by: Briand, F., Monaco, CIESM, 16 Boulevard de Suisse, MC-98000, Monaco, 132 pp., 2009.

CIESM: Designing Med-SHIP: a program for repeated oceanographic surveys, No 43, CIESM Workshop Monographs, edited by: Briand, F., Monaco, CIESM, 16 Boulevard de Suisse, MC98000, Monaco, 164 pp., 2012.

Civitarese, G., Gačić, M., Lipizer, M., and Eusebi Borzelli, G. L.: On the impact of the Bimodal Oscillating System (BiOS) on the biogeochemistry and biology of the Adriatic and Ionian Seas (Eastern Mediterranean), Biogeosciences, 7, 3987-3997, doi:10.5194/bg-7-3987-2010, 2010.

Coll, M. and Libralato, S.: Contributions of food webmodelling to the ecosystem approach to marine resource management in the Mediterranean Sea, Fish and fisheries, 13, 60-88, 2012.

Coll, M., Lotze, H. K., and Romanuk, T. N.: Structural degradation in Mediterranean Sea food webs: testing ecological hypotheses using stochastic and mass-balance modelling, Ecosystems, 11, 939-960, 2008.

Cossarini, G., Solidoro, C., and Fonda Umani, S.: Dynamics of biogeochemical properties in temperate coastal areas of freshwater influence: Lessons from the Northern Adriatic Sea (Gulf of Trieste), Estuarine, Coast. Shelf Sci., 115, 63-74, 2012.

Crise, A., Crispi, G., and Mauri, E.: Seasonal three-dimensional study of the nitrogen cycle in the Mediterranean Sea, Part 1: Model implementation and numerical results, J. Marine Syst., 18, 287-312, 1998.

Crispi, G., Crise, A., and Solidoro, C.: Three-dimensional oligotrophic ecosystem models driven by physical forcings: the Mediterranean Sea case, Environ. Model. Softw., 13, 483-490, 1998.

Crombet, Y., Leblanc, K., Quéguiner, B., Moutin, T., Rimmelin, P., Ras, J., Claustre, H., Leblond, N., Oriol, L., and Pujo-Pay, M.: Deep silicon maxima in the stratified oligotrophic Mediterranean Sea, Biogeosciences, 8, 459-475, doi:10.5194/bg-8-459-2011, 2011.

Cushman-Roisin, B. and Korotenko, K. A.: Mesoscaleresolving simulations of summer and winter bora events in the Adriatic Sea, J. Geophys. Res., 112, C11S91, doi:10.1029/2006JC003516, 2007.

Demirov, E. and Pinardi, N.: Simulation of the Mediterranean Sea circulation from 1979 to 1993: Part 1. The interannual variability, J. Marine Syst., 33, 23-50, 2002.

De Rijk, S., Hayes, A., and Rohling, E. J.: Eastern Mediterranean sapropel S1 interruption: an expression of the onset of climatic deterioration around 7 kyr BP, Mar. Geol., 153, 337-343, 1999.

Diaz, F., Raimbault, P., Conan, P.: Small-scale study of primary productivity during spring in a Mediterranean coastal area (Gulf of Lions), Cont. Shelf Res., 20, 975-996, 2000.

Dima, M. and Lohmann, G.: A hemispheric mechanism for the Atlantic multidecadal oscillation, J. Climate, 20, 2706-2719, 2007.

Dobricic, S., Pinardi, N., Adani, M., Tonani, M., Fratianni, C., Bonazzi, A., and Fernandez, V.: Daily oceanographic analyses by Mediterranean Forecasting System at the basin scale, Ocean Sci., 3, 149-157, doi:10.5194/os-3-149-2007, 2007.
Dobricic, S., Pinardi, N., Testor, P., and Send, U.: Impact of data assimilation of glider observations in the Ionian Sea (Eastern Mediterranean), Dynam. Atmos. Oceans, 50, 78-92, 2010.

D'Ortenzio, F. and Ribera d'Alcalà, M.: On the trophic regimes of the Mediterranean Sea: a satellite analysis, Biogeosciences, 6, 139-148, doi:10.5194/bg-6-139-2009, 2009.

D’Ortenzio, F., Iudicone, D., Montegut, C. B., Testor, P., Antoine, D., Marullo, S., Santoleri, R., and Madec, G.: Seasonal variability of the mixed layer depth in the Mediterranean Sea as derived from in situ profiles, Geophys. Res. Lett., 32, L12605, doi:10.1029/2005GL022463, 2005.

D’Ovidio, F., Fernández, V., Hernández-García, E., and López, C.: Mixing structures in the Mediterranean Sea from finitesize Lyapunov exponents, Geophys. Res. Lett., 31, L17203, doi:10.1029/2004GL020328, 2004.

Dufau-Julliand, C., Marsaleix, P., Petrenko, A., and Dekeyser, I.: Three-dimensional modeling of the Gulf of Lions hydrodynamics (northwest Mediterranean during January 1999 and late winter 1999: Western Mediterranean Intermediate Water's (WIW's) formation and its cascading over the shelf break, J. Geophys. Res., 109, C11002, doi:10.1029/2003JC002019, 2004.

Ediger, D. and Yilmaz, A.: Characteristics of deep chlorophyll maximum in the North-eastern Mediterranean with respect to environmental conditions, J. Marine Syst., 9, 291-303, 1996.

Ediger, D., Tuğrul, S., and Yilmaz, A.: Vertical profiles of particulate organic matter and its relationship with chlorophyll $a$ in upper layer of the NE Mediterranean Sea, J. Marine Syst., 55, 311-326, 2005.

Efrati, S., Lehahn, Y., Rahav, E., Kress, N., Herut, B., Gertman, I., Heifetz, E.: Intrusion of coastalWaters into the pelagic eastern Mediterranean: in situ and satellite-based characterization, Biogeosciences, 10, 3349-3357, doi:10.5194/bg-10-3349-2013, 2013.

Emeis, K.-C., Sakamoto, T., Wehausen, R., and Brumsack, H. J.: The sapropel record of the eastern Mediterranean Sea - results of Ocean Drilling Program Leg 160, Palaeogeogr. Palaeoclim. Palaeoecol., 158, 371-395, 2000.

Estrada, M.: Primary production in the northwestern Mediterranean, Sci. Mar., 60, 55-64, 1996.

Feliks, Y. and Itzikowitz, S.: Movement and geographical distribution of anticyclonic eddies in the Eastern Levantine Basin, DeepSea Res., 34, 1499-1508, 1987.

Fiala, M., Sournia, A., Claustre, H., Marty, J. C., Prieur, L., and Vétion, G.: Gradients of phytoplankton abundance, composition and photosynthesis pigments across the Almeria-Oran front (SW Mediterranean Sea), J. Marine Syst., 5, 223-233, 1994.

Finkel, Z. V., Beardall, J., Flynn, K. J., Quigg, A., Rees, T. A. V., and Raven, J. A.: Phytoplankton in a changing world: cell size and elemental stoichiometry, J. Plankton Res., 32, 119-137, 2010.

Flecha, S., Pérez, F. F., Navarro, G., Ruiz, J., Olivé, I., RodríguezGálvez, S., Costas, E., and Huertas, I. E.: Anthropogenic carbon inventory in the Gulf of Cádiz, J. Mar. Systems, 92, 67-75, doi:10.1016/j.jmarsys.2011.10.010, 2012.

Foltz, G. R., Grodsky, S. A., and Carton, J. A.: Seasonal mixed layer heat budget of the tropical Atlantic Ocean. J. Geophys. Res., 108, 3146, doi:10.1029/2002JC001584, 2003.

Francombe, L. M., von der Heydt, A., and Dijkstra, H. A.: North Atlantic Multidecadal Climate Variability: an Investigation of 
Dominant Time Scales and Processes, J. Climate, 23, 36263638, doi:10.1175/2010JCLI3471.1, 2010.

Fraschetti, S., Guarnieri, G., Bevilacqua, S., Terlizzi, A., Claudet, J., Russo, G. F., and Boero, F.: Conservation of Mediterranean habitats and biodiversity countdowns: what information do we really need?, Aquatic Conservation: Marine and Freshwater Ecosystems, 21, 299-306, 2011.

Gačić, M., Eusebi Borzelli, G. L., Civitarese, G., Cardin, V., and Yari, S.: Can internal processes sustain reversals of the ocean upper circulation? The Ionian Sea example, Geophys. Res. Lett., 37, L09608, doi:10.1029/2010GL043216, 2010.

Gačić, M., Civitarese, G., Eusebi Borzelli, G. L., Kovačević, V., Poulain, P.-M., Theocharis, A., Menna, M., Catucci, A., and Zarokanellos, N.: On the relationship between the decadal oscillations of the Northern Ionian Sea and the salinity distributions in the Eastern Mediterranean, J. Geophys. Res., 116, C12002, doi:10.1029/2011JC007280, 2011.

Gačić, M., Schroeder, K., Civitarese, G., Cosoli, S., Vetrano, A., and Eusebi Borzelli, G. L.: Salinity in the Sicily Channel corroborates the role of the Adriatic-Ionian Bimodal Oscillating System (BiOS) in shaping the decadal variability of the Mediterranean overturning circulation, Ocean Sci., 9, 83-90, doi:10.5194/os-983-2013, 2013.

Galil, B. S.: A sea under siege-alien species in the Mediterranean, Biol. Invasions, 2, 177-186, 2000.

Galil, B. S., Nehring, S., and Panov, V.: Waterways as invasion highways-impact of climate change and globalization, in: Biological invasions, 59-74, Springer Berlin Heidelberg, 2007.

Garcia-Lafuente, J., Delgado, J., Sanchez Roman, A., Soto, J., Carracedo, L., and Dýaz del Rio, G.: Interannual variability of the Mediterranean outflow observed in Espartel sill, western Strait of Gibraltar, J. Geophys. Res., 114, C10018, doi:10.1029/2009JC005496, 2009.

Gasparini, J. P., Ortona, A., Budillon, G., Astraldi, M., and Sansone, E.: The effect of the Eastern Mediterranean Transient on the hydrographic characteristics in the strait of Sicily and in the Tyrrhenian Sea, Deep-Sea Res. Pt. I, 52, 915-935, 2005.

Gerin, R., Poulain, P. M., Taupier-Letage, I., Millot, C., Ben Ismail, S., and Sammari, C.: Surface circulation in the Eastern Mediterranean using drifters (2005-2007), Ocean Sci., 5, 559574, 2009, http://www.ocean-sci.net/5/559/2009/.

Gertman, I., Pinardi, N., Popov, Y., and Hecht, A.: Aegean Sea Water Masses during the Early Stages of the Eastern Mediterranean Climatic Transient (1988-1990), J. Phys. Oceanogr., 36, 18411859, 2006.

Gomez Gesteira, J. L., Dauvin, J. C., and Salvande Fraga, M.: Taxonomic level for assessing oil spill effects on soft-bottom sublittoral benthic communities, Mar. Pollut. Bull., 46, 562-572, 2003.

Guarnieri, A., Oddo, P., Bortoluzzi, G., Pinardi, N., and Ravaiolo, M.: The Adriatic Basin Forecasting System: new model and system development, in: Proceedings of the 5th International Conference on EuroGOOS, edited by: Dhalin, H., Fleming, N., and Petersson, S. E., 184-190, 2010.

Guerzoni, S., Chester, R., Dulac, F., Herut, B., Migon, C., Molinaroli, E., Moulin, C., Rossini, P., Saydam, C., Soudine, A., and Ziveri, P.: The role of atmospheric deposition in the biogeochemistry of the Mediterranean Sea, Prog. Oceanogr., 44, 147-190, 1999.
Hamad, N., Millot, C., and Taupier-Letage, I.: A new hypothesis about the surface circulation in the eastern basin of the Mediterranean Sea, Prog. Oceanogr., 66, 287-298, 2005.

Hamad, N., Millot, C., and Taupier-Letage, I.: The surface circulation in the eastern basin of the Mediterranean Sea, Sci. Mar., 70, 457-503, 2006.

Herrmann, M., Somot, S., Sevault, F., Estournel, C., and Déqué, M.: Modeling the deep water convection in the northwestern Mediterranean Sea using an eddy-permitting and an eddyresolving model: Case study of winter 1986-1987, J. Geophys. Res., 113, C04011, doi:10.1029/2006JC003991, 2008.

Herrmann, M., Diaz, F., Estournel, C., Marsaleix, C., Pulses, C.: Impact of atmospheric and oceanic interannual variability on the Northwestern Mediterranean Sea pelagic planktonic ecosystem and associated carbon cycle, J. Geophys. Res., 118, 5792-5813, doi:10.1002/jgrc.20405, 2013.

Heslop, E., Ruiz, S., Garau, B., Allen, J., Tintoré, J., LopezJurado, J.-L., and Schroeder, K.: Variability in upper layer transports in the Balearic Sea, using new data from glider missions, 5th Everyone's Gliding Observatories Workshop, Gran Canaria, Spain, 14-18 March, 2011.

Hodges, B. A. and Fratantoni, D. M.: A thin layer of phytoplankton observed in the Philippine Sea with a synthetic moored array of autonomous gliders, J. Geophys. Res., 114, C10020, doi:10.1029/2009JC005317, 2009.

Hoskins, B. J., Draghici, I., and Davies, H. C.: A new look at the omega-equation, Q. J. Roy. Meteorol. Soc., 104, 31-38, 1978.

Howell, M. W., Thunell, R. C., Di Stefano, E., Sprovieri, R., Tappa, E. J., and Sakamoto, T.: Stable isotope chronology and paleoceanographic history of sites 963 and 964, Eastern Mediterranean Sea, in: Proc. ODP, Sci. Results, edited by: Robertson, A. H. F., Emeis, K.-C., Richter, C., and Camerlenghi, A., 160, 167-180, 1998.

Huertas, I. E., Ríos, A. F., García-Lafuente, J., Makaoui, A., Rodríguez-Gálvez, S., Sánchez-Román, A., Orbi, A., Ruíz, J., and Pérez, F. F.: Anthropogenic and natural $\mathrm{CO}_{2}$ exchange through the Strait of Gibraltar, Biogeosciences, 6, 647-662, doi:10.5194/bg-6-647-2009, 2009.

Huertas, I. E., Rios, A. F., Garcia-Lafuente, J., Navarro, G., Makaoui, A., Sanchez-Roman, A., Rodriguez-Galvez, S., Orbi, A., Ruiz, J., and Perez, F. F.: Atlantic forcing of the Mediterranean oligotrophy, Global Biogeochem. Cy., 26, GB2022, doi:10.1029/2011GB004167, 2012.

Incarbona, A., Di Stefani, E., Patti, B., Pelosi, N., Bonomo, S., Mazzola, S., Sprovieri, R., Tranchida, G., Zgozi, S., and Bonanno, A.: Holocene millennial-scale productivity variations I the Sicily channel (Mediterranean Sea), Paleoceanography, 23, PA3204, doi:10.1029/2007PA001581, 2008.

Ioannone, A., Catucci, A., Grasso, M., and Eusebi Borzelli, G. L.: Decadal variability and scales of the sea surface structure in the northern Ionian, Cont. Shelf Res., 31, 37-46, 2011.

Isern-Fontanet, J., Garcia-Ladona, E., and Font, J.: Vortices of the Mediterranean Sea: an altimetric perspective, J. Phys. Oceanogr., 36, 87-103, 2006.

Ivanov, V. V., Shapiro, G. I., Huthnance, J. M., Aleynik, D. L., and Golovin, P. N.: Cascades of dense water around the world ocean, Prog. Oceanogr., 60, 47-98, 2004.

Jordi, A., Basterretxea, G., Orfila, A., and Tintoré, J.: Analysis of the circulation and shelf-slope exchanges in the continental mar- 
gin of the northwestern Mediterranean, Ocean Sci., 2, 173-181, doi:10.5194/os-2-173-2006, 2006.

Jordi, A., Basterretxea, G., and Angléss, S.: Influence of ocean circulation on phytoplankton biomass distribution in the Balearic Sea: study based on sea-viewing wide field-of-view sensor and altimetry satellite data, J. Geophys. Res., 114, C11005, doi:10.1029/2009JC005301, 2009.

Josey, S. A., Somot, S., and Tsimplis, M.: Impacts of atmospheric modes of variability on Mediterranean Sea surface heat exchange, J. Geophys. Res., 116, C02032, doi:10.1029/2010JC006685, 2010.

Kantha, L. H. and Carniel, S.: A note on mixing in stably stratified flows, J. Atmos. Sci., 66, 2501-2505, doi:10.1175/2009JAS3041.1, 2009.

Kantha, L. H. and Clayson, C. A.: On leakage of energy from turbulence to internal waves in the oceanic mixed layer, Ocean Dynam., 57, 151-156, doi:10.1007/s10236-006-0100-3, 2007.

Kontoyiannis, H., Theocharis, A., and Nittis, K.: Structures and characteristics of newly formed water masses in the NW Levantine during 1986, 1992, 1995, in: The Eastern Mediterranean as a Laboratory Basin for the Assessment of Contrasting Ecosystems, edited by: Malanotte-Rizzoli, P. and Eremeev, V. N., Kluwer Academic Publishers, 1999.

Kontoyiannis, H., Papadopoulos, V., Kazmin, A., Zatsepin, A., and Georgopoulos, D.: Climatic variability of the sub-surface sea-temperatures in the Aegean-Black Sea system and relation to meteorological forcing, Clim. Dynam., 39, 1507-1525, doi:10.1007/s00382-012-1370-8, 2012.

Koppelmann, R., Bottger-Schnack, R., Mobius, J., and Weikert, H.: Trophic relationships of zooplankton in the eastern Mediterranean based on stable isotope measurements, J. Plankton Res., 31, 669-686, 2009.

Krichak, S. O. and Alpert, P.: Decadal trends in the East Atlantic/West Russia pattern and the Mediterranean precipitation, Int. J. Climatol., 25, 183-192, 2005.

Krom, M. D., Brenner, S., Kress, N., Neori, A. and Gordon, L. I.: Nutrient distributions during an annual cycle across a warmcore eddy from the E. Mediterranean Sea, Deep Sea Res. Pt. 1, 40, 805-825, 1993.

Krom, M. D., Herut, B., and Mantoura, R. F. C.: Nutrient budget for the Eastern Mediterranean: implications for phosphorus limitation, Limnol. Oceanogr., 49, 1582-1592, 2004.

Lapeyre, G. and Klein, P.: Impact of the small-scale elongated filaments on the oceanic vertical pump, J. Mar. Res., 64, 835-851, 2006.

Lascaratos, A. and Nittis, K.: A high-resolution three-dimensional numerical study of intermediate water formation in the Levantine Sea, J. Geophys. Res., 103, 18497-18511, doi:10.1029/98JC01196, 1998.

Lascaratos, A., Roether, W., Nittis, K., and Klein, B.: Recent changes in deep water formation and spreading in the eastern Mediterranean Sea: a review, Prog. Oceanogr., 44, 5-36, 1999.

Laskar, J., Robutel, P., Joutel, F., Gastineau, M., Correia, A. C. M., and Levrard, B.: A long-term numerical solution for the insolation quantities of the Earth, Astronomy Astrophys., 428, 261285, 2004.

Lauzier, M. S. and Sindlinger, L.: On the source of Mediterranean overflow water property changes, J. Phys. Oceanogr., 39, 1800$1817,2009$.
La Violette, P. E., Tintoré, J., and Font, J.: The surface circulation of the Balearic Sea, J. Geophys. Res., 95, 1559-1568, 1990.

Lazzari, P., Solidoro, C., Ibello, V., Salon, S., Teruzzi, A., Béranger, K., Colella, S., and Crise, A.: Seasonal and interannual variability of plankton chlorophyll and primary production in the Mediterranean Sea: a modelling approach, Biogeosciences, 9, 217-233, doi:10.5194/bg-9-217-2012, 2012.

Lee, C. M., Askari, F., Book, J., Carniel, S., Cushman-Roisin, B., Dorman, C., Doyle, J., Flament, P., Harris, C. K., Jones, B. H., Kuzmic, M., Martin, A., Ogston, M., Orlic, H. Perkins, P.-M., Poulain, J., Pullen, A., Russo, C. Sherwood, P., Signell, R. P., and Thaler, D.: Northern Adriatic response to a wintertime Bora wind event, Eos T. AGU, 86, 157-165, doi:10.1029/2005EO16001, 2005.

Lermusiaux, P. F. J. and Robinson, A. R.: Features of dominant mesoscale variability, circulation patterns and dynamics in the Strait of Sicily, Deep Sea Res., 48, 1953-1997, 2001.

Lévy, M., Klein, P., and Ben Jelloul, M.: New production stimulated by high-frequency winds in a turbulent mesoscale eddy field, Geophys. Res. Lett., 36, L16603, doi:10.1029/2009GL039490, 2009.

Libralato, L. and Solidoro, C.: Bridging biogeochemical and food web models for an End-to-End representation of marine ecosystem dynamics: The Venice lagoon case study, Ecol. Model., 220, 2960-2971, 2009.

Longhurst, A. R.: Ecological Geography of the Sea, Elsevier Science, New York, 552 pp., 1998.

Malanotte-Rizzoli, P. and Bergamasco, A.: The wind and thermally driven circulation of the Eastern Mediterranean Sea, Part 2: The baroclinic case, Dynam. Atmos. Oceans, 15, 355-419, 1991.

Malanotte-Rizzoli, P., Manca, B., Ribera d'Alcalà, M., Theocharis, A., Bergamasco, A., Bregant, D., Budillon, G., Civitarese, G., Georgopoulos, D., Michelato, A., Sansone, E., Sarazzato, P., Sovermezoglou, E.: A synthesis of the Ionian Sea hydrography, circulation and water mass pathways during POEM-Phase I, Progr. Oceanogr., 39, 153-204, 1997.

Malanotte-Rizzoli, P., Manca, B. B., Ribera d'Alcalà, M., Theocharis, A., Brenner, S., Budillon, G., and Özsoy, E.: The Eastern Mediterranean in the 80s and in the 90s: the big transition in the intermediate and deep circulations, Dynam. Atmos. Oceans, 29, 365-395, 1999.

Malanotte-Rizzoli, P., Manca, B. B., Marullo, S., Ribera d'Alcalà, M., Roether, W., Theocharis, A., Bergamasco, A., Budillon, G., Sansone, E., Civitarese, G., Conversano, F., Gertman, I., Hernt, B., Kress, N., Kioroglou, S., Kontoyannis, H., Nittis, K., Klein, B., Lascaratos, A., Latif, M. A., Özsoy, E., Robinson, A. R., Santoleri, R., Viezzoli, V., and Kovacevic, D., The LIWEX group: the Levantine Intermediate Water Experiment, the Levantine basin as a laboratory for multiple water mass formation processes, J. Geophys. Res., 9, 8101, doi:10.1029/2002JC001643, 2003.

Manca, B. B., Kovačević, V., Gačić, M., and Viezzoli, D.: Dense water formation in the Southern Adriatic Sea and spreading into the Ionian Sea in the period 1997-1999, J. Marine Syst., 33, 133154, 2002.

Markaki, Z., Loye-Pilot, M.-D., Violaki, K., Benyahya, L., and Mihalopoulos, N.: Variability of atmospheric deposition of dissolved nitrogen and phosphorus in the Mediterranean and possi- 
ble link to the anomalous seawater N/P ratio, Mar. Chem., 120, 187-194, 2010.

Marullo, S., Buongiorno Nardelli, B., Guarracino, M., and Santoleri, R.: Observing the Mediterranean Sea from space: 21 years of Pathfinder-AVHRR sea surface temperatures (1985 to 2005): reanalysis and validation, Ocean Sci., 3, 299-310, doi:10.5194/os3-299-2007, 2007.

Marullo, S., Artale, V., and Santoleri, R.: The SST multidecadal variability in the Atlantic-Mediterranean region and its relation to AMO, J. Climate, 24, 4385-4401, doi:10.1175/2011JCLI3884.1, 2011.

McGill, D. A.: A preliminary study of the oxygen and phosphate distribution in the Mediterranean Sea, Deep Sea Res. (1953), 8, 259-268, 1961.

McGillicuddy Jr., D. J., Robinson, A. R., Siegel, D. A., Jannasch, H. W., Johnson, R., Dickey, T. D., McNeil, J., Michaels, A. F., and Knap, A. H.: Influence of mesoscale eddies on new production in the Sargasso Sea, Nature, 394, 263-265, 1998.

Menna, M., Poulain, P.-M., Zodiatis, G., and Gertman, I.: On the surface circulation of theLevantinesub-basin derived from Lagrangian drifters and satellite altimetry data, Deep Sea Res. Pt. I, 65, 46-58, 2012.

MerMex group: Marine Ecosystems Responses to climatic and anthropogenic forcings in the Mediterranean, Progr. Oceanogr., 91, 97-166, 2011.

Miller, A. R.: Physical Oceanography of the Mediterranean Sea: a discourse, Rapp. Comm. Int. Mer Med., 17, 857-871, 1963.

Millot, C.: Some features of the Algerian Current, J. Geophys. Res., 90, 7169-7176, 1985.

Millot, C.: Circulation in the Western Mediterranean Sea, J. Marine Syst., 20, 423-442, 1999.

Millot, C.: Interannual salinification of the Mediterranean inflow, Geophys. Res. Lett., 34, L21609, doi:10.1029/2007GL031179, 2007.

Millot, C.: Levantine Intermediate Water characteristics: an astounding general misunderstanding! Scientia Marina, 77, 02148358, doi:10.3989/scimar.03518.13A, 2013.

Millot, C. and Taupier-Letage, I.: Circulation in the Mediterranean Sea, in: The Handbook of Environmental Chemistry, vol. 5, Part K, edited by: Saliot, A., Springer-Verlag, 29-66, 2005.

Millot, C., Candela, J., Fuda, J.-L., and Tber, Y.: Large warming and salinification of the Mediterranean outflow due to changes in its composition, Deep-Sea Res., 53, 656-666, doi:10.1016/j.dsr.2005.12.017, 2006.

Morel, A., Huot, Y., Gentili, B., Werdell, P. J., Hooker, S. B., and Franz, B. A.: Examining the consistency of products derived from various ocean color sensors in open ocean (Case 1) waters in the perspective of a multi-sensor approach, Remote. Sens. Environ., 111, 69-88, 2007.

Moutin, T., Van Wambeke, F., and Prieur, L.: Introduction to the Biogeochemistry from the Oligotrophic to the Ultraoligotrophic Mediterranean (BOUM) experiment, Biogeosciences, 9, 38173825, doi:10.5194/bg-9-3817-2012, 2012.

Murat, A.: Pliocene-Pleistocene occurrence of sapropels in the Western Mediterranean Sea and their relation to Eastern Mediterranean sapropels, in: Proc. ODP, Sci. Results, edited by: Zahn, R., Comas, M. C., and Klaus, A., 161, 519-527, 1999.
Navarro, G., Vázquez, Á., Macías, D., Bruno, M., and Ruiz, J.: Understanding the patterns of biological response to physical forcing in the Alborán Sea (western Mediterranean), Geophys. Res. Lett., 38, L23606, doi:10.1029/2011GL049708, 2011.

Nencioli, F., d'Ovidio, F., Doglioli, A. M., and Petrenko, A. A.: Surface coastal circulation patterns by in-situ detection of Lagrangian coherent structures, Geophys. Res. Lett., 38, L17604, doi:10.1029/2011GL048815, 2011.

Niewiadomska, K., Claustre, H., Prieur, L., and d'Ortenzio, F.: Submesoscale physical-biogeochemical coupling across the Ligurian current (northwestern Mediterranean) using a bio-optical glider, Limnol. Oceanogr., 53, 2210-2225, 2009.

Nilsson, J. A., Dobricic, S., Pinardi, N., Taillandier, V., and Poulain, P. M.: On the assessment of Argo float trajectory assimilation in the Mediterranean Forecasting System, Ocean Dynam., 61, 1475-1490, 2011.

Onken, R. and Yüce, H.: Winter circulation and convection in the Antalya basin (Eastern Mediterranean), J. Phys. Oceanogr., 30, 1099-1110, 2000.

Özsoy, E., Hecht, A., and Ünlüata, Ü.: Circulation and hydrography of the Levantine Basin, Results of POEM coordinated experiments 1985/1986, Prog. Oceanogr., 22, 125-170, 1989.

Özsoy, E., Hecht, A., Ünlüata, Ü., Brenner, S., Oğuz, T., Bishop, J., Latif, M. A., and Rosentroub, Z.: A review of the Levantine Basin circulation and its variability during 1985-88, Dynam. Atmos. Oceans, 15, 421-456, 1991.

Özsoy, E., Hecht, A., Ünlüata, Ü., Brenner, S., Sur, H. I., Bishop, J., Latif, M. A., Rozentraub, Z., and Oğuz, T.: A synthesis of the Levantine circulation and hydrography, 1985-1990, Deep Sea Res. Part II, 40, 1075-1119, 1993.

Palanques, A., Puig, P., Latasa, M., and Scharek, R.: Deep sediment transport induced by storms and dense shelf-water cascading in the northwestern Mediterranean basin, Deep-Sea Res. Pt. I, 56, 425-434, 2009.

Parsons, T. R. and Lalli, C. M.: Jellyfish population explosions: revisiting a hypothesis of possible causes, La mer, 40, 111-121, 2002.

Pascual, A., Buongiorno Nardelli, B., Larnicol, G., Emelianov, M., and Gomis, D.: A case of an intense anticyclonic eddy in the Balearic Sea (western Mediterranean), J. Geophys. Res.-Oceans, 107, 4-1, 2002.

Pascual, A., Ruiz, S., and Tintoré, J.: Combining new and conventional sensors to study the Balearic Current, Sea Technol., 51, 32-36, 2010.

Pasqual, A., Sanchez-Vidal, A., Zúñiga, D., Calafat, A., Canals, M., Durrieu de Madron, X., Puig, P., Heussner, S., Palanques, A., and Delsaut, N.: Flux and composition of settling particles across the continental margin of the Gulf of Lion: the role of dense shelf water cascading, Biogeosciences, 7, 217-231, doi:10.5194/bg-7217-2010, 2010.

Pérez-Folgado, M., Sierro, F. J., Flores, J.-A., Grimalt, J. O., and Zahn, R.: Paleoclimatic variations in foraminifer assemblages from the Alboran Sea (Western Mediterranean) during the last $150 \mathrm{kyr}$ in ODP Site 977, Mar. Geol., 212, 113-131, 2004.

Pierini, S. and Rubino, A.: Modeling the oceanic circulation in the area of the Strait of Sicily: the remotely forced dynamics, J. Phys. Ocean, 31, 1397-1412, 2001. 
Pinardi, N. and Coppini, G.: Preface "Operational oceanography in the Mediterranean Sea: the second stage of development;; Ocean Sci., 6, 263-267, doi:10.5194/os-6-263-2010, 2010.

Pinardi, N. and Masetti, E.: Variability of the large scale general circulation of the Mediterranean Sea from observations and modelling: a review, Palaeoecology, 158, 153-173, 2000.

Pinot, J. M., Lopez-Jurado, J. L., and Riera, M.: The Canales experiment (1996-1998): interannual, seasonal, and mesoscale variability of the circulation in the Balearic channels, Prog. Oceanogr., 55, 335-370, doi:10.1016/S0079-6611(02)00139-8, 2002.

Pisacane, G., Artale, V., Calmanti, S., and Rupolo, V.: Decadal oscillations in the Mediterranean Sea: a result of the overturning circulation variability in the Eastern Basin?, Clim. Res., 31, 257271, 2006.

POEM group: General circulation of the Eastern Mediterranean, Earth Sci. Rev., 32, 285-309, doi:10.1016/0012-8252(92)90002B, 1992.

Polimene, L., Pinardi, N., Zavatarelli, M. and Colella, S.: The Adriatic Sea ecosystem seasonal cycle: validation of a threedimensional numerical model, J. Geophys. Res, 112, C03S19, doi:10.1029/2005JC003260, 2007.

Poulain, P.-M., Menna, M., and Mauri, E.: Surface geostrophic circulation of the Mediterranean Sea derived from drifter and satellite altimeter data, J. Phys. Oceanogr., 42, 973-990, 2012.

Puillat, L., Taupier-Letage, I., and Millot, C.: Algerian eddies lifetime can near 3 years, J. Marine Syst., 31, 245-259, 2002.

Riandey, V., Champalbert, G., Carlotti, F., Taupier-Letage, I., and Thibault-Bothac, D.: Zooplankton distribution related to the hydrodynamic features in the Algerian Basin (western Mediterranean Sea) in summer 1997, Deep-Sea Res. Pt. I, 52, 2029 2048, 2005.

Ribera d'Alcalà, M., Civitarese, G., Conversano, F., and Lavezza, R.: Nutrient ratios and fluxes hint at overlooked processes in the Mediterranean Sea, J. Geophys. Res., 108, 8106, doi:10.1029/2002JC001650, 2003.

Ridame, C., Moutin, T., and Guieu, C.: Does phosphate adsorption onto Saharan dust explain the unusual N/P ratio in the Mediterranean Sea?, Ocean. Acta, 32, L12608, 629-634, 2003.

Rixen, M., Beckers, J., Levitus, S., Antonov, J., Boyer, T., Maillard, C., Fichaut, M., Balopoulos, E., Iona, S., Dooley, H., Garcia, M., Manca, B., Giorgetti, A., Manzella, G., Michailov, N., Pinardi, N., and Zavatarelli, M.: The Western Mediterranean Deep Water: a proxy for climate change, Geophys. Res. Lett., 32, L12608, doi:10.1029/2005GL022702, 2005.

Robinson, A.: Eddies in Marine Science (Topics in Atmospheric and Oceanographic Sciences), Springer-Verlag, 609 pp., 1983.

Robinson, A., Leslie, W., Theocharis, A., and Lascaratos, A.: Mediterranean Sea circulation, in: Encyclopedia of Ocean Sciences, Academic Press Ltd., London, 1689-1706, 2001.

Robinson, A. R., Golnaraghi, M., Leslie, W. G., Artegiani, A., Hecht, A., Lazzoni, E., Michelato, A., Sansone, E., Theocharis, A., and Ünlüata, Ü.: The Eastern Mediterranean general circulation: features, structure and variability, Dynam. Atmos. Oceans, 15, 215-240, 1991.

Robinson, A. T. and Golnaraghi, M.: The physical and dynamical oceanography of the Mediterranean Sea, in: Ocean Processes in Climate Dynamics: Global and Mediterranean Examples, edited by: Malanotte-Rizzoli, P. and Robinson, A. R., Kluwer Academic Publishers, 255-306, 1994.

Roether, W. and Lupton, J. E.: Tracers confirm downward mixing of Tyrrhenian Sea upper waters associated with the Eastern Mediterranean Transient, Ocean Sci., 7, 91-99, doi:10.5194/os7-91-2011, 2011.

Roether, W., Manca, B. B., Klein, B., Bregant, D., Georgopoulos, D., Beitzel, V., Kovacević, V., and Luchetta, A.: Recent changes in Eastern Mediterranean deep waters, Science, 271, 333-335, 1996.

Roether, W., Klein, B., Manca, B. B., Theocharis, A., and Kioroglou, S.: Transient Eastern Mediterranean deep waters in response to the massive dense-water output of the Aegean Sea in the 1990s, Prog. Oceanogr., 74, 540-571, 2007.

Rohling, E. J.: Review and new aspects concerning the formation of Mediterranean sapropels, Mar. Geol., 122, 1-28, 1994.

Rohling, E. J., Cane, T. R., Cooke, S., Sprovieri, M., Bouloubassi, I., Emeis, K. C., Schiebel, R., Kroon, D., Jorissen, F. J., Lorre, A., and Kemp, A. E. S.: African monsoon variability during the previous interglacial maximum, Earth Planet. Sc. Lett., 202, 61-75, 2002.

Rosentraub, Z. and Brenner, S.: Circulation over the southeastern continental shelf and slope of the Mediterranean Sea: direct current measurements, winds, and numerical model simulations, J. Geophys. Res., 112, C11001, doi:10.1029/2006JC003775, 2007.

Roussenov, V., Stanev, E., Artale, V., and Pinardi, N.: A seasonal model of the Mediterranean Sea general circulation, J. Geophys. Res., 100, 13515-13538, 1995.

Ruiz, S., Pascual, A., Garau, B., Faugère, Y., Alvarez, A., and Tintoré, J.: Mesoscale dynamics of the Balearic Front, integrating glider, ship and satellite data, J. Marine Syst., 78, 3-16, 2009a.

Ruiz, S., Pascual, A., Garau, B., Pujol, I., and Tintoré, J.: Vertical VELOCITIES in the upper ocean from glider and altimetry data, Geophys. Res. Lett., 36, p. 72, doi:10.1029/2009GL038569, 2009b.

Salihoğlu, İ., Saydam, C., Baştürk, Ö., Goemen, D., Hatipoğlu, E., and Yilmaz, A.: Transport and distribution of nutrients and chlorophyll $a$ by mesoscale eddies in the Northeastern Mediterranean, Mar. Chem., 29, 375-390, 1990.

Sannino, G., Herrmann, M., Carillo, A., Rupolo, V., Ruggiero, V., Artale, V., and Heimbach, P.: An eddy-permitting model of the Mediterranean Sea with a two-way grid refinement at the Strait of Gibraltar, Ocean Model., 30, 56-73, doi:10.1016/j.ocemod.2009.06.002, 2009.

Santinelli, C., Manca, B. B., Gasparini, G. P., Nannicini, L., and Seritti, A.: Vertical distribution of dissolved organic carbon (DOC) in the Mediterranean Sea, Clim. Res., 31, 205-216, 2006.

Santinelli, C., Nannicini, L., and Seritti, A.: DOC dynamics in the meso and bathypelagic layers of the Mediterranean Sea, DeepSea Res. Pt. II, 57, 1446-1459, 2010.

Saunders, P. M.: The instability of a baroclinic vortex, J. Phys. Oceanogr., 3, 61-65, 1973.

Schneider, A., Tanhua, T., Körtzinger, A., and Wallace, D. W. R.: High anthropogenic carbon content in the eastern Mediterranean, J. Geophys. Res., 115, C12050, doi:10.1029/2010JC006171, 2010.

Schroeder, K., Ribotti, A., Borghini, M., Sorgente, R., Perilli, A., and Gasparini, G. P.: An extensive western Mediterranean deep 
water renewal between 2004 and 2006, Geophys. Res. Lett., 35, L18605, doi:10.1029/2008GL035146, 2008.

Schroeder, K., Josey, S. A., Herrmann, M., Grignon, L., Gasparini, G. P., and Bryden, H. L.: Abrupt warming and salting of the Western Mediterranean Deep Water after 2005: atmospheric forcings and lateral advection, J. Geophys. Res., C08029, doi:10.1029/2009JC005749, 2010.

Schroeder, K., Garcia-Lafuente, J., Josey, S. A., Artale, V., Buongiorno Nardelli, B., Carrillo, A., Gacic, M., Gasparini, G. P., Herrmann, M., Lionello, P., Ludwig, W., Millot, C., Ozsoy, E., Pisacane, G., Sanchez-Garrido, J. C., Sannino, G., Santoleri, R., Somot, S., Struglia, M., Stanev, E., Taupier-Letage, I., Tsimplis, M. N., Vargas-Yanez, M., Zervakis, V., and Zodiatis, G.: Climate of the Mediterranean Region - From the past the future, edited by: Lionello, P., Elsevier, 187-256, 2012.

Send, U., Font, J., Krahmann, G., Millot, C., Rhein, M., and Tintore, J.: Recent advances in observing the physical oceanography of the western Mediterranean Sea, Prog. Oceangr., 44, 37-64, 1999.

Shea, K. and Chesson, P.: Community ecology theory as a framework for biological invasions, TRENDS in Ecology Evolution, 17, 170-176, 2002.

Signell, R. P., Carniel, S., Cavaleri, L., Chiggiato, J., Doyle, J., Pullen, J., and Sclavo, M.: Assessment of wind quality for oceanographic modeling in semi-enclosed basins, J. Marine Syst., 53, 217-233, doi:10.1016/j.jmarsys.2004.03.006, 2005.

Siokou-Frangou, I., Zervoudaki, S., Christou, E. D., Zervakis, V., and Georgopoulos, D.: Variability of mesozooplankton spatial distribution in the North Aegean Sea, as influenced by the Black Sea waters outflow, J. Marine Syst., 78, 557-575, 2009.

Sprovieri, M., Pelosi, N., Sprovieri, R., Incarbona, A, and Ribera d'Alcalà, M.: L'evoluazione del clima nell' area mediterranea durante l'intervallo 20000-70 000 anni, in Clima e Cambiamenti Climatic: le Attivitá di Ricerca del CNR, edited by: Carli, B., Cavarretta, G., Colacino, M., and Fuzzi, S., Consiglio Nazionale delle Ricerche, Rome, 177-180, 2007.

Stammer, D.: Global characteristics of ocean variability estimated from regional TOPEX/POSEIDON altimeter measurements, J. Phys. Oceanogr., 27, 1743-1769, 1997.

Stommel, H.: Thermohaline convection with two stable regimes of flow, Tellus, 2, 224-230, 1961.

Sullivan, J. M., McManus, M. A., Cheriton, O. M., BenoitBird, K. J., Goodman, L., Wang, Z., Ryan, J. P., Stacey, M., Van Holliday, D., Greenlaw, C., Moline, M. A., and McFarland, M.: Layered organization in the coastal ocean: an introduction to planktonic thin layers and the LOCO project, Cont. Shelf Res., 30, 1-6, 2010.

Sur, H., Özsoy, E., and Ünlüata, Ü.: Simultaneous deep and intermediate depth convection in the Northern Levantine Sea, Winter 1992, Oceanol. Acta, 16, 33-43, 1993.

Taupier-Letage, I., Puillat, I., Millot, C., and Raimbault, P.: Biological response to mesoscale eddies in the Algerian Basin, J. Geophys. Res., 108, 3245, doi:10.1029/1999JC000117, 2003.

Theocharis, A., Balopolos, E., Kioroglou, S., Kontoyannis, H., and Iona, A.: A synthesis of the circulation and hydrography of the South Aegean Sea and the Straits of the Cretan Arc (March 1994-January 1995), Prog. Oceanogr., 44, 469-509, 1999 a.
Theocharis, A., Nittis, K., Kontoyiannis, H., Papageorgiou, E., and Balopoulos, E.: Climatic changes in the Aegean Sea influence the Eastern Mediterranean thermohaline circulation (1986-1997), Geophys. Res. Lett., 26, 1617-1620, 1999b.

Theocharis, A., Klein, B., Nittis, K., and Roether, W.: Evolution and status of the Eastern Mediterranean Transient (1997-1999), J. Mar. Syst., 33-34, 91-116, 2002a.

Theocharis, A., Lascaratos, A., and Sofianos, S.: Variability of sea water properties in the Ionian, Cretan and Levantine seas during the last century, in: Tracking Long-Term Hydrological Change in the Mediterranean Sea, CIESM Workshop Series, 16, edited by: Briand, F. and Millot, C., Monaco, CIESM, 16 boulevard de Suisse, MC-98000, Monaco, 71-78, 2002b.

Tintoré, J., Vizoso, G., Casas, B., Renault, L., Ruiz, S., Garau, B., Pascual, A., Martínez-Ledesma, M., Gomez-Pujol, L. L., and Orfila, A.: Designing Med-SHIP: a Program for Repeated Oceanographic Surveys, CIESM Workshop Monographs, 43, edited by: Briand, F., CIESM, 16 boulevard de Suisse, MC-98000, Monaco, 164 pp., 2012.

Tonani, M., Pinardi, N., Dobricic, S., Pujol, I., and Fratianni, C.: A high-resolution free-surface model of the Mediterranean Sea, Ocean Sci., 4, 1-14, doi:10.5194/os-4-1-2008, 2008.

Triantafyllou, G., Hoteit, I., Korres, G. and Petihakis, G.: Ecosystem modeling and data assimilation of physical-biogeochemical processes in shelf and regional areas of the Mediterranean Sea, App. Num. Anal. Comp. Math., 2, 262-280, 2005.

Triantafyllou, G., Korres, G., Hoteit, I., Petihakis, G., and Banks, A. C.: Assimilation of ocean colour data into a Biogeochemical Flux Model of the Eastern Mediterranean Sea, Ocean Sci., 3, 397-410, doi:10.5194/os-3-397-2007, 2007.

UNEP-MAP-RAC/SPA: Classification of Benthic Marine Habitat Types for the Mediterranean Region, UNEP RAC SPA, Tunis, 2006.

Van Wambeke, F., Lefèvre, D., Prieur, L., Sempéré, R., Bianchi, M., Oubelkheir, K., and Bruyant, F.: Distribution of microbial biomass, production, respiration, dissolved organic carbon and factors controlling bacterial production across a geostrophic front (Almeria-Oran, SW Mediterranean Sea), Mar. Ecol. Prog. Ser., 269, 1-15, 2004.

Vervatis, V. D., Sofianos, S. S., and Theocharis, A.: Distribution of the thermohaline characteristics in the Aegean Sea related to water mass formation processes (2005.2006 winter surveys), J. Geophys. Res., 116, C09034, doi:10.1029/2010JC006868, 2011.

Vilibić, I. and Supić, N.: Dense water generation on a shelf: the case of the Adriatic Sea, Ocean Dynam., 55, 403-415, 2005.

Volpe, G., Banzon, V. F., Evans, R. H., Santoleri, R., Mariano, A. J., and Sciarra, R.: Satellite observations of the impact of dust in a low-nutrient, low-chlorophyll region: Fertilization or artifact?, Global Biogeochem. Cy., 23, GB3007, doi:10.1029/2008GB003216, 2009.

Wang, F., Vieira, M., Salat, J., Tintoré, J., and La Violette, P. E.: A shelf/slope filament off the Northeast Spanish Coast, J. Mar. Res., 46, 321-332, 1988.

Winters, K. B. and Young, W. R.: Available potential energy and buoyancy variance in horizontal convection, J. Fluid Mech., 629, 221-231, 2009.

Winters, K. B., Lombard, P. N., Riley, J. J., and D'Asaro, E. A.: Available potential energy and mixing in density stratified fluids, J. Fluid Mech., 289, 115-128, 1995. 
Wunsch, C.: The vertical partition of oceanic horizontal kinetic energy, J. Phys. Oceanogr., 27, 1770-1794, 1997.

Wunsch, C. and Stammer, D.: The global frequency-wave number spectrum of oceanic variability estimated from TOPEX/POSEIDON altimetric measurements, J. Geophys. Res., 100, 24895-24910, 1995.

Xoplaki, E., Gonzalez-Rouco, F. J., Luterbacher, J., and Wanner, H.: Mediterranean summer air temperature variability and its connection to the large-scale atmospheric circulation and SSTs, Clim. Dynam., 20, 723-739, 2003.

Xoplaki, E., Gonzalez-Rouco, F. J., Luterbacher, J., and Wanner, H.: Wet season Mediterranean precipitation variability: influence of large-scale dynamics, Clim. Dynam., 23, 63-78, doi:10.1007/s00382-004-0422-0, 2004.

Yacobi, Y. Z., Zohary, T., Kress, N., Hecht, A., Robarts, R. D., Waiser, M., Wood, A. M. and Li, W. K. W.: Chlorophyll distribution throughout the southeastern Mediterranean in relation to physical structure of the water mass, J. Marine Syst., 6, 179-190, 1995.

Yılmaz, A. and Tuğrul, S.: The effect of cold and warm-core eddies and the distribution and stoichiometry of dissolved nutrients in the Northeastern Mediterranean, J. Marine Syst., 16, 253-268, 1998.
Yılmaz, A., Ediger, D., Baştürk, Ö., and Tuğrul, S.: Phytoplankton fluorescence and deep chlorophyll maxima in the northeastern Mediterranean, Oceanol. Acta, 17, 69-77, 1994.

Zavatarelli, M. and Mellor, G. L.: A numerical study of the Mediterranean Sea circulation, J. Phys. Oceanogr., 25, 1384-1414, 1995.

Zervakis, V., Geogopoulos, D., and Deakopoulos, P. G.: The role of the North Aegean in triggering the recent Eastern Mediterranean climatic changes, J. Geophys. Res., 105, 26103-26116, doi:10.1029/2000JC900131, 2000.

Zoccolotti, L. and Salusti, E.: Observation of vein of very dense water in the southern Adriatic Sea, Cont. Shelf Res., 7, 535-551, 1987.

Zodiatis, G., Drakopoulos, P., Brenner, S., and Groom, A. S.: Variability of the Cyprus warm core eddy during the CYCLOPS project, Deep-Sea Res. Part II, 52, 2897-2910, 2005.

Zodiatis, G., Hayes, R. D., Lardner, R., and Georgio, G.: Subregional forecasting and observing system in the Eastrn Mediterranean Levantine Basin: the Cyprus Coastal Ocean Forecasting and Observing System (CYCOFS), in: Towards an integrated system of Mediterranean marine observatories, edited by: Briand, F. CIESM Workshop Monographs, 34, 101-106, 2008. 